\title{
IDENTIFICAÇÃO DE NEMATÓIDES FITOPARAS ITOS DO RIO GRANDE DO SUL - BRASIL
}

CESAR ANTONIO SPERANDIO

Engenheiro Agrônomo

Orientador: Prof. Dr. Ailton Rocha Monteiro

Tese apresentada à Escola Superior de Agricultura "Luiz de Queiroz", da Universidade de São Paulo, para obtenção do título de Doutor em Agronomia, área de concentração: Fitopatologia.

P I R A C I C A B A

ESTADO DE SÃo PAULO - BRASil

Abril - 1992 
Ficha catalográfica preparada pela seção de Livios da Divisão de Biblioteca e Documentaçãa - PCAPfuSP

Sperandio, Cesar Antonio

P742i Identificação de nematóides fitoparasitos do Rio Gran de do Sul - Brasil. ePiracicaba, 199210 13

121p. ilus.

Tese - ESALQ

Bibliografia.

1. Nematóide parasito de planta - Identificação - Rio Grande do Sul I. Escola Superior de Agricultura Luiz de Queiroz, Piracicaba

CDD $\quad 632.6513$ 


\section{IDENT IFICAÇÃO DE NEMATÓIDES FITOPARASITOS DO RIO GRANDE DO SUL - BRASIL}

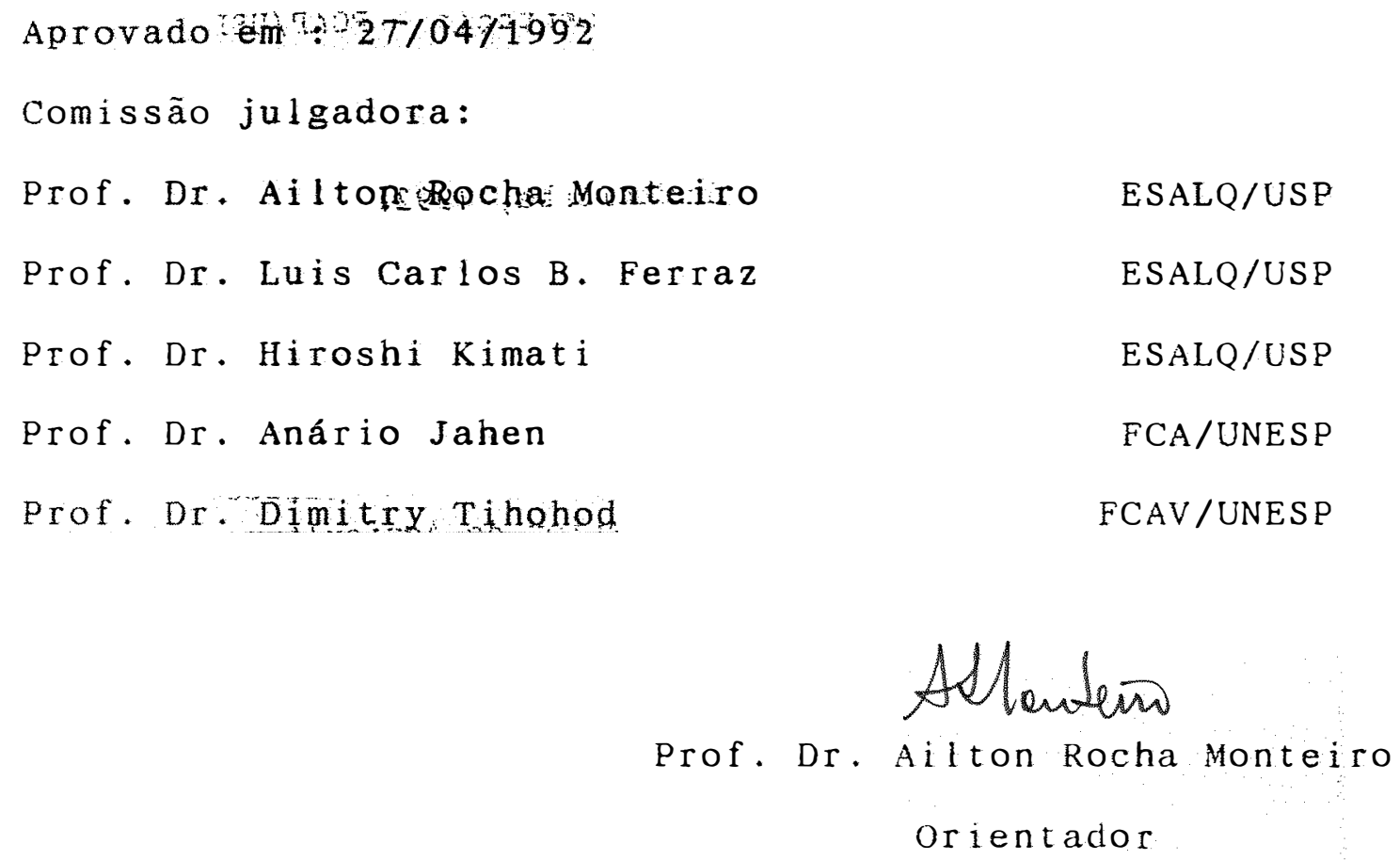


DED I CATÓR I A

\author{
A meus pais \\ Pedro e Hilária \\ Ofereço
}

Ao filho RODRIGO, pela alegria que trouxe, e à espôsa CRISTINA, pelo incentivo, compreensăo e apôio,

DEDICO . 
AGRADEC I MENTOS

O autor deseja mostrar o seu reconhecimento a todas as pessoas que contribuíram de uma forma direta ou indireta para a realização deste trabalho e agradecer em especial:

Ao Prof. Dr. Ailton Rocha Monteiro pela valiosa orientação e ensinamentos transmitidos;

Ao Prof. Dr. Luiz Carlos C. Barbosa Ferraz pelas sugestões e estímulo;

Aos Colegas Professôres do Departamento de Fitossanidade da Faculdadade de Agronomia "Eliseu Maciel", da Universidade Federal de Pelotas pelo apôio, amizade e incentivo à realização do presente curso;

À CAPES pela concessão da bolsa de estudo;

Aos Professores, colegas de curso e funcionários dos Departamentos de Fitopatologia e Zoologia pelo apóio e agradável convívio. 


\section{SUMÁRIO}

Páginas

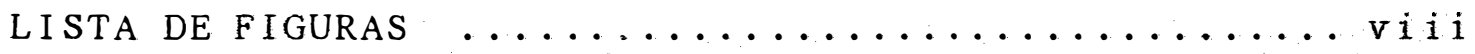

LiSTA DE ABREVIATURAS E S'IMBOLOS $\ldots \ldots \ldots \ldots \ldots \ldots \ldots \ldots$

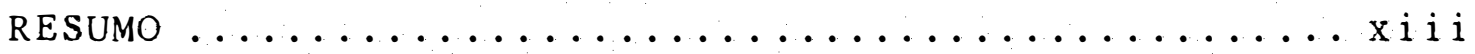

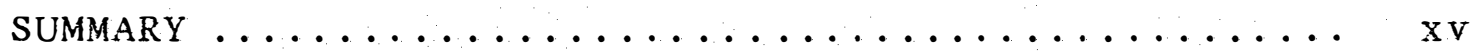

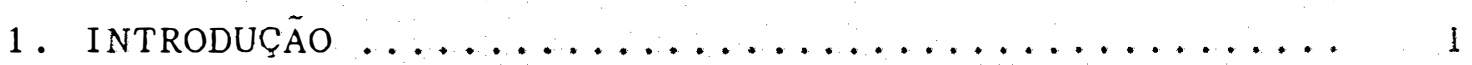

2. REVISÃO DE LITERATURA .................. 3

3. MATERIAL E METODÓ $\ldots \ldots \ldots \ldots \ldots \ldots \ldots \ldots \ldots \ldots \ldots$

3.1. Coleta de amostras ...................... 14

3.2. Processamento das amostras ............ 16

3.3. Preparações microscópicas e análise ........ 17

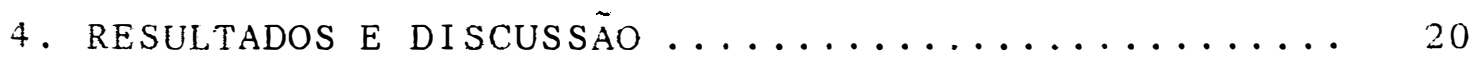

4.1. Posição sistemática das espécies encontradas. 20

4.2. Considerações sobre as espécies .......... 26

4.2.1. Espécies já nominadas

01. Tylenchus davanei .......... 26

02 . Cephalenchus leptus ......... 27

03. Coslenchus alacinatus ........ 28

04. Psilenchus hilarulus .......... 29

05. Ditylenchus dipsaci ......... 31

06. Triversus hollisi ......... 32

07 . Pratylenchus brachyurus ....... 33 
08. P. scribneri .............. 34

09. P. zeae ................ 35

10. Radopholus similis ........... 36

11. Hoplolaimus galeatus .......... 38

12. Aorolaimus perscitus ......... 39

13. Helicotylenchus dihystera...... 40

14. H. crenacauda ............... 42

15. Rotylenchus caudaphasmidius ..... 43

16. Scutellonema brachyurus ....... 44

17. S. bizanae ................ 45

18. Meloidogyne exigua .......... 46

19. M. incognita ............. 47

20. M. javanica ............. 48

21. Criconema demani ........... 48

22. Criconemella palustris........ 50

23. C. reedi................ 51

24. C. sphaerocephala .......... 52

25. C. xenoplax ............. 53

26. Hemicriconemoides minutus ...... 54

27. Ogma civellae ........... 55

28. Hemicycliophora poranga ........ 56

29. H. riра ............... 57

30. H. tenuistriata ........... 58

31. Caloosia paradoxa ........... 59

32. Paratylenchus aquaticus ........6 60 
33. Aphelenchus avenae.......... 61

34. Aphelenchoides besseyi ........ 62

35. Xiphinema californicum ........ 54

36. X. krugi ............... 65

37. Paratrichodorus minor........ 66

4.2.2. Espécies ainda inominadas

38. Dolichodorus sp. ........... 68

39. Tylenchorhynchus sp. "A" ...... ?1

40. Tylenchorhynchus sp. "B" ...... 75

41. Helicotylenchus sp........... 78

42. Criconema sp. "A" ......... 82

43. Cri conema sp. "B" .......... 85

44. Criconemella sp. ............. 39

45. Discocriconemella sp. ......... 92

5. REFERÊNCIAS BIBLIOGRÁFICAS ............ 96

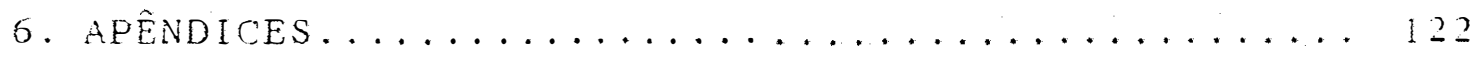


vi i i

\section{LISTA DE FIGURAS}

Pági na

Fig. 1. Municípios do Estado do Rio Grande do Sul, onde foram coletadas amostras de solo e raízes de diferentes plantas, para análise nematológica $\ldots \ldots \ldots \ldots \ldots \ldots \ldots$

Fig. 2. Dol ichodorus sp. ................ 70

Fig. 3. Tylenchorhynchus sp. "A"............ 73

Fig. 4. Tylenchorhynchus sp. "B" ........... 77

Fig. 5. Helicotylenchus sp.................. 81

Fig. 6. Criconema sp. "A" ................ 84

Fig. 7. Criconema sp. "B" ............... 88

Fig. 8. Criconemella sp. ................. 91

Fig. 9. Discocriconeme lla sp. .............. 95 


\section{LISTA DE ABREVIATURAS E SIMBOLOS}

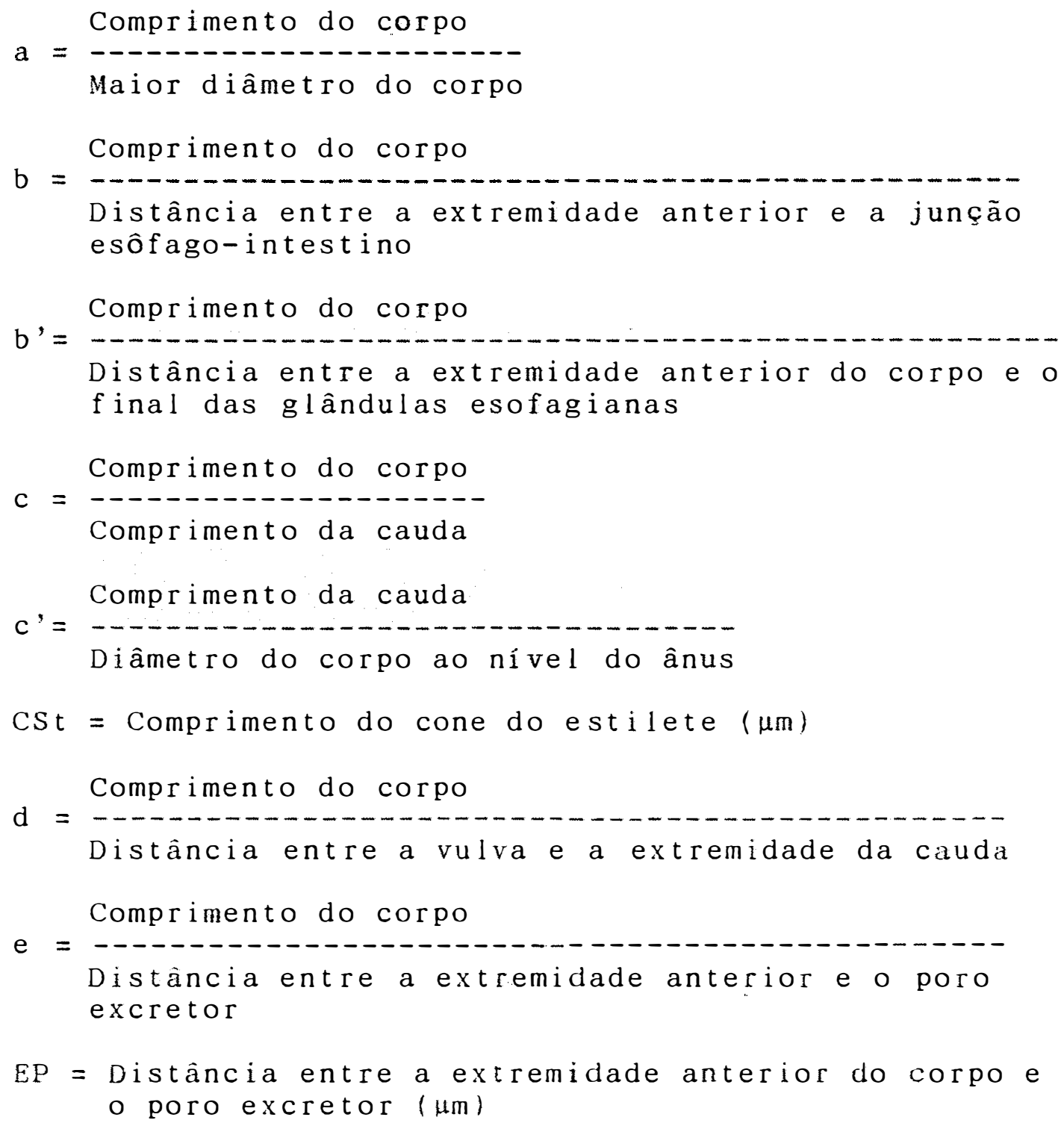




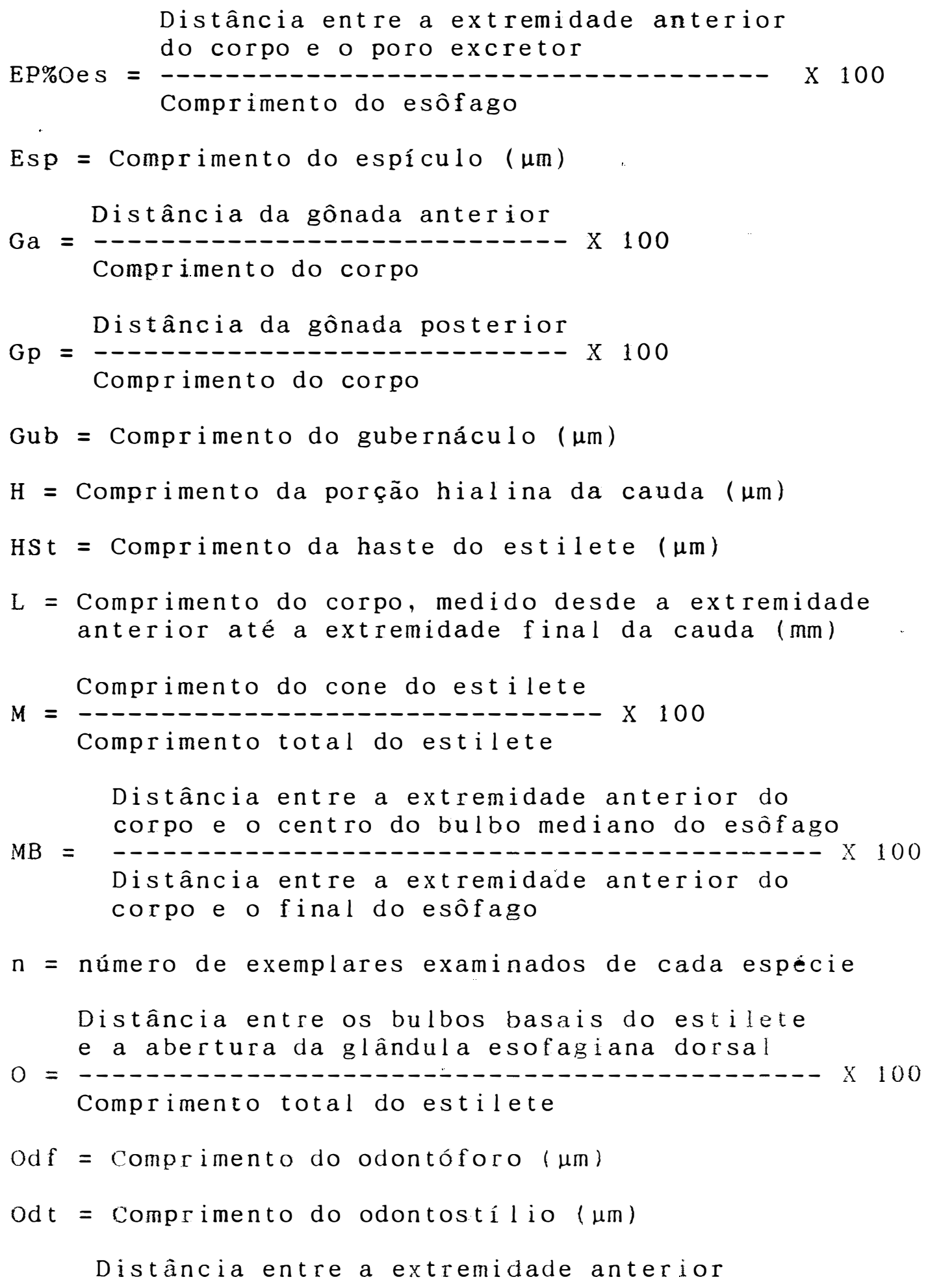




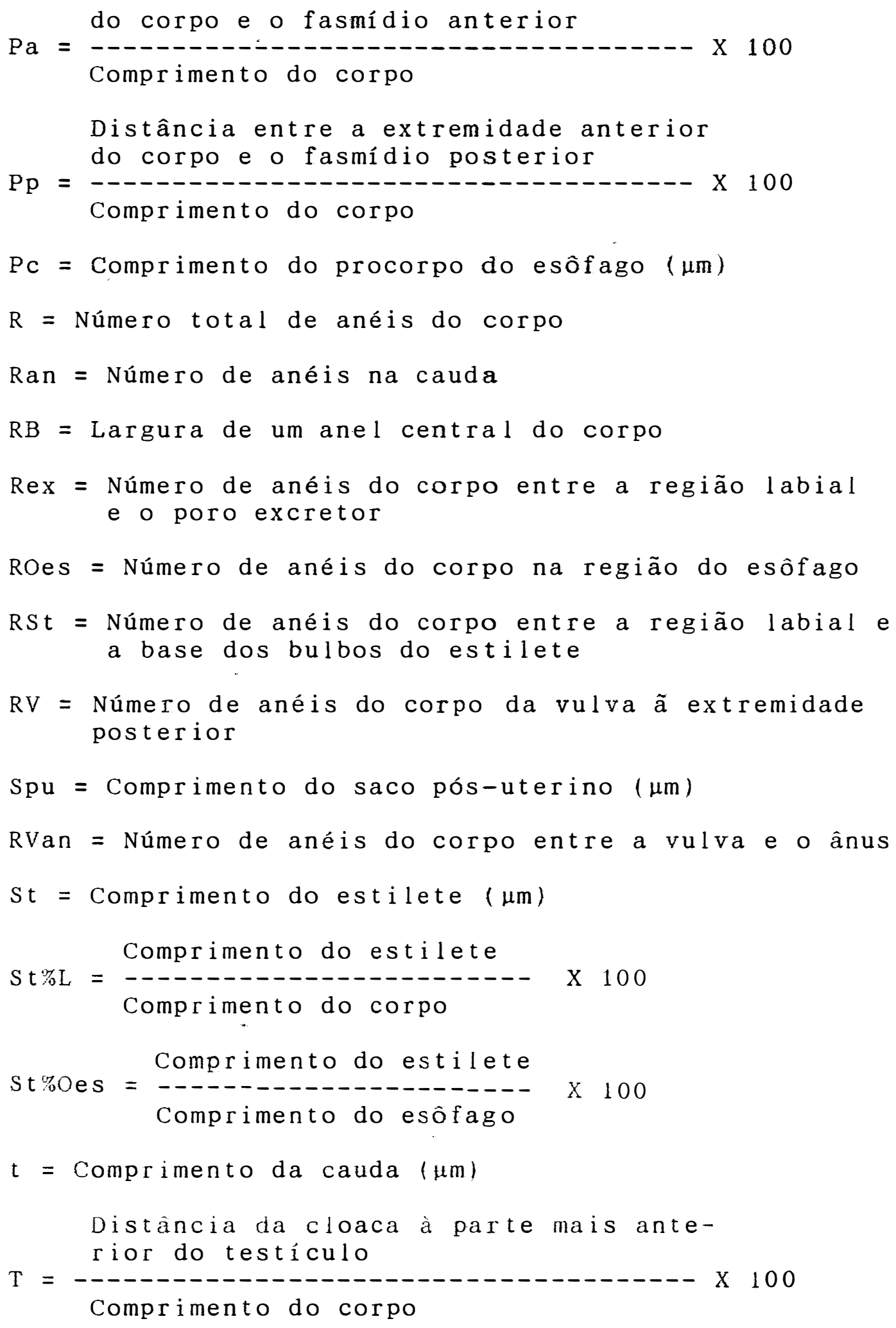




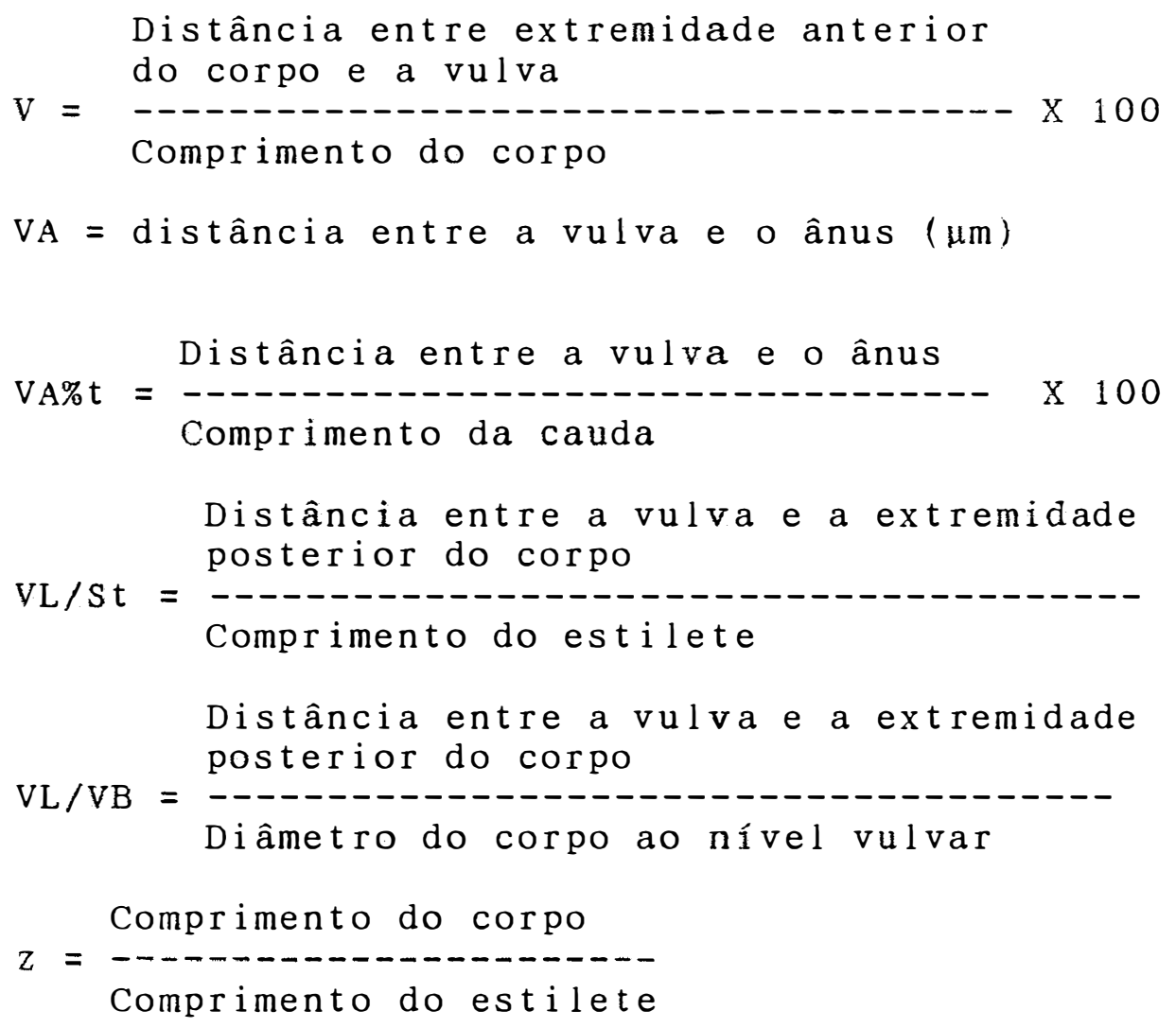


$x$ i i i

\title{
IDENTIFICAÇÃO DE NEMATÓIDES FITOPARASITOS DO RIO GRANDE DO SUL - BRASIL
}

\author{
Autor: Cesar Antonio Sperandio \\ Orientador: Prof. Dr. Ailton Rocha Monteiro
}

\section{RESUMO}

O estudo dos nematóides das ordens Tylenchida (sensu MAGGENTI et a l., 1987) e Dorylaimida (familias Longidoridae e Trichodoridae), obtidos de 210 amostras de solo de rizosfera, processadas pelo método de JENKINS (1964), e raízes de 32 espécies de plantas, processadas pelo método do Fun i l-de-Baermann (FLEGg \& HOOPER, 1970), de 21 municípios do Rio Grande do Sul, Brasil, revelou a ocorrência de 8 espécies ainda inominadas ( Dolichodorus sp., Tylenchorhynchus sp."A", Tylenchorhynchus sp. "B", Helicotylenchus sp., Criconema sp. "A" e Criconema sp. "B". Criconemella sp., e Discocriconemella sp.) e de 37 espécies já conhecidas da Ciência (Tylenchus davainei, Cephalenchus leptus, Coslenchus alacinatus, Psil enchus hilarulus, Ditylenchus dipsa- 
ci(*), Triversus hollisi, Pratylenchus brachyurus(*), P. zeae(*), P. scribneri(*), Radopholus similis, Hoplolaimus galeatus, Aorolaimus perscitus, Helicotylenchus dihystera(*), H. crenacauda, Rotylenchus caudaphasmidius, Scutellonema brachyurus, s. bizanae, Meloidogyne exigua, M. incognita(*), M. javanica(*), Criconema demani, Criconemella palustris, C. reedi, C. sphaerocephala, C. xenoplax, Hemicriconemoides minutus, ogma civellae, Hemicycliophora poranga, H. ripa, H. tenuistriata, Caloosia paradoxa, Paratylenchus aquaticus, Aphelenchus avenae(*), Aphelenchoides besseyi(*), Xiphinema californicum, X. krugi e Paratrichodorus minor). Destas últimas, somente nove (as marcadas com asterisco) já haviam sido relatadas para o Rio Grande do Sul. Sinônimos, resultados da mensuração, observações sobre a morfologia lou descrição, diagnose e desenhos para as espécies inominadas) e ocorrências (locais e plantas associadas) sào apresentados para cada espécie. 


\section{IDENTIFICATION OF PLANT-PARASITIC NEMATODES IN RIO GRANDE DO SUL - BRAZIL.}

Author: CESAR ANTONIO SPERANDIO Adviser: PROF. DR. AILTON ROCHA MONTEIRO

\section{SUMMARY}

The study of nematodes of the orders Tylenchida (sensu MAGGENTI et al., 1987) and Dorylaimida (fami1 ies Longidoridae and Trichodoridae), recovered from 210 samples of soil around roots by Jenkins technique and from roots by Baermann-funnel technique, collected in 21 counties of the state of "Rio Grande do Sul", Brazil, resulted in the records of eight innominate species (Dolichodorus sp., Tylenchorhynchus sp. "A", Tylenchorhynchus sp. "B", Helicotylenchus sp., Criconema sp. "A", Criconema sp. "B", Criconemella sp. and Discocriconemella sp.l and of 37 species already known by science 1 Tylenchus davanei, Cephalenchus leptus, Coslenchus alacinatus. Psilenchus hilarulus, Ditylenchus dipsaci(*), Triversus hollisi, Pratylenchus brachyurus(*), P. scribneri(*), P. zeae(*), Radopholus similis, Hoplolaimus galeatus, Aorolaimus perscitus, Helicotylenchus dihystera(*), H. crenacauda, Rotylenchus cauda- 
phasmidius, Scutellonema brachyurus, S. bizanae, Meloidogyne exigua, M. incognita(*), M. javanica(*), Criconema demani, Criconemella palustris, C. reedi, C. sphaerocephala, C. xenoplax, Hemicriconemoides minutus, ogma civellae, Hemicycliophora poranga, H. ripa, H. tenuistriata, Caloosia paradoxa, Paratylenchus aquaticus, Aphelenchus avenae(*), Aphelenchoides besseyi(*), Xiphinema californicum, X. krugi, and Paratrichodorus minor). These, except the nine ones with asterisk, are new records for the state of "Rio Grande do Sul". Junior synonyms for the species, mean and range of measurements, morphological variations of the known species or descriptions, diagnoses and drawings of innominate species, hosts and localities of samples are given. 


\section{INTRODUÇÃO}

Apesar de o Rio Grande do Sul ser um importante Estado produtor agrícola e empregar técnicas modernas em sua produção, a ocorrência e a importância de agentes patogênicos como nematóides, fungos, bactérias e vírus que afetam suas principais culturas, ainda não são devidamente conhecidos.

Pouco mais de três dezenas de trabalhos, a maior parte publicada nas últimas três décadas, encerram informações sobre nematóides fitoparasitos do Rio Grande do Sul. Há registro de 25 gêneros e de 37 espécies ident if icadas.

Certamente isso está muito longe de corresponder a nematofauna fitoparasita do Estado, e decorre principalmente do pequeno número de nematologistas para invest igá-1a.

o presente trabalho faz o inventário das referências bibliográficas pertinentes e identifica os gêneros e espécies de nematóides das ordens Týlenchida (todas as familias) e Dorylaimida (familias Longidoridae e Trichodoridae), fitoparasitos comprovados ou suspeitos extraidos de 210 amostras solo e raizes de plantas, cul- 
tivadas ou nativas, de 21 municípios do Estado do Rio Grande do Sul. 


\section{REVISÃO DE LITERATURA.}

Os registros de ocorrência de nematóides fitoparasitos no Estado do Rio Grande do Sul, encontrados na revisão bibliográfica, são dados a seguir em ordem cronológica de publicação.

BRASIL (1910), ao tratar da cultura do trigo, registrou que " ....a anguilulla é a única das seis enfermidades enumeradas que atacam o trigo e não é causada por fungos...", mas a redação não esclarece se o nematóide do grão do trigo, Anguina tritici (steinbuch, 1799) Filipjev, 1935, foi realmente verificado no Rio Grande do Sul.

COSTA NETO (1937), trabalhando no laboratório de Agronomia e Biologia da Secretaria do Estado, atribuiu a Heterodera marioni (Cornu, 1879) Marcinowsky, 1909 (como eram então identificadas as espécies do gênero Me loidogyne Goeldi, 1887 , as galhas observadas nos sistemas radiculares de salsa (Petroselium sativum Hoffm.) e de cenoura (Daucus carota L.) cultivadas em Porto Alegre. de fumo (Nicotina tabacum L.) em S. Pedro e Santa Cruz e de pessegueiros (Prunus persica Batsch.) em Canoas, Mon- 
tenegro e S. Pedro, bem como nas plantas invasoras carurú (Amaranthus deflexus L.), guanxuma ( $s i d a$ rhombifolia L.) e juá (Solanum aculeatissimum Jacq.).

ANDR'ASSY (1967) registrou a ocorrência de Helicotylenchus erythrinae (zimmermann, 1904) Golden, 1956 em serapilheira de mata em amostra procedente de Santa Maria, Rio Grande do Sul.

LORDELLO (1969a) identificou Meloidogyne javanica (Treub, 1885) Chitwood, 1949 em raízes de beterraba (Beta vulgaris L.) em material coletado em Santa Maria.

LORDELLO (1969b) relatou Aphelenchoides besseyi Christie, 1942 em arroz (Oryza sativa L.) no Brasil, ao encontrá-lo em grãos procedentes do município de Pelotas. MONTEIRO (1963) já o havia registrado em folhas de moranguinho (Fragaria sp.) cultivado no Estado de São Paulo.

LORDELLO \& MARINI (1974), em amostras coletadas em Porto Alegre, identificaram Meloidogyne incognita (Kofoid \& White, 1919) Chitwood, 1949 parasitando raízes de beterraba (Beta vulgaris L.), chicória (Cichorium intybus L.) e alface (Lactuca sativa L.) e M. javanica, raizes de chicória e alface. Do solo aderente às raízes da chicória obtiveram Aphelenchus avenae Bastian, 1865. De amostras recebidas de Santa Maria identificaram 
M. javanica, Pratylenchus brachyurus (Godfrey, 1929) Filipjev \& Sch. Stekhoven, 1941 e Helicotylenchus sp. em raízes de soja (Glycine max Merrill), e Helicotylenchus sp. e Xiphinema sp. em rizosfera de milho (Zea mays L.). M. javanica foi ainda encontrada em raízes de oliveira (Olea europaea L.) procedentes de Itaqui. Pareceu-lhes ser Meloidogyne arenaria (Neal, 1889) Chitwood, 1949 a espécie que infestava pesadamente raízes de lúpulo (Humulus lupulus L.) procedentes de Passo Fundo.

BARKER (1974), em relatório para o Projeto Nacional da Soja, citou a ocorrência, e frequências respectivas, de Meloidogyne (7\%), Pratylenchus (19\%), Tylenchorhynchus (7\%), Helicotylenchus (93\%), Trichodorus (8\%), Xiphinema (2\%), Criconemoides (28\%), scutellonema (13\%), Hoplolaimus (7\%) e Longidorus $(2 \%)$ em cultura de soja nos estados do Rio Grande do Sul e Santa Catarina. As espécies principais foram M. javanica, M. incognita, P. brachyurus, Helicotylenchus dihystera e Trichodorus christiei Allen, 1957. Destacou que as espécies de Meloidogyne e Pratylenchus podiam ser os mais importantes nematóides da soja no Brasil.

LUZZARDI (1974) informou que, em raizes e solo de trigo (Triticumsp.), de plantas cloroticas e com desenvolvimento aquém do normal, enviados pelo IPEAS IInstituto de Pesquisa e Experimentação Agronomica do 
Sul) ao Professor Luiz Gonzaga E. Lordello, foram identificados nematóides filiados aos gêneros Helicotylenchus, Tylenchorhynchus e Xiphinema.

GOMES et al. (1976) verificaram que $M . j a-$ vanica era a espécie mais prejudicial para a cultura da soja no Estado, informaram também que esta espécie estava sendo disseminada com muita rapidez nas lavouras tradicionais das principais regiões produtoras, como a região do Alto Uruguai, Missões, Depressão Central bem como esta já estava presente na região Litorânea.

LEHMAN et al. (1976) analisaram cêrca de 104 amostras de solo e raízes de soja, colhidas na época da floração, procedentes de diversas lavouras dos Estados de Santa Catarina e Rio Grande do Sul, e registraram a presença de nematóides filiados aos gêneros Meloidogyne, Pratylenchus, Hoplolaimus, Helicotylenchus, Tylenchorhynchus, Trichodorus, Xiphinema, Criconemoides, Scutellonema e Longidorus.

SHARMA \& LOOF (1977) coletaram 6 amostras de solo e raízes no município de Passo Fundo, em culturas de cevada (Hordeum vulgare L.), milho (Zea mays L.), soja (G. max Mer.), trigo (Triticum sp.) e sorgo (Sorghum vulgare Pers.), e encontraram 10 gèneros e 14 espécies de nematóides fitoparasitos: Aphelenchoides sp., Ditylenchus sp., Helicotylenchus dihystera (Cobb, 1893) Sher, 1961, 
Helicotylenchus multicinctus (Cobb, 1893) Golden, 1956, M. incognita, Nothocriconema mutabile (Taylor, 1936) De Grisse \& Loof, 1965, Peltamigratus holdemani Sher, 1964 , P. brachyurus, Rotylenchulus reniformis Linford \& Oliveira, 1940, Tylenchus sp., T. leptosoma de Man, 1880, T. minutus Cobb, 1893, T. sakia (??: não há registro de espécie descrita com esse nome; provavelmente, os autores se referiam a uma espécie do gênero Sakia Khan, 1964 e ocorreu um lapsus calamil e Xiphinema sp.. Somente $H$. dihystera ocorreu em todas as amostras; as demais espécies ocorreram em apenas uma das amostras.

ANTONIO \& LEHMAN (1978) registraram a ocorrência de $M$. javanica parasitando ervas daninhas associadas a culturas de soja. As plantas hospedeiras e os locais foram: mentrasto (Ageratum conyzoides L.), poáia [Borreria verticillata (L.) G. F. W. Mey] e capim-pé-degalinha [Eleusine indica (L.) Gaerth.], no município de Gravataí; apaga-fogo [Alternanthera ficoidea (L.) R. Br.], capim-pé-de-galinha e rubim (Leonurus sibiricus L. , no município de Cruz Alta.

SHARMA (1978) analisou amostras de solo e raízes de cereais e de outras culturas procedentes dos municipios de Passo Fundo, Cruz Alta e Santa Bárbara e encontrou Helicotylenchus spp. (principalmente $H$. dihystera), A. avenae, P. brachyurus, Paratrichodorus minor 
(Colbran, 1956) Siddiqi, 1974, Meloidogyne spp. (principalmente M. javanica), Peltamigratus holdemani Sher, 1964 e N. mutabile. H. dihystera predominou nas amostras de trigo (Triticum sp.) e apareceu juntamente com P. brachyurus nas de cevada (H. vulgare), triticale (XTriticosecale Vitmak.), centeio (Secale cereale L.) e azevém (Lolium sp.). Aphelenchoides spp. e A. avenae foram encontrados nas amostras de linho (Linum usitatissimum L.). Nas amostras de soja e de tremoço (Lupinus sp.) predominou o gênero Helicotylenchus. De um modo geral, Tylenchus spp., Aphelenchoides spp. e Ditylenchus spp. apareceram em todas as culturas.

CHARCHAR et al. (1980), analisando amostras procedentes dos municípios gaúchos de Canguçú, Jaguarão e Pelotas, encontraram associadas à cultura do alho (Allium sativus L.) H. dihystera, Pratylenchus penetrans (Cobb,1917) Filipjev \& Schuurmans Stekhoven, 1941, Pratylenchus zeae Graham, 1951 e Xiphinema brasiliense Lordello, 1951, além de espécies não identificadas dos gêneros Aphelenchoides, Aphelenchus. Criconemo ides, Helicotylenchus e Hemicycliophora.

Em estudo do gènero Helicotylenchus no Brasil, MOREIRA (1980) encontrou as espécies H. dihystera em amostras procedentes de plantaçöes de macieira, morangueiro, batata e cebola, e a espécie H. erythrinae asso- 
ciada a raízes de aspargo (Asparagus officinalis L.), todas no município de Pelotas. Registrou também $H$. dihystera e Helicotylenchus rotundicauda Sher, 1966, associadas a plantações de pessegueiro nos municípios de Pelotas e Bento Gonçalves.

BRANCALION et al. (1981) relataram a ocorrência de Heterodera fici Kirjanova, 1954 e M. incognita no município de Santa Cruz do Sul RS, em mudas de figueira (Ficus carica L.) procedentes de Valinhos, SP. Provavelmente tenha ocorrido uma disseminação passiva através das mudas, uma vez que $H$. fici já tinha sido relatada em S. Paulo por MONTEIRO et al. (1977).

BONETTI \& TRAGNAGO (1982), estudando resistência de soja a Meloidogyne, verificaram que $78 \%$ das 27 cultivares e 32 linhagens testadas apresentavam alta suscetibilidade a $M$. javanica. Registraram também que Meloidogyne sp. se encontrava presente nas plantações de soja nos municípios de Erechim, São Luiz Gonzaga, Santo Ângelo, São Vicente, Cachoeira do Sul, Tenente Portela, Santa Rosa, Três de Maio, Cruz Alta, Ibirubá, Julho de Castilho, Santa Maria e Gravataí. A espécie M. incognita foi encontrada somente no município de São Leopoldo. LUZ (1982) assinalou em cultura de trigo no RS nematóides fitoparasitos dos gênero Aphelenchus, Aphelenchoides, Criconemoides, Ditylenchus, Hoplolaimus, 
Longidorus, Meloidogyne, Paratylenchus, Pratylenchus, Radopholus, Trichodorus, Tylenchorhynchus, Tylenchus e Xiphinema, tendo identificado as espécies $A$. avenae, Ditylenchus dipsaci (Kühn, 1857) Filipjev, 1936, Hoplolaimus tylenchiformis Daday, 1905, Meloidogyne acrita Chitwood, 1949, Pratylenchus minyus Sher \& Allen, 1953 e Tylenchorhynchus striatus Allen, 1955.

RIBEIRO et al. (1984) verificaram a ocorrência de Meloidogyne sp. causando gallhas no sistema radicular de arroz irrigado, da cultivar Bluebelle, no município de Palmares do Sul, e suspeitaram que se tratava da espécie Meloidogyne graminicola Golden \& Birchfield, 1965. Estudando parte do material, HUANG et a 1 . (1984) identificaramno como Meloidogyne hapla Chitwood, 1949. SPERANDIO \& MONTEIRO (1991), reestudando parte do mesmo material, concluíram ser M. graminicola.

SPERANDIO ( 1985 ) encontrou Aphelenchoides fragariae (Ritzema Bos, 1890) Christie, 1932 e A. besseyi associadas a plantas de morangueiro (Fragaria sp.) no municipio de Feliz.

MONTEIRO \& COVOLO (1985) encontraram as espécies $P$. penetrans e P. brachyurus em lavoura de soja, no município de Ibirubá. Neste mesmo ano, MONTEIRO et al. (1985) relataram a ocorrência de D. dipsaci parasitando plantas de alfafa (Medicago sativa L.) no município de 
São Sebastião do Caí e SPERANDIO (1987) encontrou essa mesma espécie causando raquitismo e morte de plantas em um alfafal no município de Feliz.

ZEM et al. (1985) realizaram um levantamento das espécies de nematóides fitoparasitos que ocorrem em fumo (Nicotiana spp.) e encontraram as espécies $H$. dihystera, Hemycicliophorasp., M. arenaria, M. incognita, M. javanica, Paratrichodorus sp., P. brachyurus, P. zeae, Pratylenchus sp. e Xiphinema elongatum Schuurmans Stekhoven \& Teunissen, 1938, em amostras procedentes de diversos municípios produtores de fumo dos Estados de $S$. Catarina e Rio Grande do Sul.

D. dipsaci foi encontrada por MENDES (1987) em amostras de bulbos de alho procedentes dos municípios de caxias do Sul e Flôres da Cunha.

MONTEIRO et a 1. (1987) encontraram Pratylenchus scribneri steiner in Sherbakoff \& Stanley, 1943, H. dihystera, Meloidogyne sp., Xiphinema sp, Tylenchus sp. e Ditylenchus sp. em amostras procedentes de pomares e viveiros de macieira localizados no município de vacaria.

SPERANDIO (1987), fazendo um levantamento preliminar da ocorrència de nematóides fitoparasitos, em pomares no município de Pelotas, encontrou Aphelenchus sp., Aphelenchoides sp., Hel icotylenchus sp., Hemicyclio- 
phora sp. e Tylenchulus semipenetrans Cobb, 1913 associados a plantas cítricas; M. incognita, M. javanica, Pratylenchus sp., e Psilenchus sp. em pomares de figueira; Aphelenchus sp., M. javanica, Paratrichodorus sp. e Xiphinema sp. em pomares de macieira [Malus silvestris (L.) Mill.] e pessegueiro; e Aphelenchus sp., Helicotylenchus sp., Meloidogyne sp. e Xiphinema sp. associados a plantas de videira (Vitis vinifera L.).

SUDO \& ESPINDOLA (1987) realizaram levantamento da ocorrência de nematóides nas áreas produtoras de fumo (Nicotiana spp.), nos Estados do Paraná, Santa Catarina e Rio Grande do Sul, entre os anos de 1978 a 1985, e encontraram as espécies $M$. javanica em $50 \%$ das amostras, M. incognita em $20 \%$ e, a ocorrência destas duas espécies na mesma amostra chegou a $30 \%$. Neste mesmo levantamento encontraram esporadicamente $M$. arenaria e $M$. hapla associadas à cultura em questão.

CAFÉ FILHO \& HUANG (1988) encontraram poucos exemplares de P. brachyurus, P. zeae e Pratylenchus coffeae (Zimmerman, 1898) Filipjev \& Stekhoven, 1941 nos municípios de Pelotas e Bento Gonçalves associados a iferentes culturas. Nestes mesmos municipios, Pratylenchus jordanensis Hashim, 1983 foi encontrada associada somente à plantas de Vitis sp., seu hospedeiro tipo, e uma espécie que só descreveram posteriormente (Pratylenchus pseu- 
dofallax), associada a Malus silvestris. No ano seguinte, de amostras procedentes de Veranópolis (Lageadinho) e de Pelotas, descreveram a espécie Pratylenchus pseudofallax (CAFÉ FILHO \& HUANG, 1989).

Ver 1 ista por ordem alfabética dos gêneros e espécies de nematóides fitoparasitos encontrados no RS, entre os anos de 1910 - 1989, no anexo 1. 


\section{MATERIAL E MÉTODO}

\subsection{Coleta de amostras.}

As amostras de solo e raízes utilizadas no presente trabalho foram obtidas junto ao sistema radicular de plantas cultivadas, de pastagens nativas em campos de criação de animais e do interior de reflorestamentos e de matas nativas. Coletou-se de 1,5 a $2,0 \mathrm{~kg}$ de solo por amostra, aproximadamente, com uma pá reta, da superfície até a profundidade de $40 \mathrm{~cm}$. Raízes das plantas econômicas, em algumas amostras em mistura com as de ervas daninhas, principalmente gramíneas, também foram colhidas. Solo e raízes foram acondicionados em sacos plásticos, devidamente etiquetados e levados para processamento no laboratório de fitopatologia da Faculdade de Agronomia "Eliseu Maciel", da Universidade Federal de Pelotas, Pelotas-RS.

A amostragem foi feita entre os anos de 1982 a 1987 , em diferentes épocas, em 21 municipios abrangendo várias regiões do Estado do Rio Grande do Sul. O número de amostras coletadas por município dependeu das oportunidades, sendo maior em Pelotas. 


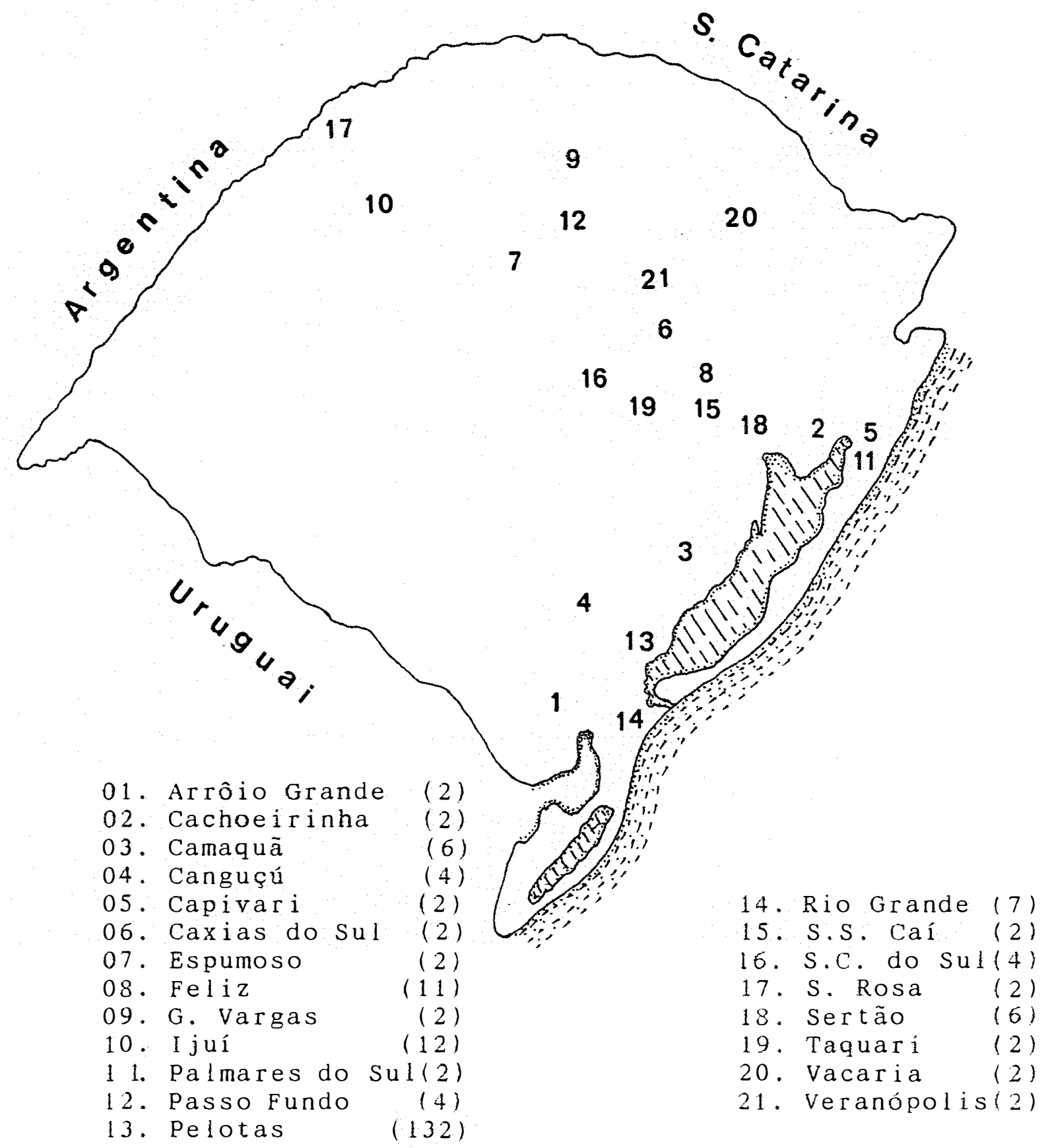

Fig. 1. Municípios do Estado do Rio Grande do Sul, onde amostras de solo e de raízes foram coletadas para exame nematológico. A quantidade de amostras por município figura entre parênteses. 


\subsection{Processamento das amostras.}

3.2.1. Extração. A separação dos nematóides das amostras de solo foi pelo método de flutuação-sedimentação e peneiramento, por vêzes combinado com o método do funil-de-Baermann (FLEGG \& HOOPER, 1970), ou com centrifugação em solução de sacarose, segundo o método descrito por JENKINS (1964). As peneiras usadas foram as de números 80,250 e 325, com aberturas de malha de $177 \mu \mathrm{m}, 62 \mu \mathrm{m}$ e $44 \mu \mathrm{m}$, respectivamente, da marca solotest.

As raízes foram lavadas com água corrente, cortadas com tesoura em pedaços de aproximadamente $1 \mathrm{~cm}$ de comprimento e colocadas em funil de Baermann por 72 horas.

No final dos processos tinha-se uma suspensão de nematóides em aproximadamente $10 \mathrm{ml}$ de água.

3.2.2. Fixação. Os nematóides foram mortos por aquecimento da suspensão em Banho-Maria, à temperatur a máxima de $60^{\circ} \mathrm{C}$, pelo tempo de um minuto, conforme o método descrito em HOOPER (1970a). Em seguida adicionouse a amostra igual volume de fixador de Golden mas com o dobro da concentração, isto é, contendo 4 partes de glicerina, 16 partes de formalina a $40 \%$ e 80 partes de água. As amostras assim processadas e fixadas foram conservadas em vidros claros, com tampa tipo "snap- 
cap" e volume aproximado de $20 \mathrm{ml}$. Essas amostras passaram a ser chamadas de amostras estoques.

\subsection{Preparações Microscópicas e Análise.}

3.3.1. Desidratação e infiltração com glicerina. Cada amostra estoque foi transferida para uma placa de Petri e observada em um estereomicroscópio. Os exemplares escolhidos foram transferidos, um a um, com auxílio de um bastão de bambú com ponta aguçada, para um vidro-de-relógio tipo "BPI" ("Bureau Plant Industry"), contendo solução de Seinhorst de concentração normal ( 20 partes de álcool $96^{\circ} \mathrm{GL}, 2$ partes de glicerina e 78 partes de água destilada). O BPI foi colocado em uma estufa, regulada a temperatura de $42^{\circ} \mathrm{C}$, onde permaneceu por tempo suficiente para que ocorresse uma completa evaporação do álcool e água e a impregnação dos nematóides com glicerina, conforme o método descrito em HOOPER (1970a).

\subsubsection{Montagem das 1 âminas. Para a monta-}

gem de lâminas permanentes, seguiu-se o método descrito por HOOPER (1970a). Os exemplares com caracteristicas mor fológicas semelhantes, aparentando ser da mesma espécie. foram transferidos do BPI para lamina, contendo pequena gota de glicerina desidratada. Para suportar a laminula e evitar danos nos exemplares, três pedaços de fibra de vidro, de diâmetro aproximadamente igual aos dos exempla- 
res, foram colocados ao redor da gota de glicerina. Parafina de ponto de fusão $56-58^{\circ} \mathrm{C}$ foi aplicada de modo a circundar a glicerina. Depois de cobrir com lamínula, a lâmina foi aquecida para derreter a parafina. Após esfriada e solidificada a parafina, completou-se a selagem aplicando uma camada de "Zut", ou de "esmalte-de-unha", nos bordos da lamínula. Cada lâmina recebeu etiqueta de identificação.

3.3.3. Montagem de lâminas especiais. Para estudo da região labial em vista frontal, de secções transversais do corpo e da vulva em vista ventral, foram montadas lâminas em geléia dura de glicerina, conforme o método descrito em southey (1970). Para observações de perineais de fêmeas de Meloidogyne spp., as preparações foram feitas seguindo-se o método descrito por TAYLOR et a 1. (1955) e por HARTMAN \& SASSER (1985).

3.3.4. Mensuração dos exemplares. As medidas foram obtidas com auxílio de ocular com escala micrométrica, exceto para os nematóides de corpo muito curvo ou em espiral. Neste caso, a mensuração do comprimento do corpo foi realizada com auxil io de curvímetro, passado em desenho de linha, feito com câmara clara, representando o eixo longitudinal de um extremo a outro do nematóide. Quanto a abreviaturas e símbolos, foram seguidos os descritos em HOOPER (1970b). 
3.3.5.Identificação. Os trabalhos de identificação foram feitos no laboratório de nematologia do Departamento de Zoologia da Escola Superior de Agricultura "Luiz de Queiroz", Piracicaba - SP, entre os anos de 1989 a 1991, utilizando sua biblioteca.

Para a classificação e diagnose dos Tylenchina, seguiu-se os conceitos de MAGGENTI et al. (1987); GERAERT \& RASKI (1987); FORTUNER \& MAGGENTI (1987); LUC \& FORTUNER (1987); FORTUNER \& LUC (1987); LUC (1987); FORTUNER (1987) e RASKI \& LUC (1987). Para a subordem Aphelenchina, adotou-se a subdivisão apresentada por SIDDIQI (1980b), que a considera como ordem, mas aqui é tomada como subordem, de acordo com MAGGENT et al. (1987). Para Longidoridae e Trichodoridae aceitou-se as classificações adotadas por ANDRÁSSY (1976).

A relação de plantas, das quais foram coletadas amostras de solo e raízes para o presente trabalho, é apresentada no apêndice 2 . 


\section{RESULTADOS E DISCUSSÃO}

4.1. Posição sistemática das espécies encontradas

Ordem TYLENCHIDA Thorne, 1949

Subordem TYLENCHINA Thorne, 1949

Superfamília Tylenchoidea örley, 1880

Famil i a Tylenchidae ôr ley, 1880

Subfamília Tylenchinae õrley, 1880

Gênero Tylenchus Bastian, 1895

Espécies: Tylenchus davainei Bastian, 1865

Subfamilia Tylodorinae Paramonov, 1967

Gênero Cephalenchus Goodey, 1962

Espécie: Cephalenchus leptus (Siddiqi, 1963)

Knobloch, 1972

Subfamília Atylenchinae Skarbilovich, 1959

Gênero Coslenchus Siddiqi, 1978

Espécie: Coslenchus alacinatus Siddiqi, 1980

Subfamilia Boleodorinae Khan, 1964

Gènero Psilenchus de Man, 1921

Espécie: Psilenchus hilarulus de Man, 1921 
Família Anguinidae Nicoll, 1935 (1926)

Gênero Ditylenchus Filipjev, 1936

Espécie: Ditylenchus dipsaci (Kühn, 1857) Filipjev, 1936

Família Dolichodoridae Chitwood, 1950

Gênero Dolichodorus Cobb, 1914

Espécie: Dolichodorus sp.

Famil ia Belonolaimidae Whitehead, 1960

Subfamília Telotylenchinae Siddiqi, 1960

Gênero Tylenchorhynchus Cobb, 1913

Espécies: Tylenchorhynchus sp. a

Tylenchorhynchus sp. b

Gênero Triversus Sher, 1974

Espécie: Triversus hollisi (Siddiqi, 1976)

Fortuner \& Luc, 1987

Familia Pratylenchidae Thorne, 1949

Gênero Pratylenchus Filipjev, 1936

Espécies: Pratylenchus brachyurus (Godfrey, 1929) Filipjev \& Schuurmans Stekhoven, 1941

P. scribneri Steinet in Sherbakoff \& Stanley, 1943

P. zeae Graham, 1951

Gênero Radopholus Thorne, 1949 
Espécie: Radopholus similis (Cobb, 1893) Thorne , 1949

Família Hoplolaimidae Filipjev, 1934

Subfamil ia Hoplolaiminae Filipjev, 1934

Gênero Hoplolaimus von Daday, 1905

Espécie: Hoplolaimus galeatus (Cobb, 1913)

Thorne, 1935

Gênero Aorolaimus Sher, 1963

Espécie: Aorolaimus perscitus Doucet, 1980

Gênero Helicotylenchus Steiner, 1945

Espécies: Helicotylenchus dihystera (Cobb,

1893 ) Sher, 1961

H. crenacauda Sher, 1966

Helicotylenchus sp.

Gênero Rotylenchus Filipjev, 1936

Espécie: Rotylenchus caudaphasmidius Sher, 1965

Gênero Scutellonema Andrássy, 1958

Espécies: Scutellonema brachyurus (Steiner,

1938) Andrássy, 1958

S. bizanae Van Den Berg \& Heyns, 1973

Família Heteroderidae Filipjev \& Schuurmans Stekhoven, 1941

Subfamilia Meloidogyninae Skarbilovich, 1959

Gênero Meloidogyne Goeldi, 1887

Espécies: Meloidogyne exigua Goeldi, 1887 
M. incognita (Kofoid \& White, 1919) Chitwood, 1949

M. javanica (Treub, 1885) Chitwood, 1949

Superfamília Criconematoidea Taylor, 1936

Família Criconematidae Taylor, 1936

Subfamília Criconematinae Taylor, 1936

Gênero Criconema Hofmãnner \& Menzel, 1914

Espécies: Criconema demani Micoletzki, 1925

Criconema sp. a

Criconema sp. b

Gênero Criconemella De Grisse \& Loof, 1965

Espécies: Criconemella palustris (Luc, 1970)

Luc \& Raski, 1981

C. reedi (Diab \& Jenkins, 1966)Luc \& Raski, 1981

C. sphaerocephala (Taylor,

Luc \& Raski, 1981

C. xenoplax (Raski, 1952) Luc \& Ras-

ki, 1981

Criconemella sp.

Gènero Discocriconeme 1/a De Grisse \& Loof, 1965

Espécie: Discocriconemella sp. 
Gênero Hemicriconemoides Chitwood \& Birchfield, 1957

Espécie: Hemicriconemoides minutus Esser, 1960

Gênero Ogma Southern, 1914

Espécie: Ogma civellae (Steiner, 1949) Luc \& Raski, 1987

Subfamília Hemicycliophorinae Skarbilovich, 1959

Gênero Hemicycliophora de Man, 1921

Espécies: Hemicycliophora poranga Monteiro \& Lordello, 1978

H. ripa Doucet, 1982

H. tenuistriata Doucet, 1982

Gênero Caloosia Siddiqi \& Goodey, 1964

Espécie: Caloosia paradoxa (Luc, 1958) Brzes$\mathrm{ki}, \quad 1974$

Família Tylenchulidae Skarbilovich, 1947

Subfamilia Paratylenchinae Thorne, 1949

Gênero Paratylenchus Micoletzky, 1922

Espécie: Paratylenchus aquaticus Merny, 1966

Subordem APHELENCHINA Geraert, 1966

Superfamília Aphelenchoidea Fuchs, 1937

Famil ia Aphelenchidae Fuchs. 1937

Gênero Aphelenchus Bastian, 1865

Espécie: Aphelenchus avenae Bastian, 1865 
Superfamília Aphelenchoidoidea Skarbilovich, 1947

Família Aphelenchoididae Skarbilovich, 1947

Subfamil ia Aphelenchoidinae Skarbilovich, 1947

Gênero Aphelenchoides Fisher, 1894

Espécie: Aphelenchoides besseyi Christie, 1942

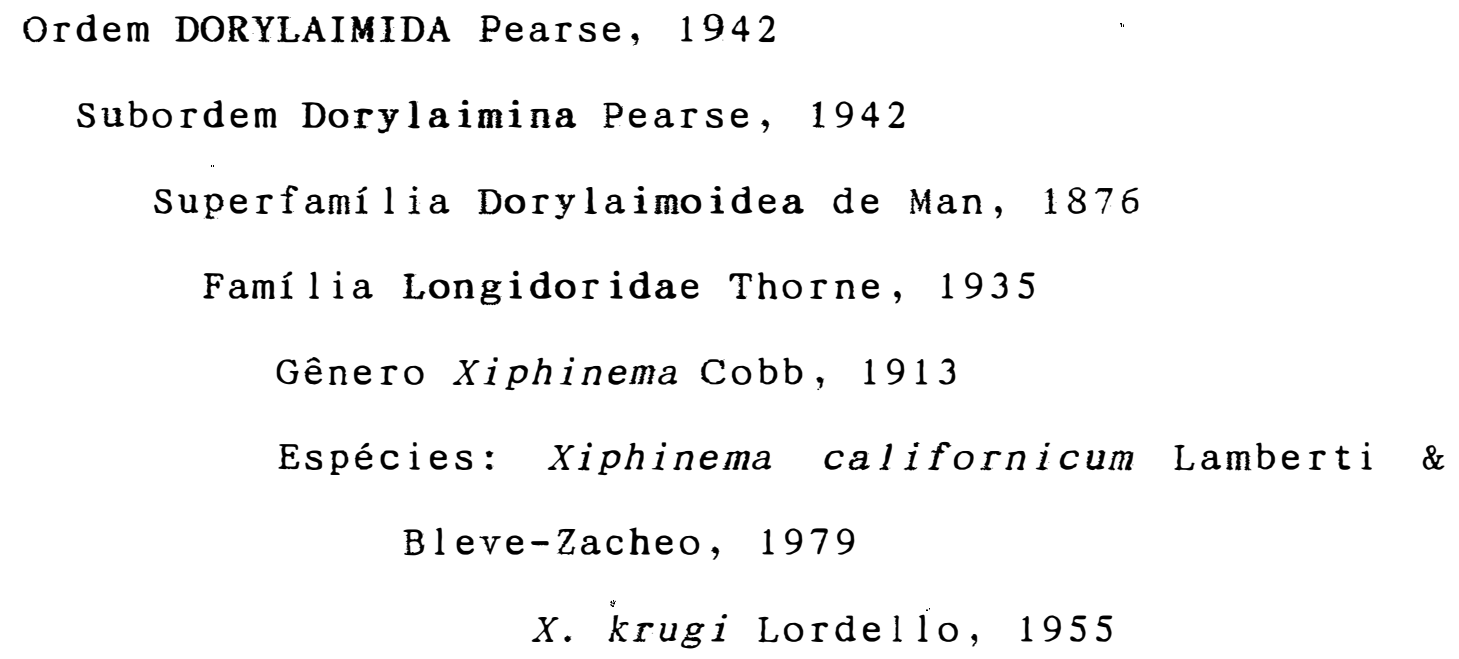

Subordem Diphtherophorina Coomans \& Loof, 1970

Famil ia Trichodoridae Thorne, 1953

Gênero Paratrichodorus Siddiqi, 1974

Espécie: Paratrichodorus minor (Colbran, 1956)

Siddiqi , 1974 


\subsection{Considerações sobre as espécies}

\subsubsection{Espécies já nominadas}

01. Tylenchus davainei Bastian, 1865

\section{S inônimos}

Anguillulina davainei (Bastian, 1865)

Goodey, 1932; Anguillulina (Tylenchus) davainei (Bastian 1865 ) Goodey, 1932 (Schneider, 1939).

\section{Mensurações}

Fêmeas $(\mathrm{n}=8): \mathrm{L}=0,85(0,83-0,87) \mathrm{mm}$;

$a=33,5(32,9-34,2) ; b=6,7(6,5-7,0) ; c=6,0$ $(5,6-6,3) ; c^{\prime}=8,6(8,5-8,7) ; O=13,4(9,0-20,0) ;$ $M=41,4(40,0-45,0) ; V=61,6(60,8-62,8) ; \mathrm{St}=17,5$ $(16,9-18,6) \mu \mathrm{m} ; \mathrm{t}=145,0(144,0-147,0) \mu \mathrm{m} ; \quad \mathrm{EP}=109$ $(108-110) \mu \mathrm{m} ; \mathrm{MB}=45,4(40,0-47,0) ; \mathrm{VA}=190,0$ $(184,7-196,6) \mu \mathrm{m}$.

Macho: não encontrado.

Observações

As características morfológicas observadas, bem como as mensurações obtidas, estão de acordo com a descrição de ANDŔ́ASSY (1977) para a espécie, com exceção de um exemplar que apresenta comprimento do corpo mais curto $(L=0,67 \mathrm{~mm})$ e as faixas externas do campo lateral 
areoladas, em vez de crenada, como é descrito para espécie.

Ocorrência

A espécie foi encontrada em solo junto as raízes de plantas de pessegueiro e videira (Pelotas) e em mata nativa (Canguçú).

Este é o primeiro relato da espécie para o Estado, já encontrada em 'rizosfera de cacaueiros na Bahia (SHARMA \& SHER, 1973) e Espírito Santo (SHARMA \& SHER， 1974) .

02. Cephalenchus leptus (Siddiqi, 1963) Knobloch, 1972 Mensurações

Fêmeas $(n=6): L=0,65(0,61-0,69) \mathrm{mm}$; $a=46,9(41-51,1) ; b=6,7(5,3-7,9) ; c=3,2(3,1$ $-3,5) ; \quad c^{\prime}=19,5(15,0-23,3) ; \quad M=52,2(45,4-$ $54,5) ; \quad V=59,3(57,1-61,9) ; \quad S t=16,7(16,5-18,0)$ $\mu \mathrm{m} ; \quad \mathrm{R}=216(208-230) ; \mathrm{RSt}=11 ;$ ROes $=48(45-50) ;$ $\operatorname{Rex}=36(35-38) ; \operatorname{RVan}=37(35-38) ; t=196(187-$ 210) $\mu \mathrm{m} ; \mathrm{EP}=68,7(57,5-75,0) \mu \mathrm{m}$.

Machos $(n=3): L=0,65(0,57-0,73) \mathrm{mm}$;

$a=41,2(38,0-45,0) ; b=7,6(7,2-8,1) ; c=3,9(3,7$

$-4,2) ; c^{\prime}=15,2(13,6-17,1) ; M=54,5 ;$ Esp $=19,0(18,0$ 
$-19,5) \mu \mathrm{m} ; \mathrm{St}=16,5 \mu \mathrm{m} ; \mathrm{t}=166(135-184) \mu \mathrm{m} ; \mathrm{EP}=72$ $(69-75) \mu \mathrm{m}$.

Observações

Não se dispondo da descrição original de Siddiqi(1963), recorreu-se às redescrições de ANDRÁSSY (1984) e RASKI \& GERAERT (1986), pelas quais foi possível identificar a espécie. Machos de $C$. leptus não constam da descrição original da espécie, mas foram descritos por KNOBLOCH (1972), com eles concordando o material brasileiro.

Ocorrência

A espécie foi encontrada em solo de resteva de arroz irrigado (Camaquã) e de gramíneas nativas não identificadas, caquizeiro e sorgo sacarino (Pelotas). Obteve-se de 1 a 2 exemplares por amostra, totalizando 6 fêmeas e 3 machos. É a primeira observação desta espécie no Brasil.

03. Coslenchus alacinatus Siddiqi, 1980 Mensurações

Fêmeas $(\mathrm{n}=6): L=0,56(0,52-0,65) \mathrm{mm}$;

$a=32,9(29,1-38,0) ; b=6,1(5,9-6,7) ; c=5,5(5,0$

$-5,9) ; \quad c^{\prime}=10,9(10-11,6) ; V=64,9(62,8-67,6) ;$

$S t=10,2(9,0-10,5) \mu m ; M \mathbf{s}=51,0(45,4-63,0) ;$ RSt 
$=5-7 ; \operatorname{Rex}=38(35-40) ; \operatorname{ROes}=47(45-52) ; \operatorname{RVan}=$ $39(36-44) ; t=101,7(90-111) \mu \mathrm{m}$.

Macho: não encontrado.

Observações

O material concorda com a descrição original da espécie (SIDDIQI, 1980a).

Ocorrência

Essa espécie foi encontrada em solo junto a plantas de citros (Pelotas) e de mata nativa (Canguçú). E o primeiro relato do gênero e espécie para o RS.

O gênero já havia sido registrado no Brasil. As espécies Coslenchus bisexualis Siddiqi, 1981 e C. areolatus (Egunjobi, 1967) Siddiqi, 1978 foram encontradas na Bahia por RASHID et al. (1987), associadas a cacaueiros.

04. Psilenchus hilarulus de Man, 1921

Mensurações

$$
\begin{aligned}
& \text { Fêmeas }(\mathrm{n}=2): \mathrm{L}=1,11(1,06-1,16) \mathrm{mm} ; \\
& \mathrm{a}=44,0(40,8-47,3) ; \mathrm{b}=7,6(7,4-7,7) ; \mathrm{c}=7,8(7,8 \\
& -7,9) ; \mathrm{c}^{\prime}=8,5(8,1-9,0) ; \mathrm{Pc}=64,2(64,0-64,5) ; \\
& \mathrm{V}=48,0(47,6-48,0) ; \mathrm{St}=18,0(16,5-19,5) \mu \mathrm{m} ; \mathrm{Ga} \\
& =30,0(29,0-31,0) ; \mathrm{Gp}=28,0(26,0-31,0) ; \mathrm{MB}= \\
& 45,5(41,3-49,0) ; \mathrm{t}=141,0(135,0-147,0) \mu \mathrm{m} .
\end{aligned}
$$


$\operatorname{Machos}(\mathrm{n}=5): \mathrm{L}=0,94(0,84-1,36) \mathrm{mm}$ $a=47,8(42,1-54,1) ; b=6.6(5,7-7,5) ; \quad c=7,22$ $(6,1-9,7) ; \quad c^{\prime}=8,50(6,4-10,0) ; \quad P c=59,6(51,0-$ $67,0) ; \mathrm{St}=18,3(18,0-19,5) \mu \mathrm{m} ; \mathrm{MB}=46,6(45,2-$ $48,0) ; E s p=24,1(23,0-27,0) \mu \mathrm{m} ; \quad t=144,4(127,0-$ $168,0) \mu \mathrm{m}$.

Observaçōes

As características morfológicas observadas, bem como as mensurações obtidas, estão de acordo com a descrição de THORNE (1949) para a espécie, com exceção para os valores ligeiramente maiores de a para machos e fêmeas $(a=42,1-54,1$ vs. $32-36$ e $40,8-47,3$ Vs. $33-$ 38, respectivamente) e b para fêmeas $(b=7,4-7,7$ Vs. $6,5-7,1)$.

Ocorrência

Esses adultos medidos e alguns outros, juntamente com larvas, foram obtidos em solo de mata nativa na localidade de Quilombo e em pomares de citros, caquizeiro e figueira (Pelotas). E o primeiro relato da espécie para o RS, porém o gênero Psilenchus já havia sido encontrado por SPERANDIO (1987), em rizosfera de figueira, de um pomar no município de Pelotas. No Brasil, essa espécie já tinha sido encontrada em rizosfera de seringueira (Hevea brasilensis Mull. Arg.) e em melão-são-caetano 
(Momordica charantia L.) na Bahia (SHARMA \& LOOF, 1973; 1974, respectivamente).

05. Ditylenchus dipsaci (Kühn, 1857) Filipjev, 1936 Sinônimos

Anguillula dipsaci Kühn, 1857; Tylenchus dipsaci (Kühn, 1857) Bastian, 1865; vide a grande lista de sinônimos em HOOPER (1972).

Mensurações

Fêmeas $(n=15): L=1,10(0,87-1,30) \mathrm{mm}$;

$a=46,9(45,0-51,0) ; \quad b=7,2(6,7-7,6) ; \quad c=12,3$ $(10,9-13,7) ; \quad c^{\prime}=5,3(4,7-6,5) ; \quad V=80,7(80,0$

$-81,5) ; \quad S t=12,0 \mu \mathrm{m} ; \quad \mathrm{Spu}=57,0 \mu \mathrm{m} ; \quad \mathrm{t}=90,0(79,5$

$-102,0) \mu \mathrm{m} ; \quad \mathrm{MB}=37,8(36,0-42,6) ; \quad \mathrm{EP}=117(105$

$-127) \mu \mathrm{m} ; \mathrm{Ga}=47,9 \cdot(36,2-51,7)$.

Machos $(n=10): L=1.10(0,97-1,31) \mathrm{mm}$

$a=46,2(40,5-54,6) ; b=6,7(6,3-7,0) ; c=14,0$ $(13,3-15,4) ; c^{\prime}=4,4(4,0-5,2) ; \quad$ Esp $=22,2(21,0-$ $22,5) \mu \mathrm{m} ; \mathrm{Gub}=10,2(9,0-10,5) \mu \mathrm{m} ; \mathrm{St}=11,7(10,5-$ $12,0) \mu \mathrm{m} ; \quad \mathrm{T}=68,0(58,8-76,2) ; \mathrm{t}=79,2(72,0-$ $93,0) \mu \mathrm{m} ; \quad \mathrm{MB}=36,9(34,4-40,0) ; \quad \mathrm{EP}=117,6(112,0-$ $127,0) \mu \mathrm{m}$. 


\section{Observações}

As características morfológicas observadas e as mensurações obtidas estão de acordo com a descrição de HOOPER (1972) para a espécie, exceto para a, que tem valores um pouco inferiores aos apresentados por esse autor (fêmeas: $a=45,0-51,0$ Vs. $50,0-64,0$; machos: a $=40,5-54,6$ Vs. $58,0-74,0)$.

Ocor rência

Essa nociva espécie foi encontrada em rizosfera de plantas de alfafa (Feliz) e alho (Pelotas). Já havia sido registrada no RS parasitando plantas de alfafa (MONTEIRO et al. 1985; SPERANDIO \& QUEIROZ FILHO, 1987) e em bulbos de alho (MENDES, 1987).

06. Triversus hollisi (Siddiqi, 1976) Fortuner \& Luc, 1987

\section{Mensurações}

Fêmea $(\mathrm{n}=1): \mathrm{L}=0,82 \mathrm{~mm} ; \mathrm{a}=37,6 ; \mathrm{b}=$ 6,$0 ; c=11 ; c^{\prime}=5,6 ; \mathrm{St}=24,2 \mu \mathrm{m} ; \mathrm{V}=52,2 ; \mathrm{MB}=5,1 ;$ $E P=99,0 \mu \mathrm{m} ; \quad P C=45,1 \mu \mathrm{m} ; \quad t=74,8 \mu \mathrm{m} ; \quad d=2,0 ; \mathrm{e}=$ 8,$3 ; z=34,2 ; \quad \mathrm{VL} / \mathrm{VB}=17,9 ; \mathrm{VL} / \mathrm{St}=16,3 ; \mathrm{VA} \% \mathrm{t}=429,0 ;$ St\%L $=2,9 ;$ St\%Oes $=17,5 ;$ EP\%Oes $=71,8$. Macho $(n=1): L=0,69 \mathrm{~mm} ; a=35,3 ; b=$ 6,$5 ; \quad c=24,2 ; \quad C^{\prime}=1,9 ; \quad S t=25,5 \mu \mathrm{m} ; \quad M=47,0 ; E P=$ 
$99,0 \mu \mathrm{m} ; \mathrm{O}=11,7 ; \mathrm{MB}=51,1 ; \mathrm{T}=60,8 ; \mathrm{Esp}=28,5 \mu \mathrm{m} ; \mathrm{Gub}$ $=16,5 \mu \mathrm{m}$.

Observações

As características morfológicas observadas e as mensurações obtidas concordam com a descrição original de SIDDIQI (1976) para a espécie.

Ocorrência

Os únicos exemplares obtidos foram encontrados em rizosfera de cana-de-açúcar na Estação Experimental da Central - EMBRAPA (Pelotas). E o primeiro relato do gênero e da espécie para o RS.

07. Pratylenchus brachyurus (Godfrey, 1929) Filipjev \& Schuurmans Stekhoven, 1941

S i nôn imos

Tylenchus brachyurus Godfrey, 1929; Tylen- . chus (Chitinotylenchus) brachyurus Godfrey, 1929 (Filipjev, 1934); Anguillulina brachyurus (Godfrey 1929) Goodey, 1932; Pratylenchus pratensis in Thorne, 1940, partim; Pratylenchus leiocephalus steiner, 1949 e Pratylenchus steineri Lordello, Zamith \& Boock, 1954. Mensurações

Fêmeas $(n=10): L=0,56(0,49-0,63) \mathrm{mm}$; $a=26,4(23,3-28,2) ; b=6,8(6,3-7,4) ; b=3,9$ 
$(2,9-4,7) ; c=18,6(14,5-21,7) ; \quad V=86,3(84,3$

$-88,0) ; \mathrm{St}=18,3(18,0-19,5) \mu \mathrm{m}$.

Macho: não encontrado.

Observações

As características morfológicas observadas e as mensurações obtidas estão de acordo com as descrições de CORBETT (1976); CORBETT \& CLARK (1983); LOOF (1960, 1978); LORDELLO et a 1.(1954) e SHER \& ALLEN (1953) para a espécie. Esses exemplares apresentam comprimento de estilete ligeiramente superior aos valores registrados por CAFE FILHO \& HUANG (1988), de material coletado em Pelotas e Bento Gonçalves.

Ocorrências

Essa espécie, já conhecida no RS, foi encontrada em solo cultivado com crotalária (Crotalaria juncea L.), em área anteriormente ocupada por soja, no Município de Ijuí, e em solo e raízes de fumo, em plantação comercial na localidade de Santa Auta (Camaquã).

08. Pratylenchus scribneti steiner, in sherbakoff \& Stanley, 1943

Sinônimo

Pratylenchus penetrans (Cobb, 1917) partim. 
Mensurações

$$
\begin{aligned}
& \text { Fêmeas }(\mathrm{n}=8): \mathrm{L}=0,45(0,42-0,50) \mathrm{mm} ; \\
& \mathrm{a}=31,5(28,8-38,9) ; \mathrm{b}=6,1(5,6-6,9) ; \mathrm{b}=3,8 \\
& (3,4-4,3) ; \mathrm{c}=16,1(13,2-17,6) ; \mathrm{V}=77,7(77,0 \\
& -79,1) ; \mathrm{St}=15,0 \mu \mathrm{m} ; \mathrm{Spu}=16,5(15,0-18,0) \mu \mathrm{m} ; \mathrm{Ga} \\
& =28,0(25,1-30,2) .
\end{aligned}
$$

Macho: não encontrado.

Observações

As características morfológicas e as mensurações obtidas concordam com a descrição de LOOF (1985) para a espécie. Os caracteres observados também concordam com os descritos por CAFÉ FILHO \& HUANG (1988); FREDERICK \& TARJAN (1989) e HANDOO \& GOLDEN (1989).

Ocorrências

A espécie foi encontrada em solo coletado junto a plantas de macieira (Vacaria) e pessegueiro (Pelotas). Anteriormente, MONTEIRO et a l. (1987) relataram-na associada à macieira em amostras procedentes do município de Vacaria.

\section{Pratylenchus zeae Graham, 1951}

Si nôn imo

Pratylenchus cubensis Razzivin \& O'Reil1y, 1976. 
Mensurações

Fêmeas $(\mathrm{n}=12): \mathrm{L}=0,44(0,36-0,53) \mathrm{mm} ;$
$\mathrm{a}=29,7(24,6-32,3) ; \mathrm{b}=6,4(4,9-7,1) ; \mathrm{c}=15,9$
$(12,3-19,6) ; \mathrm{V}=70,8(69,6-72,8) ; \mathrm{St}=15,5(15,0-$
$15,5) \mu \mathrm{m} ; \mathrm{Spu}=15,0(13,5-31,5) \mu \mathrm{m} ; \mathrm{Ga}=29,1(24,4-$
$34,4) \mu \mathrm{m}$.

Machos: não encontrado.

Observações

Concordando com as descrições de SHER \& ALLEN (1953); FORTUNER (1976); LOOF (1978); CAFÉ FILHO \& HUANG (1988), os exemplares obtidos no RS não mostraram variações apreciáveis.

Ocorrências

A espécie, assinalada por CHARCHAR et al. (1980) no RS, foi encontrada em solo de batata, ervas daninhas não identificadas, cana-de-açúcar, pastagens nativa e trigo todas no Município de Pelotas; de fumo (Camaquã) e de grama de jardim (Caxias do Sul). Exemplares também foram extraídos das raízes de gramíneas.

10. Radopholus similis (Cobb, 1893) Thorne, 1949 S inôn imos

Tylenchus similis Cobb, 1893; Tylenchus granulosus Cobb, 1893; Tylenchus biformis Cobb, 1909; 
Tylenchus acutocaudatus Zimmermann, 1898 e outros. Ver 1 ista completa em ORTON WILLIAMS \& SIDDIQI (1973).

Mensurações

$$
\begin{aligned}
& \text { Fêmeas }(\mathrm{n}=10): \mathrm{L}=0,54(0,44-0,64) \mathrm{mm} ; \\
& \mathrm{a}=29,9(24,0-35,8) ; \mathrm{b}=6,1(4,9-7,2) ; \mathrm{c}=9,3 \\
& (8,0-11,2) ; \mathrm{c}^{\prime}=4,2(3,3-5,3) ; \mathrm{V}=57,5(55,7-58) ; \\
& \mathrm{St}=16,2(15,0-16,5) \mu \mathrm{m} ; \mathrm{Ga}=20,0(18,4-21,2) ; \mathrm{Gp}= \\
& 18,7(15,5-21,0) ; \mathrm{EP}=84,0(75,0-91,5) \mu \mathrm{m} ; \mathrm{H}=7,1 \\
& (6,0-7,5) \mu \mathrm{m} ; \mathrm{t}=58,3(51,0-64,5) \mu \mathrm{m} . \\
& \qquad \mathrm{Macho}(\mathrm{n}=1): \mathrm{L}=0,49 \mathrm{~mm} ; \mathrm{a}=25,0 ; \mathrm{b}= \\
& 4,1 ; \mathrm{c}=8,4 ; \mathrm{c}^{\prime}=4,8 ; \mathrm{MB}=66,0 ; \mathrm{EP}=79,5 \mu \mathrm{m} ; \mathrm{T}=46,8 ; \\
& \text { Esp = } 16,5 \mu \mathrm{m} ; \mathrm{H}=6,0 \mu \mathrm{m} ; \mathrm{t}=58,5 \mu \mathrm{m} . \\
& \text { Observações }
\end{aligned}
$$

Fêmeas: as características morfológicas observadas bem como as mensurações obtidas estão de acordo com a descrição de SHER (1968) para a espécie, com exceção para o comprimento do corpo $(L=0,44-0,64$ Vs. 0.52 $-0,88 \mathrm{~mm})$, estilete $(15,0-16,5 \mathrm{Vs} \cdot 17-20 \mu \mathrm{m})$ e porção hialina da cauda $(\mathrm{H}=6,0-7,5 \mathrm{Vs} .9 .0-16,0 \mu \mathrm{m})$ com valores menores.

Macho: o único macho observado apresenta comprimento do corpo $(\mathrm{L}=0,49 \mathrm{Vs} .0,59-0,67 \mu \mathrm{m})$ e porção hialina da cauda $(\mathrm{H}=5,2 \mathrm{Vs} .7-11 \mu \mathrm{m})$ menores que as apresentadas por SHER (1968). 
Ocorrências

Essa espécie, agora assinalada no Estado, foi encontrada na rizosfera de gramíneas nativas não identificadas em campo de criação de animais e em eucaliptal (Pelotas).

11. Hoplolaimus galeatus (Cobb, 1913) Thorne, 1935 Sinônimos

Nemonchus galeatus Cobb, 1913; Hoplolaimus coronatus Cobb, 1923 e Hoplolaimus tylenchiformis in Andrássy, 1958 , partim.

Mensurações

$$
\begin{aligned}
& \text { Fêmeas }(\mathrm{n}=14): \mathrm{L}=1,51(0,97-1,95) \mathrm{mm} ; \\
& \mathrm{a}=24,7(17,3-28,8) ; \mathrm{b}=10,4(9,2-13,0) ; \mathrm{b}=7,2 \\
& (6,9-8,0) ; \mathrm{c}=50,2(44,7-68,0) ; \mathrm{c}=0,7(0,5-1,0) ; \\
& \mathrm{O}=16,2(13,0-19,0) ; \mathrm{V}=55,2(52,5-57,0) ; \mathrm{St}=48,3 \\
& (48,2-49,0) \mu \mathrm{m} ; \mathrm{M}=52,7(50,0-56,2) ; \mathrm{Pa}=28,7(23,0- \\
& 39,5) ; \mathrm{Pp}=79,3(72,0-85,0) ; \mathrm{t}=24,8(22,5-30,0) \mu \mathrm{m} . \\
& \mathrm{a}=26,3(20,5-33,0) ; \mathrm{b}=9,5(8,4-11,0) ; \mathrm{b}=7,1 \\
& (6,3-7,3) ; \mathrm{c}=35,8(30,4-39,6) ; \mathrm{c}=1,4(1,0-1,6) ; \\
& 0=15,5(13,0-18,0) ; \mathrm{St}=48,0(45,0-52,5) \mu \mathrm{m} ; \mathrm{Pa}= \\
& 27,6(24,0-31,4) ; \mathrm{Pp}=77,1(74,0-81,0) ; \mathrm{Esp}=48,3 \\
& (46,5-51,0) \mu \mathrm{m} ; \mathrm{Gub}=25,8(24,0-27,0) \mu \mathrm{m} .
\end{aligned}
$$


Observações

O material concorda com $H$. galeatus segundo descrição de SHER (1963a) e de ORTON WILliAMS (1973b). Ocorrências

Relatada no país primeiramente por MENDONÇA (1976) em abacaxizeiro cultivado em Bastos, SP, essa espécie é agora assinalada no RS (Pelotas), em solo de beterraba açucareira, citros, figueira, pastagem nativa, pessegueiro e videira.

12. Aorolaimus perscitus (Doucet, 1980) Fortuner, 1987 S inôn i mo

Peltamigratus perscitus Doucet, 1980.

Mensurações

$$
\begin{aligned}
& \text { Fêmeas }(\mathrm{n}=9): \mathrm{L}=0,90(0,81-1,01) \mathrm{mm} ; \\
& \mathrm{a}=27,9(23,6-31,2) ; \mathrm{b}=8,8(7,4-10,3) ; \mathrm{b}=6,1 \\
& (5,1-7,7) ; \mathrm{c}=72,1(62,5-83,5) ; \mathrm{c}=0,56(0,42 \\
& -0,66) ; \mathrm{O}=21,5(17,3-22,7) ; \mathrm{V}=56,6(54,7-58,7) ; \\
& \mathrm{St}=33,1(31,5-34,5) \mu \mathrm{m} ; \mathrm{Pa}=74,7(69,6-85,5) ; \mathrm{Pp}= \\
& 86,9(83,8-88,8) ; \mathrm{t}=12,6(9,0-15,0) \mu \mathrm{m} . \\
& \mathrm{a}=31,7(29,4-34,1) ; \mathrm{b}=8,5(8,2-8,8) ; \mathrm{b}=5,8(5,8- \\
& 5,9) ; \mathrm{c}=51,0(50,9-51,2) ; \mathrm{c}=0,90(0,80-1,00) ; \\
& 0=22,5(20,0-25,0) ; \mathrm{St}=30,0 \mu \mathrm{m} ; \mathrm{Pa}=83,2(82,1-
\end{aligned}
$$


$84,2) ; \mathrm{Pp}=87,8(87,5-88,2) ; \mathrm{t}=15,7(15,0-16,5) \mu \mathrm{m}$;

Esp $=27,5(27,0-28,5) \mu \mathrm{m} ; \mathrm{Gub}=14,0 \mu \mathrm{m}$.

Observações

O material analisado concorda satisfatoriamente com a descrição original de DOUCET (1980), especialmente as fêmeas. Entretanto, os machos do material brasileiro são menores que os da Argentina $(L=0,76-0,84$ Vs. $0,92-0,94 \mathrm{~mm}$ ) e apresentam valores maiores para c $(c=50,9-51,2$ Vs. 41,6-43,7), o $(0=20,0-25,0$ Vs $13,5-19,0)$ e Esp $(\operatorname{Esp}=27,0-28,5 \mathrm{Vs} .33,5-35,0 \mu \mathrm{m})$. Ocorrências

Os exemplares foram encontrados em solo da rizosfera de alho, pessegueiro e gramíneas nativas, todas em Pelotas. Essa espécie, originalmente descrita na Argentina, agora é assinalada no Brasil.

13. Helicotylenchus dihystera (Cobb, 1893) Sher, 1961 S inôn imos

Tylenchus dihystera Cobb, $1893 ;$ T. olaae Cobb, 1906; T. spiralis Cassidy, 1930; Tylenchorhynchus olaae (Cobb, 1893) Micoletzki, 1922; Aphelenchus dubius var.peruensis Steiner, 1920 ; Helicotylenchus nannus steiner, 1945; H. crenatus Das, 1960; H. flatus Román, 1965; H. punicae Swarup \& Sethi, 1968 e H. paraconcavus Rashid \& Khan, 1974 . 
Mensurações

$$
\begin{gathered}
\text { Fêmeas }(\mathrm{n}=15): \mathrm{L}=0,63(0,58-0,68) \mathrm{mm} ; \\
\mathrm{a}=27,9(25,0-30,7) ; \mathrm{b}=5,8(5,4-6,7) ; \mathrm{b}=4,5 \\
(4,0-4,9) ; \mathrm{c}=45,1(41,2-57,2) ; \mathrm{c}^{\prime}=1,0(0,9-1,1) ; \\
\mathrm{O}=40,0(30-50) ; \mathrm{M}=46,4(41,0-50,0) ; \mathrm{St}=24,1 \\
(22,5-25,5) \mu \mathrm{m} ; \mathrm{V}=63,5(61,8-65,3) . \\
\text { Macho: não encontrado. }
\end{gathered}
$$

Observações

A morfologia dos exemplares estudados concorda com as descrições de SHER (1966) e de SIDDIQI (1972) para a espécie. As diferenças encontradas na forma da cauda se enquadram nas observacões feitas por FORTUNER (1984 a; b) e FORTUNER et al. (1981). Os valores das mensurações aqui obtidos concordam com os relatados por MENDONÇA (1976) de uma populacão associada a plantas de milho cultivadas em S. Maria.

Ocorrências

A espécie em questão foi encontrada no solo junto ao sistema radicular de plantas de alfafa (Feliz), al ho (Rio Grande), acácia-negra, álamo, alface, bambú, batata, beterraba, berinjela, cana-de-açúcar, caquizeiro, chorão, ervas daninhas não identificadas, eucalipto, hortência, milho, pessegueiro, pinus, sorgo, trigo, tomateiro (Pelotas), citros (Pelotas e Taquari), figueira (Santa Cruz do Sul), grama-de-jardim (Caxias do Sul), macieira 
(Pelotas e Vacaria), horta doméstica (Espumoso), soja (Ijuí, Passo Fundo e Santa Rosa), arroz (Camaquã), erva mate (Sertão), fumo (Camaquã), mata nativa. (Canguçú), morangueiro (Feliz e São Sebastião do Caí), videira (Pelotas e Veranópolis). Obteve-se máis de sete centenas de exemplares.

\section{Helicotylenchus crenacauda Sher, 1966}

S inônimos

Helicotylenchus pteracercus Singh, 1971 ; H. paracrenacauda Phukan \& Sanwal, 1981 e H. pteracercusoides Fotedar \& Kaul, 1985

Mensurações

$$
\begin{aligned}
& \text { Fêmeas }(\mathrm{n}=11): \mathrm{L}=0,74(0,65-0,88) \mathrm{mm} ; \\
& \mathrm{a}=29,8(25,6-33,3) ; \mathrm{b}=6,3(5,6-7,4) ; \mathrm{b}^{\prime}=5,0(4,2 \\
& -6,1) ; \mathrm{c}=37,4(32,0-43,0) ; \mathrm{c}=1,3(1,0-1,5) ; \\
& 0=0,5(0,47-0,52) ; \mathrm{M}=48,0(41,1-50,0) ; \mathrm{V}=63,7 \\
& (62,1-65,2) ; \mathrm{St}=25,3(24,0-27,0) \mu \mathrm{m} ; \mathrm{t}=20,1(18,0- \\
& 24,0) \mu \mathrm{m} .
\end{aligned}
$$$$
\text { Macho: não encontrado. }
$$

Observações

Os exemplares aqui observados concordam com a descrição original da espécie (SHER, 1966). 
Ocorrências

Essa espécie foi encontrada associada à resteva de arroz irrigado (Camaquã), cana-de-açúcar, fi- . gueira e pessegueiro (Pelotas) e $\operatorname{soja}$ (Santa Cruz do Sul). Esta é a primeira citação da espécie no RS. No Brasil, ela já fora encontrada associada à rizosfera de bananeira na Bahia (SHARMA \& LOOF, 1984).

\section{Rotylenchus caudaphasmidius Sher, 1965}

Mensurações

$$
\begin{aligned}
& \text { Fêmeas }(n=9): L=0,60(0,51-0,67) \mathrm{mm} \text {; } \\
& a=26,4(23,2-28,9) ; b=6,2(5,7-7,0) ; b^{\prime}=4,8(4,5 \\
& -6,2) ; c=49,3(40,8-57,7) ; c^{\prime}=0,8(0,6-1,0) ; 0= \\
& 20,0(18,0-23,0) ; M=48,9(46,7-53,0) ; V=62,8(61,1 \\
& -65,7) ; \quad S t=26,3(24,5-29,5) \mu \mathrm{m} ; t=12,3(10,5- \\
& 13,5) \mu \mathrm{m} ; E P=95,5(82,5-103,5) \mu \mathrm{m} . \\
& \operatorname{Machos}(\mathrm{n}=7): \mathrm{L}=0,56(0,52-0,59) \mathrm{mm} \text {; } \\
& a=30,0(26,8-32,9) ; b=5,9(5,4-6,5) ; b^{\prime}=4,8(4,5 \\
& -5,3) ; \quad c=35,0(32,5-40,0) ; \quad c^{\prime}=1,4(1,1-1,7) ; \\
& O=21,3(18,7-26,6) ; \quad M=51,4(47,0-53,3): \quad S t= \\
& 23,3(22,5-25,5) \mu \mathrm{m} ; \quad \mathrm{EP}=89,7(84,0-94,5) \mu \mathrm{m} ; \mathrm{MB}= \\
& 65,7(64,5-69,0) ; \quad E s p=23,3(22,5-25,5) \mu \mathrm{m} ; \quad t= \\
& 16,2(13,5-18,0) \mu \mathrm{m} \text {. }
\end{aligned}
$$


Observacões

$$
\text { Os exemplares estudados concordam com a }
$$

descrição original da espécie (SHER, 1965). Comparados com uma população encontrada na Áfica do Sul, descrita por VAN DEN BERG (1986), apresentam valores de L, a, b' e o menores.

Ocorrências

Essa espécie foi encontrada associada à solo de rizosfera de plantas de eucalipto, pessegueiro (Pelotas), fumo (Camaquã), em mata nativa (Canguçú). E' o primeiro relato da espécie para o RS. Já havia sido encontrada associada à rizosfera de cafeeiro e em solo de mata no Estado de São Paulo por MENDONÇA (1976), de mamoeiro (Carica papaya L.) no Espírito Santo por SHARMA (1976) e a bananeira (Musa sp.) na Bahia por SHARMA \& LOOF $(1984)$.

16. Scutellonema brachyurus (Steiner, 1938) Andrássy, 1958

S inônimos

Rotylenchus brachyurus Steiner, 1938; Rotylenchus coheni J. B. Goodey, 1952: Scutellonema coheni (J. B. Goodey, 1952) Andrássy, 1958; Rotylenchus boocki Lor ello, 1957; Scutellonema boocki (Lordello, 1957) An- 
drássy, 1958; S. orientale Rashid \& Khan, 1974; S. ramái Verma, 1972 e S. sheri Edward \& Rai, 1970.

Mensurações

$$
\begin{gathered}
\text { Fêmeas }(\mathrm{n}=12): \mathrm{L}=0,73(0,67-0,79) \mathrm{mm} ; \\
\mathrm{a}=26,9(19,1-31,7) ; \mathrm{b}=7,4(6,4-8,4) ; \mathrm{b}^{\prime}=5,7(5,1 \\
-6,4) ; \mathrm{c}=77,0(72,3-84,4) ; \mathrm{c}^{\prime}=0,5(0,4-0,6) ; \mathrm{M}= \\
29,3(23,5-35,2) ; \mathrm{V}=60,7(58,9-63,3) ; \mathrm{St}=25,5 \mathrm{\mu m} . \\
\text { Macho: não encontrado. }
\end{gathered}
$$

Observações

$$
\text { Os exemplares encontrados no RS apresentam }
$$
comprimento de estilete pouco menor ( $\mathrm{St}=25,5 \mathrm{Vs}, 27-$ $31 \mathrm{~mm}$ ) que os descritos por SHER (1963b) e SIDDIQI (1974) Ôcorrências

Ela foi encontrada em amostras coletadas na rizosfera de plantas de hortência, pinos, chorão e tomateiro (Pelotas). É a primeira ocorrência no RS, já assinalada no Brasil por CESNIK (1957) e LORDELLO (1957), associada à plantas ornamentais.

17. Scutellonema bizanae Van Den Berg \& Heyns, 1973 Mensurações

Fêmeas $(n=3): L=0.69(0,68-0,72) \mathrm{mm}:$

$a=27,1(23,9-30,9) ; b=7,2(6.5-7,7) ; b=4,9(4,4$

$-5.3): \quad c=48.3(45,5-51,5) ; \quad c^{1}=0.80(0,75-0.83) ;$ 
$M=49,0(47,0-50,0) ; V=59,1(56,7-62,5) ; S t=26,5$ $(25,5-27,0) \mu \mathrm{m} ; \mathrm{Ga}=27,1(26,1-28,0) ; \mathrm{Gp}=27,0(23,4$ $-30,1) ; \mathrm{MB}=47,1(43,1-49,4) ; \quad \mathrm{EP}=115,0(106,5-$ $123,0) \mu \mathrm{m} ; \mathrm{t}=14,0-18,0 \mu \mathrm{m}$.

Machos $(n=3): L=0,68(0,63-0,76) \mathrm{mm}$;

$a=33,1(28,1-37,5) ; b=7,4(7,0-7,8) ; b^{\prime}=4,9(4,6$

$-5,1) ; c=36,8(33,8-42,2) ; c^{\prime}=1,0(0,8-1,3) ; M=$ 50,$0 ; S t=24,5(24,0-25,5) . \mu m ; T=43,0(39,5-46,2) ;$ $M B=43,2(42,0-44,0) ; E P=109(102-112) \mu \mathrm{m} ; \quad \mathrm{EsP}=$ $123,0(22,5-24,0) \mu \mathrm{m} ; \mathrm{t}=18,0 \mu \mathrm{m}$.

Observações

O material estudado concorda coma descrição original da espécie VAN DEN BERG \& HEYNS (1973).

Ocorrência

A espécie foi encontrada no solo de rizosfera de plantas de hortência nos jardins da FAEM - UFPel (Pelotas). É a primeira citação para o Brasil.

\section{Meloidogyne exigua Goeldi, 1887}

S inôn imo

Heterodera exigua (Goeldi, 1897 ) Marcinows-

ki, 1909.

observaços

A configuração perineal das fèmeas e as caracteristicas dos machos concordam com as descriçōes de 
LORDELLO \& ZAMITH (1958); JEPSON (1987); TAYLOR \& SASSER (1978) e CAIN (1974) para a espécie.

Ocorrência

Essa espécie, agora assinalada pela primeira vez no RS, foi encontrada associada somente a raízes de tomateiro, em uma antiga área experimental do IPEAS, em Pelotas.

19. Meloidogyne incognita (Kofoid \& White, 1919) Chitwood, 1949

\section{Sinônimos}

Oxyurus incognitus Kofoid \& White, 1919 ; Heterodera incognita (Kofoid \& White, 1919) Sandground, 1923 ; Meloidogyne incognita acrita Chitwood, 1949; M. elegans da Ponte, 1977; M. acrita Chitwood, 1949 e M. incognita inornata Lordello, 1956.

Observações

As características morfológicas observadas, principalmente da configuração perineal das fêmeas e da região cefálica e estilete das f̂êmeas e machos, estão de acordo com descrições para a espécie em EISENBACK et a 1. (1981); JEPSON (1987); ORTON WILLIAMS (1973a) e TAYLOR \& SASSER (1978).

Ocorrências

Essa espécie foi encontrada em raízes 
de figueira, pessegueiro e tomateiro (Pelotas). Conhecida no Estado desde 1974 (LORDELLO \& MARINI, 1974).

20. Meloidogyne javanica (Treub, 1885) Chitwood, 1949 S inôn imos

Heterodera javanica Treub, 1885; Tylenchus (Heterodera) javanicus (Treub, 1885) Cobb, 1890 ; Anguillula javanica (Treub, 1885) Lavergne, 1901; Meloidogyne javanica bauruensis Lordello, 1956; M. lordelloi da Ponte, 1969 e M. lucknowica Singh, 1969.

Observações

As características morfológicas observadas, principalmente da configuração perineal das fêmeas e morfologia dos machos, estão de acordo com as descrições para a espécie em EISENBACK et a 1. (1981); JEPSON (1987); ORTON WILLIAMS (1972a) e TAYLOR \& SASSER (1978). Ocorrências

Ela foi encontrada em raízes de berinjela, pessegueiro, soja e tomateiro (Pelotas); fumo (Camaquã); soja (Arrôio Grande, Ijuí, Santa Rosa). Já conhecida no RS associada à beterraba (LORDELLO, 1969a).

21. Criconema demani Micoletzki, 1925

S i nôn imos

Criconemoides demani (Micoletzki, 1925) 
Taylor, 1963; Nothocriconema demani (Micoletzki, 1925) De Grisse \& Loof, 1965; Nothocriconema demani (Micoletzki, 1925 ) Ebsary, 1981 e Criconemoides ravidus Raski \& Golden, 1966.

Mensurações

$$
\begin{aligned}
& \text { Fêmeas }(\mathrm{n}=1): \mathrm{L}=0,40 \mathrm{~mm} ; \quad \mathrm{a}=13,3 ; \\
& \mathrm{b}=3,5 ; \mathrm{c}=9,8 ; \mathrm{c}=2,2 ; \mathrm{St}=69,0 \mu \mathrm{m} ; \mathrm{M}=89,1 ; \\
& \mathrm{MB}=72,0 ; \mathrm{V}=82,7 ; \mathrm{Ga}=45,0 ; \mathrm{St} \% \mathrm{~L}=17,2 ; \mathrm{St} \% \text { Oes }= \\
& 61,3 ; \mathrm{VL} / \mathrm{VB}=2,6 ; \mathrm{VL} / \mathrm{St}=1,1 ; \mathrm{R}=79 ; \mathrm{RSt}=15 ; \mathrm{ROes}= \\
& 21 ; \mathrm{RV}=16 ; \quad \text { RVan }=5 ; \mathrm{Ran}=10 ; \mathrm{RB}=5,1 \mu \mathrm{m} . \\
& \text { Macho: não encontrado. }
\end{aligned}
$$

\section{Observações}

As características morfológicas observadas, bem como as mensurações obtidas, estão de acordo com a descrição para Nothocriconema demani (DE GRISSE, 1969), com exceção para o número de anéis do corpo (R) e anéis entre a vulva e o ânus (RVan), que no exemplar encontrado no RS sao em números ligeiramente superiores ( $R=79$ Vs. $63-77$ e RVan $=5$ Vs. $3-4$, respectivamente).

Ocorrência

O único exemplar encontrado estava associado à rizosfera de gramíneas nativas não identificadas, em campo de criação de animais, na Estação Experimental da Central - EMBRAPa (Pelotas). É a primeira ocorrência para o Brasil. 
22. Criconeme11a palustris (Luc, 1970) Luc \& Raski, 1981

\section{Sinônimos}

Criconemoides onoensis f. Kindia Luc, 1959 ; C. palustris Luc, 1970 e Macrophostonia palustris (Luc, 1970) Loof \& De Grisse, 1973 .

\section{Mensurações}

$$
\begin{aligned}
& \text { Fêmeas }(\mathrm{n}=2): \mathrm{L}=0,38(0,37-0,40) \mathrm{mm} ; \\
& \mathrm{a}=14,4(13,8-15,1) ; \mathrm{b}=3,9(3,6-4,3) ; \mathrm{c}=21,7 \\
& (20,7-22,7) ; \mathrm{c}^{\prime}=0,9(0,8-1,0) ; \mathrm{V}=92,4(92,3- \\
& 92,5) ; \mathrm{St}=53,5 \mathrm{\mu m} ; \mathrm{EP}=98,7(94,0-103,5) \mu \mathrm{m} ; \mathrm{R}= \\
& 120 ; \mathrm{RSt}=19 ; \mathrm{ROes}=30-32 ; \mathrm{Rex}=32-33 ; \mathrm{RVan}= \\
& 3 ; \mathrm{Ran}=6 ; \mathrm{VL} / \mathrm{VB}=1,0-1,1 ; \mathrm{VL} / \mathrm{St}=0,50 ; \mathrm{St} \%= \\
& 14,3(13,8-14,9) ; \mathrm{St} \% \text { Oes }=57,2(53,9-60,5) . \\
& \text { Macho: não encontrado. }
\end{aligned}
$$

Observações

As características morfológicas observadas e as mensurações obtidas estão de acordo com a descrição da espécie (LUC, 1970), com exceção para o comprimento do corpo ligeiramente menor $(\mathrm{L}=0,37-0,40$ Vs. $0,40-0,49)$ e comprimento do estilete ligeiramente maior $(\mathrm{St}=53,5 \mathrm{Vs} .46-52 \mu \mathrm{m})$.

Ocorrência

$$
\text { Essa espécie foi encontrada em solo da }
$$
rizosfera de pessegueiro (Pelotas), sendo esta a pri- 
meira referência para o RS mas já havia sido assinalada no Brasil segundo MONTEIRO \& FERRAZ (1988).

\section{Criconeme 1 la reedi (Diab \& Jenkins, 1966) Luc \& Raski, 1981}

Mensurações

$$
\begin{aligned}
& \text { Fêmeas }(\mathrm{n}=7): \mathrm{L}=0,41(0,34-0,49) \mathrm{mm} ; \\
& \mathrm{a}=14,5(12,1-16,8) ; \mathrm{b}=4,4(4,1-4,8) ; \mathrm{c}=19,2 \\
& (16,6-23,9) ; \mathrm{c}=1,1(1,0-1,2) ; \mathrm{M}=74,3(72,7- \\
& 77,1) ; \mathrm{V}=90,6(88,7-94,0) ; \mathrm{St}=51,0(49,5-54,0) \mu \mathrm{m} ; \\
& \mathrm{EP}=89,0(75,0-96,0) \mu \mathrm{m} ; \mathrm{R}=99(91-103) ; \mathrm{RSt}=15- \\
& 17 ; \mathrm{ROeS}=23-24 ; \mathrm{Rex}=24-27 ; \mathrm{RV}=9-11 ; \mathrm{RVan}= \\
& 3-5 ; \mathrm{Ran}=5-7 ; \mathrm{VL} / \mathrm{VB}=1,4(1,2-1,5) ; \mathrm{VL} / \mathrm{St}= \\
& 0.80(0,69-0,93) ; \mathrm{St} \% \mathrm{~S} \mathrm{~S}=55,3(50,0-58,9) ; \mathrm{St} \% \mathrm{~L}= \\
& 12,3(10,5-14,5) .
\end{aligned}
$$

Macho: não encontrado

Observações

O material questão se conforma com a descrição de C. reedi (Diab \& Jenkins, 1966) Luc \& Raski, 1981 (DIAB \& JENKINS, 1966), com exceção do comprimento do estilete, que é ligeiramente mais curto lst= $49,5-54,0$ Vs. $51,0-62,0)$, do número de anéis do corpo, que é menor $(R=91-103 \mathrm{Vs} \cdot 104-112)$ e da posse de espermateca com espermatozóides Vs. ausência de espermateca. 
Ocorrência

Essa espécie foi encontrada junto a solo de rizosfera em resteva de arroz irrigado (Camaquã). Não foi encontrada referência desta espécie no Brasil, sendo, portanto, este o primeiro registro.

24. Criconemel la sphaerocephala (Taylor, 1936) Luc \& Raski , 1981

\section{Sinônimos}

$$
\text { Criconemoides sphaerocephala Taylor, }
$$

1936 ; Criconemoides citri steiner, 1949; Criconemoides georgii Prasad, Khan \& Mathur, 1965 e Macroposthonia sphaerocephala (Taylor, 1936) De Grisse \& Loof, 1965. Mensurações

$$
\begin{aligned}
& \text { Fêmeas }(\mathrm{n}=8): \mathrm{L}=0,30(0,24-0,35) \mathrm{mm} ; \\
& \mathrm{a}=10,8(10-12,5) ; \mathrm{b}=3,3(3,0-3,7) ; \mathrm{c}=35,3 \\
& (27,5-39,6) ; \mathrm{M}=69,6(68,5-71,4) ; \mathrm{St}=53,2(52,5 \\
& -57,0) \mu \mathrm{m} ; \quad \mathrm{V}=93,6(90,3-94,3) ; \mathrm{R}=63(61-66) ; \\
& \text { RSt }=11-12 ; \quad \text { ROes }=18-19 ; \quad \operatorname{Rex}=22(21-23) ; \\
& \text { RV }=4-5 ; \quad \text { RVan }=2-3 ; \operatorname{Ran}=1-3 ; \quad \mathrm{St} \% \mathrm{~L}=17,1 \\
& (14,7-21,2) ; \mathrm{St} \% \mathrm{ges}=57,9(51,4-63,3) ; \mathrm{VL} / \mathrm{VB}=0,6 \\
& (0,5-0,8) ; \mathrm{VL} / \mathrm{St}=0.34(0,31-0,37) . \\
& \text { Macho: não encontrado. }
\end{aligned}
$$

Observações 
ticas morfológicas observadas estão de acordo com a descrição de ORTON WILLIAMS (1973c).

Ocortências

Essa espécie foi encontrada em rizosfera de fumo cultivado em Santa Auta (Camaqua) e em solo de um eucaliptal (Pelotas). É a primeira ocorrência no RS.

25. Criconemel la xenoplax (Raski, 1952) Luc \& Raski, 1981

Sinôn imos

Criconemoides xenoplax Raski, 1952 ; Criconemoides nainitalense Edward \& Misra, 1963; Macroposthonia nainitalense (Edward \& Misra, 1963) De Grisse \& Loof, 1965 ; Criconema pruni Siddiqi, 1961; Mesocticonema pruni (Siddiqi, 1961) Andrássy, 1965 e Macroposthonia xenoplax (Raski, 1952) De Grisse \& Loof, 1965.

\section{Mensurações}

$$
\begin{aligned}
& \text { Fêmeas }(n=8): L=0,56(0,47-0,63) \mathrm{mm} \text {; } \\
& a=13,5(11,6-15,5) ; \quad b=4,1(3,8-4,7) ; \quad c=19,0 \\
& (18,1-21,0) ; \quad c^{\prime}=0,8(0,7-0,9) ; \quad V=92,7(91,1- \\
& 93,3) ; \quad S t=78,8(78,0-81,0) \mu \mathrm{m} ; \quad \mathrm{EP}=150(130-175) \\
& \mu \mathrm{m} ; \mathrm{Ga}=47,0(43,0-49,7) ; M=74,9(72,2-76,9) ; \mathrm{R}= \\
& 108(101-110) ; \operatorname{RSt}=17(16-18) ; \operatorname{ROes}=26(25-31) ; \\
& \operatorname{Rex}=32(30-34) ; \operatorname{RV}=7-10 ; \operatorname{RVan}=2-3 ; \operatorname{Ran}=5- \\
& 7 ; \quad \mathrm{VL} / \mathrm{VB}=0,9(\bullet, 8-1,0) ; \quad \mathrm{St} \% \mathrm{~L}=14,2(12,8-16,5) ;
\end{aligned}
$$


St\%Oes $=59,7(55,9-65,0) ; \mathrm{VL} / \mathrm{St}=0,52(0,45-0,67)$. Macho: não encontrado.

Observações

As mensurações obtidas, bem comọ as características morfológicas observadas, estão de acordo com a descrição de ORTON WILLIAMS (1972b) para a espécie. Ocorrências

A espécie foi encontrada associada à rizosfera de plantas de citros e pessegueiro, ambas em Pelotas. Esta é a primeira citação da espécie no RS, embora já tenha sido relatada de rizosfera de cafeeiro no Estado de MG por CAMPOS et al. (1987). Foi também registrada em pessegueiro com declínio em Santo Antônio do Pinhal, SP, por MONTEIRO et al. (1990).

\section{Hemicriconemoides minutus Esser, 1960}

Mensurações

$$
\begin{aligned}
& \quad \text { Fêmea }(\mathrm{n}=1): \mathrm{L}=0,34 \mathrm{~mm} ; \mathrm{a}=16,4 ; \mathrm{b}= \\
& 3,0 ; \mathrm{c}=25,5 ; \mathrm{c}^{\prime}=1,1 ; \mathrm{St}=76,5 \mu \mathrm{m} ; \mathrm{CSt}=67,5 \mu \mathrm{m} ; \mathrm{M}= \\
& 88,2 ; \mathrm{MB}=76,0 ; \mathrm{V}=92,1 ; \mathrm{Ga}=43,4 ; \mathrm{R}=88 ; \mathrm{RSt}=16 ; \\
& \text { ROes }=26 ; \quad \text { RVan }=4 ; \mathrm{Ran}=5 ; \mathrm{RB}=4,2 \mu \mathrm{m} ; \mathrm{VL} / \mathrm{VB}=1,3 ; \\
& \mathrm{VL} / \mathrm{St}=0,3 ; \mathrm{St} \% \mathrm{~L}=22,1 .
\end{aligned}
$$$$
\text { Macho: não encontrado. }
$$

Observações

O material aqui estudado concorda com a des- 
crição original (ESSER, 1960), com exceção de maiores valores de a e b, no exemplar gaúcho ( $a=16,4$ Vs. 11,313,7 e $b=25,5$ Vs. 14,2 , respectivamente).

Ocorrência

O único exemplar encontrado estava associado à rizosfera de planta invasora não identificada no interior de uma plantação de alho, na Estação Experimental Domingos Petrolini (Rio Grande). E o primeiro relato da espécie no Brasil.

27. Ogma civel lae (Steiner, 1949) Luc \& Raski, 1987 S i nôn imos

Criconema civellae steiner, 1949; Crossonema civellae (Steiner, 1949) Mehta \& Raski, 1971 ; Criconema celetum Wu, 1960; Criconema enrysoma Golden \& Friedman, 1964 e Criconema vishwanatum Edward \& Misra, 1966. Mensurações

Fêmeas $(\mathrm{n}=12): \mathrm{L}=0,47(0,39-0,52) \mathrm{mm}$;

$a=11,3(10,4-12,5) ; \quad b=3,9(3,3-4,2) ; \quad v=90,5$ $(88,4-92,1) ; \quad \mathrm{St}=83,6(81,0-88,5) \mu \mathrm{m} ; \quad \mathrm{Ga}=75,5$ $(61,5-93,3) ; \quad M=83,1(81,3-85,1) ; \quad R=44(41-45) ;$ RSt $=7-9 ; \quad$ ROes $=10-12 ; \quad \mathrm{VL} / \mathrm{VB}=1,0(0,9-1,2) ;$ St\%L $=17,1(15,9-21,0) ;$ St\%Oes $=69,8(61,1-78,5):$ $\mathrm{VL} / \mathrm{St}=0,61(0,44-0,60)$.

Macho: não encontrado. 


\section{Observaçoes}

Os parâmetros observados estão em parecença com a descrição de Criconema celetum Wu, 1960 (WU, 1960) e ilustração em Siddiqi, 1986 (SIDDIQI, 1986). Ocorrência

A espécie foi encontrada associada à plantas de pessegueiro, citros, eucalipto, gramíneas e matas nativa (Pelotas). Não foi encontrado registro de sua presença no Brasil. Quanto ao gênero, CAMPos et al. (1987) encontraram O. decalineata (Chitwood, 1957) Andrássy, 1979, em rizosfera de bananeira em MG.

28. Hemicycliophora poranga Monteiro \& Lordello, 1978 Mensurações

$$
\begin{aligned}
& \text { Fêmeas }(\mathrm{n}=13): \mathrm{L}=1,07(0.96-1.17) \mathrm{mm} ; \\
& \mathrm{a}=31,7(27,3-35,5) ; \mathrm{b}=5,6(5,3-6,5) ; \mathrm{c}=11,0(8,5 \\
& -13,0) ; \mathrm{c}^{\prime}=4,4(3,4-5,8) ; \mathrm{M}=83,1(81,6-84,0) ; \mathrm{V}= \\
& 84,3(82,7-86,0) ; \mathrm{St}=95,7(90,0-102,0) \mu \mathrm{m} ; \mathrm{Ga}= \\
& 54,8(41,0-74,4) ; \mathrm{R}=331(292-350) ; \mathrm{RSt}=28(25- \\
& 34) ; \operatorname{Rex}=60(55-65) ; \mathrm{RVan}=25(20-29) ; \mathrm{VL} / \mathrm{VB}=5,0 \\
& (4,4-5,7) ; \mathrm{VA} \%=49,5(35,7-69,2) . \\
& \text { Macho: não encontrado. }
\end{aligned}
$$

Observações

As mensurações e caracteres analisados estão em concordância com a descrição original da espécie 
de MONTEIRO \& LORDELlo (1978). Observou-se que alguns exemplares estavam sendo parasitados por Pasteuria sp. Ocorrências

A referida espécie se encontrava na rizosfera de alfafa (Feliz); citros, eucalipto, hortência e pessegueiro (Pelotas); fumo (Camaquã). Eo primeiro relato dessa espécie no RS. MONTEIRO \& LORDELLO (1978) a descreveram de solo ao redor de repolho (Brassica oleracea L. v. capitata) cultivado em Parelheiros, SP.

29. Hemicycliophora ripa Van Den Berg, 1981 Sinôn imo

Hemicycliophora rionegrens is Doucet, 1982).

Mensurações

Fêmeas $(\mathrm{n}=6): \mathrm{L}=0,80(0,77-0,86) \mathrm{mm} ;$
$\mathrm{a}=26,8(24,3-28,9) ; \mathrm{b}=5,3(5,0-5,6) ; \mathrm{c}=7,9(7,4$
$-9,0) ; \mathrm{c}^{\prime}=4,7(3,8-5,0) ; \mathrm{M}=82,7(80,7-85,1) ; \mathrm{V}=$
$80,3(79,1-81,3) ; \mathrm{Ga}=38,9(36,4-43,8) ; \mathrm{St}=84,0$
$(81,0-85,5) \mu \mathrm{m} ; \mathrm{R}=261(255-268) ; \mathrm{RSt}=25(23-26) ;$
ROeS $=45(40-47) ; \operatorname{Rex}=50(49-51) ; \mathrm{RVan}=17 ; \mathrm{Ran}=$
$48(45-50) ; \mathrm{VL} / \mathrm{VB}=7,0(5,9-7,6) ; \mathrm{VA} \% \mathrm{t}=44,5(33,3$
$-53,4) ; \mathrm{St}$ 宛 $=10,3(10,2-10,7) ; \mathrm{t}=37,3(78,0-$
$94,5) \mu \mathrm{m}$.

Macho: não encontrado. 


\section{Observaçōes}

Com exceção ao comprimento do corpo, os dema is caracteres observados e as mensurações concordam com a descrição de DOUCET (1982) para H. rionegrensis. Naquele parâmetro foram encontrados valores ligeiramente menores $(\mathrm{L}=0,77-0,86 \mathrm{Vs} \cdot 0,80-1,11 \mathrm{~mm})$ aos citados pelo autor.

\section{Ocorrências}

Ela foi encontrada na rizosfera de plantas de hortência, limoeiro e pessegueiro (Pelotas). Assinalada na Argentina, agora também no Brasil.

\section{Hemicycliophora tenuistriata Doucet, 1982} Mensurações

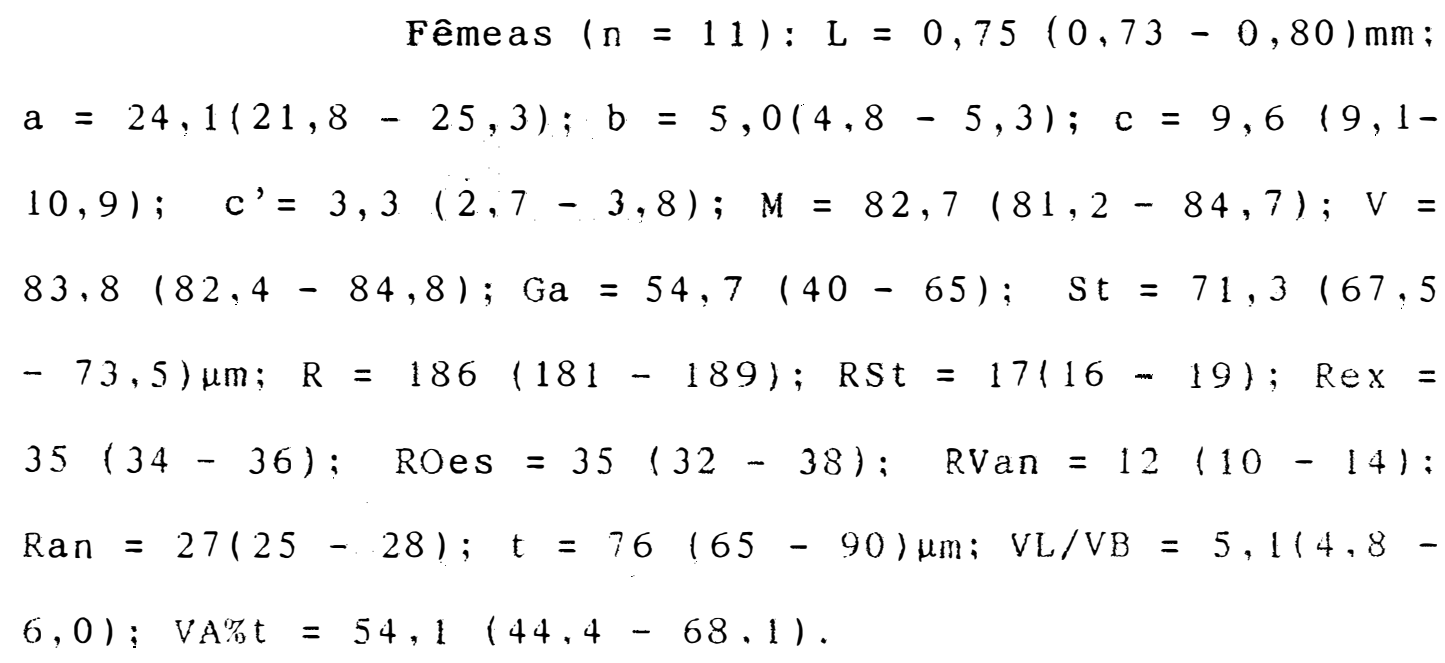


cordam com a descrição original da espécie, feita por DOUCET (1982). Para aqueles parâmetros, os exemplares estudados do RS apresentam valores máximos até o limite inferior da faixa de variação da populacao tipo (b $=4,8$ $5,3$ Vs. $5,3-6,2)$.

Ocorrência

A espécie foi encontrada em solo junto a raízes de gramíneas nativas em campo de pastoreio de animais (Pelotas). Não há registro anterior de sua ocorrência no Brasil.

31. Caloosia paradoxa (Luc, 1958) Brzeski, 1974 Sinônimos

Hemicycliophora paradoxaLuc, 1958 e Hemicaloosia paradoxa (Luc, 1958) Ray \& Das, 1978. Mensurações

$$
\begin{aligned}
& \text { Fêmea }(\mathrm{n}=1): \mathrm{L}=0,58 \mathrm{~mm} ; \mathrm{a}=24,5 ; \mathrm{b}= \\
& 6,0 ; \mathrm{c}=8,7 ; \mathrm{c}^{\prime}=3,2 ; \mathrm{M}=85,7 ; \mathrm{V}=83,9 ; \mathrm{St}=52,5 \mu \mathrm{m} ; \\
& \mathrm{Ga}=45,8 ; \quad \mathrm{R}=224 ; \mathrm{RS}=21 ; \quad \mathrm{ROes}=37 ; \quad \text { Rex }=44 ; \\
& \text { RVan }=11 ; \mathrm{Ran}=28 ; \mathrm{VL} / \mathrm{VB}=4,9 ; \mathrm{VA} \% \mathrm{t}=40.0 ; \mathrm{t}=69,0 \mu \mathrm{m} . \\
& \text { Macho: Näo encontrado. }
\end{aligned}
$$

observações

O material concorda com a descrição de uma população de Hemicaloosia paradoxa (Luc, 1958) Ray \& Das, 
1978 da Argentina, apresentada por CHAVES (1983), mas em comparação com a descrição original de LUC (1958), difere por apresentar menor comprimento do corpo ( $\mathrm{L}=0,58 \mathrm{Vs}$. $0,68-0,82)$ e do estilete $(\mathrm{St}=52,5 \mathrm{Vs} \cdot 61-65 \mu \mathrm{m}) \mathrm{e}$ número menor de anéis $(R=224$ Vs. $256-263)$.

Ocorrência

A espécie, representada por uma fêmea e duas larvas, foi encontrada em rizosfera de gramíneas nativas, em campo de pastoreio de animais, na Estação Experimental da Central - EMBRAPA (Pelotas). E o primeiro relato da espécie para o Brasil, porém o gênero (Hemicaloosia sp.) já havia sido encontrado entre os nematóides ocorrentes em rizosfera de arroz, na regiao Centro-Oeste do Brasil (UESUG \& HUANG, 1984).

\section{Paratylenchus aquaticus Merny, 1966}

S i nôn imo

Paratylenchus humilis Raski, 1975.

Mensurações

$$
\begin{array}{r}
\text { Fêmeas }(\mathrm{n}=11): \mathrm{L}=0,35(0,31-0,41) \mathrm{mm} ; \\
\mathrm{a}=32,0(27,7-34,6) ; \mathrm{b}=4,3(4,0-4,8) ; \mathrm{c}=14,7(10,8 \\
-20,4) ; \mathrm{c}^{\prime}=3,4(2,4-4,2) ; 0=25,3(16,6-34,7) ; \mathrm{V}= \\
79,3(77,2-82,6) ; \mathrm{st}=17,7(16,5-18,0) \mu \mathrm{m} ; \mathrm{d}=4,9 \\
(4,4-5,9) ; \mathrm{z}=19,4(18,1-22,1) ; \mathrm{t}=24,2(21,0-
\end{array}
$$


$28,5) \mu \mathrm{m}$.

Machos $(n=2): \quad L=0,34 \mathrm{~mm} ; \quad a=35,3-$

38,$3 ; \quad c=12,4 ; \quad c^{\prime}=3,6-4,2 ; \quad$ Esp $=16,5-19,5 \mu \mathrm{m}$;

$\mathrm{t}=22,5-27,0 \mu \mathrm{m}$.

Observações

Diferem da descrição original de MERNY (1966) no comprimento do espículo, onde os machos observados no RS apresentam valores inferiores (Esp = 16,5 $19,5$ Vs. $21-22 \mu \mathrm{m})$, e nos valores superiores no comprimento do corpo $(\mathrm{L}=0,31-0,41 \mathrm{Vs} \cdot 0,27-0,37 \mathrm{~mm})$, tanto para machos como para fêmeas.

Ocorrência

Pela primeira vez no Brasil, a espécie em questão é agora assinalada em solo junto a plantas de cana-de-açúcar e milho na Estação Experimental da Central - EMBRAPA (Pelotas).

33. Aphelenchus avenae Bastian, 1865

Sinônimos

$$
\text { Vide longa lista em HOOPER (1974). }
$$

Mensurações

Fêmeas $(\mathrm{n}=12): \mathrm{L}=0,69(0,49-0,88) \mathrm{mm}$;

$a=38,3(29,3-47,8) ; b=7,0(5,0-8,9) ; b^{\prime}=4,0(3,5$

$-4,7) ; c=30,6(26,2-34,7) ; c^{\prime}=1,7(1,4-2,0) ; V=$ 
$76,7(75,0-78,2) ; \mathrm{St}=15,3(14,2-16,5) \mu \mathrm{m} ; \mathrm{t}=22,5$ $(18,0-30,0) \mu \mathrm{m} ; \mathrm{EP}=97,6(76,5-117,0) \mu \mathrm{m} ; \mathrm{Spu}=48,0$ $(28,0-75,0) \mu \mathrm{m} ; \mathrm{Ga}=44,0(31,3-55,9)$.

Macho: não encontrado.

Observações

Os exemplares examinados apresentam similitude com a descrição da espécie, na descrição de HOOPER $(1974)$.

Ocorrências

Essa espécie encontrava-se em solo próximo a plantas de berinjela, caquizeiro, eucalipto, figueira, gramíneas nativas, mata nativa e pessegueiro (Pelotas); alho (Rio Grande); citros, (Taquari); macieira (Pelotas e Vacaria); morangueiro (Caxias do Sul e Feliz); soja (Santa Rosa); trigo (Passo Fundo) e videira (Bento Gonçalves e Pelotas). Conhecida no RS desde 1969, quando LORDELLO \& MARINI (1974) a encontraram associada à plantas de chicória.

34. Aphelenchoides besseyi Christie, 1942

Sinôn imos

Aphelenchoides oryzae Yokoo, 1948 e Astero aphelenchoides besseyi (Christie, 1942) Drozdovski, 1967 
Mensurações

$$
\begin{aligned}
& \text { Fêmeas }(\mathrm{n}=15): \mathrm{L}=0,68(0,57-0,76) \mathrm{mm} ; \\
& \mathrm{a}=48,7(42,2-51,0) ; \mathrm{b}=4,9(4,7-5,9) ; \mathrm{c}=17,6 \\
& (14,3-19,6) ; \mathrm{c}^{\prime}=4,2(3,8-5,0) ; \mathrm{V}=71,4(69,6- \\
& 73,9) ; \mathrm{St}=12,0(12,0-12,7) \mu \mathrm{m} ; \mathrm{t}=39,2(30,0-45,0) \\
& \mu \mathrm{m} ; \mathrm{EP}=76,5(70,5-85,5) \mu \mathrm{m} ; \mathrm{Spu}=45,2(37,2-52,5) \\
& \mu \mathrm{m} ; \mathrm{Ga}=27,5(20,4-35,3) . \quad \mathrm{Machos}(\mathrm{n}=10): \mathrm{L}=0,60(0,56-0,62) \mathrm{mm} ; \\
& \mathrm{a}=44,0(41,5-48,2) ; \mathrm{b}=3,9(3,5-4,4) ; \\
& (16,0-18,6) ; \mathrm{c}=3,0(2,8-3,2) ; \mathrm{St}=12,1(12,0- \\
& 12,7) \mu \mathrm{m} ; \mathrm{EP}=75,3(70,5-82,5) \mu \mathrm{m} ; \mathrm{T}=34,3(33,3 \\
& -35,3) ; \mathrm{t}=34,8(33,0-37,5) \mu \mathrm{m} ; \mathrm{Esp}=15,5(15,0- \\
& 16,0) \mu \mathrm{m} . \quad
\end{aligned}
$$

Observações

A paridade dos caracteres observados com os constantes na descrição de FRANKLIN \& SIDDIQI (1972), a identifica como $A$. besseyi.

Ocorrência

Extraida de grãos de arroz (Pelotas). Conhecida no RS desde 1969: quando foi encontrada pela primeira vez por LORDELLO $(1969 \mathrm{~b})$. 


\section{Xiphinema californicum Lamberti \& Bleve-Zacheo,} 1979

\section{S inôn imo}

Xiphinema americanum Cobb, 1913 s.l., par-

tim.

Mensuraçoes

$$
\begin{aligned}
& \text { Fêmeas }(\mathrm{n}=16): \mathrm{L}=1,66(1,50-1,87) \mathrm{mm} ; \\
& \mathrm{a}=44,1(38,8-49,5) ; \mathrm{b}=6,2(4,9-7,0) ; \mathrm{c}=49,5(44,1 \\
& -56,9) ; \quad \mathrm{c}^{\prime}=1,5(1,3-1,6) ; \mathrm{V}=51,6(49,5-53,1) ; \\
& \mathrm{St}=124,2(118,5-127,5) \mu \mathrm{m} ; \text { Odt }=77(72-81) \mu \mathrm{m} ; \text { Odf }= \\
& 47,4(45,0-52,5) \mu \mathrm{m} .
\end{aligned}
$$

Machos $(n=1): L=1,68 \mathrm{~mm} ; \mathrm{a}=65 ; \mathrm{b}=$

5,$9 ; \mathrm{c}=48,8 ; \mathrm{c}^{\prime}=1,6 ;$ Odt $=75 \mu \mathrm{m} ;$ Odf $=43,5 \mu \mathrm{m} ; \mathrm{t}=$ $34,5 \mu \mathrm{m} ; \mathrm{H}=7,5 \mu \mathrm{m} ; \mathrm{Esp}=37,5 \mu \mathrm{m}$; distância entre a extremidade anterior e anel guia $=63,5 \mu \mathrm{m}$; distância entre a abertura cloacal (ac) e o par adanal de suplementos (s) $=7,5 \mu \mathrm{m}$; distância entre ac e o primeiro par de suplementos $(\mathrm{s} 1)=18,0 \mu \mathrm{m} ; \mathrm{ac}-\mathrm{s} 2=28,5 \mu \mathrm{m} ; \mathrm{ac}-\mathrm{s} 3=41,2$ $\mu \mathrm{m} ; \mathrm{ac}-\mathrm{s} 4=62,2 \mu \mathrm{m} ; \mathrm{ac}-\mathrm{s} 5=77,2 \mu \mathrm{m} ; \mathrm{ac}-\mathrm{s} 6=107,2$ $\mu \mathrm{m} ; \mathrm{ac}-\mathrm{s} 7=140,2 \mu \mathrm{m}$.

Observações

O presente material corresponde melhor a descrição de $X$. californicum, do que a de qualquer outra espécie do grupo $X$. americanum, mas tem comprimento do corpo, comprimento do odontostilio e valor c um pouco 
menores, especialmente em relação à população tipo (fêmeas: $\mathrm{L}=1,5-1,8 \mathrm{Vs} \cdot 1,8-2,2 \mathrm{~mm} ;$ Odt $=72-81 \mathrm{Vs}$. $83-98 ; c=44-57$ Vs $58-76 ;$ macho: $\mathrm{L}=1,7 \mathrm{Vs} .1,8$ $\mathrm{mm} ; \mathrm{c}=49 \mathrm{Vs} .61 ;$ Od $\mathrm{t}=75$ Vs. $89 \mu \mathrm{m})$ (LAMBERT I \& BLEVEZACHEO, 1979). As medidas aqui encontradas se aproximam mais de uma população do Perú, estudada por ALKEMADE \& LOOF (1990), embora o comprimento do estilete das fêmeas seja menor $(\mathrm{St}=118,5-127,5 \mathrm{Vs} .136 \mu \mathrm{m})$. Observou-se que alguns exemplares estavam sendo parasitados por Pasteuria sp..

Ocortências

X. californicum foi obtida junto a raízes de acácia-negra, beterraba, eucalipto, limoeiro e pessegueiro (Pelotas). No brasil, já havia sido encontradá em Brasília (DF) e no Rio de Janeiro por LAMBERT et al. $(1987)$.

36. Xiphinema krugi Lordello, 1955

S inôn imos

Kiphinema denoudeni Loof \& Mas, 1972 e Kiphinema loos i southey \& Luc, 1973.

Mensuracoes
Fêmeas $(n=15)$ :
$L=2,1(2,0-2,3) \mathrm{mm} ;$
$a=45,1(36,5-53,1)$;
$b=5.6$
$(4.6-6.3)$;
$c=55.6$ 
$(48,2-63,8) ; c^{\prime}=1,2(1,0-1,4) ; \quad V=35,3(32,5-39,3) ;$ $S t=173,7(160,5-187,5) \mu \mathrm{m} ;$ Odt $=103,1(94,5-111,0)$ $\mu \mathrm{m} ; \operatorname{Odf}=70,6(61,5-76,5) \mu \mathrm{m} ; \mathrm{t}=39,5(37,5-43,5) \mu \mathrm{m}$. Macho: não encontrado.

Observações

Os valores das mensurações se enquadram nos da população original (LORDELlo, 1955), com exceção do menor comprimento do odontostílio $\operatorname{lodt}=94,5-111,0 \mathrm{Vs}$. $116,0-120,0 \mu \mathrm{m})$. Os exemplares do RS apresentam valores de mensurações semelhantes a populações de outros Estados Brasileiros (FERRAZ, 1980). Todas as fêmeas observadas apresentam projeção na porção terminal da cauda e o ramo anterior do ovário curto e atrofiado. Foram assinaladas várias fêmeas parasitadas por Pasteuria sp..

Ocortências

A espécie em questão foi encontrada junto a plantas de beterraba, cana-de-açúcar, eucalipto, hortência, pessegueiro (Pelotas) e morangueiro (Feliz). Descrita originalmente no Brasil (LORDELLo, 1955), agora é assinalada no RS.

37. Paratrichodorus minor (Colbran, 1956) Siddiqi, 1974 S inônimos

Trichodorus minor Colbran, 1956; Tricho- 
dorus christie, Allen, 1957 e Paratrichodorus (Nanidorus) christiei (Allen, 1957) Siddiqi, 1974.

Mensuracoes

Fêmeas $(\mathrm{n}=15): \mathrm{L}=0,64(0,53-0,78) \mathrm{mm}$;

$a=24,9(20,0-31,5) ; \quad b=5,4(4,5-6,5) ; \quad s t=30,7$ $(30,0-33,0) \mu \mathrm{m} ; \mathrm{V}=53,6(51,0-55,5) ; \mathrm{EP}=71,5(63,0-$ $91,5) \mu \mathrm{m} ; \mathrm{Ga}=19,4(16,0-24,8) ; \mathrm{Gp}=19,4(16,0-$ $24,2) ; \mathrm{EP} \% \mathrm{Oes}=61,6(53,7-78,5) ;$ St\%Oes $=26,6(22,8-$ $29,2) ; \mathrm{d}=2,2(2,1-2,8) ; \mathrm{e}=8,4(6,1-9,9) ; \mathrm{z}=20,0$ $(17,3-22,6)$.

Macho: não encontrado.

Observações

As mensurações e as características morfológicas concordam com a descrição de HOOPER (1977) para a espécie.

Ocortências

A espécie foi encontrada associada à plantas de alho e de cebola (Rio Grande); resteva de arroz irrigado (Camaquã); erva mate (Sertão); berinjela, figueira, pessegueiro e videira (Pelotas). É a primeira ocorrência da espécie no RS. 


\subsubsection{Espécies ainda inominadas}

\section{Dolichodorus sp.}

(Fig. 2. A - D)

\section{Mensurações}

Fêmea $(n=1): L=2,05 \mathrm{~mm} ; a=59,4 ; b=$ 9,$3 ; \quad c=15,9 ; \quad c^{\prime}=4,0 ; \quad M=59,6 ; \quad S t=93,0 \mu m ; t=$ $129,0 \mu \mathrm{m} ; \mathrm{MB}=60 ; \mathrm{EP}=177 \mu \mathrm{m} ; \mathrm{V}=51,5 ; \mathrm{CSt}=55,5 \mu \mathrm{m}$. Macho $(\mathrm{n}=1): \mathrm{L}=1,73 \mathrm{~mm} ; \mathrm{a}=67,9 ; \mathrm{b}=$

8,$1 ; \quad c=46,2 ; c^{\prime}=1,7 ; M=59,6 ; \quad S t=85,5 \mu \mathrm{m} ; \mathrm{CSt}=$ $51,0 \mu \mathrm{m} ;$ HSt $=34,5 \mu \mathrm{m} ; \mathrm{EP}=159 \mu \mathrm{m} ; \mathrm{t}=37,5 \mu \mathrm{m} ; \mathrm{MB}=$ 58,$4 ; E s p=51,0 \mu \mathrm{m} ; \quad \mathrm{Gub}=25,5 \mu \mathrm{m} ; \mathrm{T}=54,3$.

$$
\text { Larvas - L4 }(\mathrm{n}=4): \mathrm{L}=1,55(1,40-
$$

$1,73) \mathrm{mm} ; \quad \mathrm{a}=55,3(51,9-60,7) ; \quad \mathrm{b}=7,0(6,7-7,5) ;$ $c=16,8(15,4-18,1) ; \quad c^{\prime}=5,8(4,2-8,3) ; 0=3,3$ $(3,0-3,5) ; \quad M=63,2(60,3-66,6) ; \quad$ St $=90,0(85,5-$ $96,0) \mu \mathrm{m} ; \quad \mathrm{MB}=58,9(57,8-60,0) ; \quad t=93,0(78,0-$ $112,5) \mu \mathrm{m}$.

Descrição

Os exemplares examinados apresentam todas as caracteristicas diagnósticas do gênero, mas por se ter apenas uma fêmea e um macho, a descrição apresentada a seguir é incompleta, e o espécime deixa de ser nomeado.

Fêmea: O corpo é esbelto, subcilindrico e pouco recurvado para o lado ventral (Fig. 2. D). A região 
labial apresenta disco labial e quatro lobos distintos e é bem separada do corpo. Anelação cuticular bem marcada, com anéis de 1,5 $4 \mathrm{~m}$ de largura. Campos laterais com 3 linhas longitudinais limitando duas faixas areoladas. Fasmídios bem visíveis localizados mais ou menos na metade da cauda. Cefalídios a $4-5$ e $8-9$ anéis posteriores à região labial. O poro excretor está localizado ao nível da porção glandular basal do esôfago. Hemizonídio de tamanho equivalente a $1-2$ anéis do corpo e localizado a 7 anéis anteriores ao poro excretor. Estilete com cone medindo 2, 0 vezes ou mais o comprimento da haste (Fig. 2, A). Gônada anterior reflexa e mais desenvolvida que a posterior. Cauda é longa e conóide com afilamento gradativo até a extremidade final (Fig. 2, B - C).

Macho: Apresenta o poro excretor localizado ao nível da junção esôfago-intestino. Hemizônidio localizado a 17 anéis posteriores ao poro excretor. Cauda com ponta lisa e curta, combursa trilobada típica do gênero (Fig. 2, E).

Diagnose

Dolichodorus sp. distingue-se das demais espécies do gênero, exceto D. Iongicaudatus Doucet, 1981 e D. aquaticus Doucet, 1985 (DOUCET, 1981; 1985), por apresentar cauda da fêmea regularmente cônica. Difere de D. longicaudatus por apresentar os valores de $\mathrm{L}$ e de c 

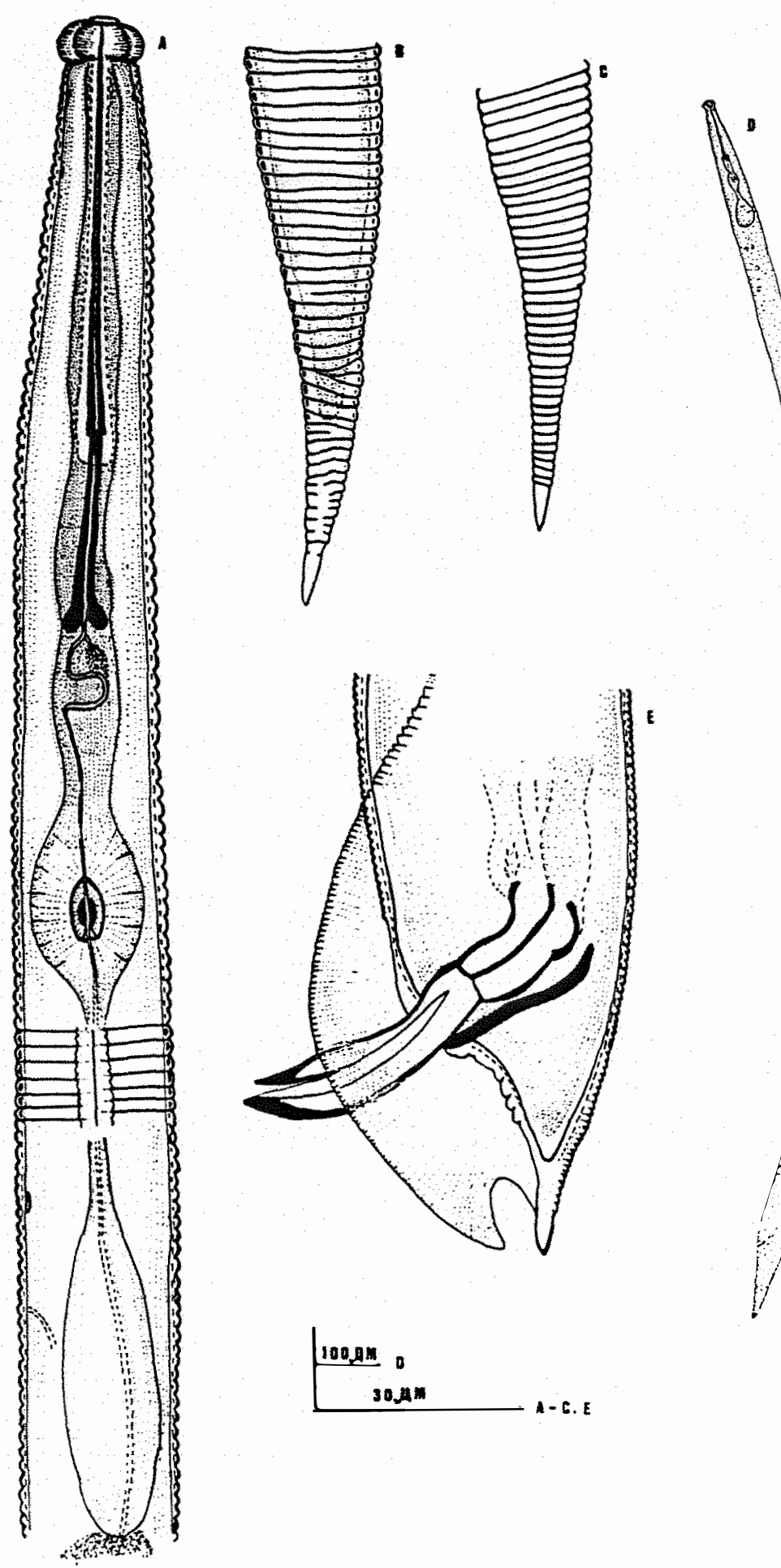

FIG. 2. Dolichodorus sp. Fêmea: A - Regiào esofagiana : 1008m D 30, Am B - Cauda; C - Cauda da larva ( L4 ); D - Corpo. Macho: E - Cauda. 
menores $(\mathrm{L}=2,05 \mathrm{Vs} \cdot 2,4-2,8 \mathrm{~mm}$ e $\mathrm{c}=15,9 \mathrm{Vs} \cdot 24-$ 31), comprimentos de estilete ( $S t=93,0 \mathrm{Vs} \cdot 79,5-88,5)$ e da cauda da fêmea maiores $(t=129,0$ Vs. $92 \mu \mathrm{m})$ e valores de $L$ e c dos machos menores. Difere de D. aquaticus por apresentar menor comprimento do corpo $(\mathrm{L}=2,05 \mathrm{vs}$. $2,5-3,5 \mathrm{~mm})$ e maior valor $c^{\prime}\left(c^{\prime}=4,0\right.$ vs. $\left.1,2-1,5\right)$. Ocorrências

A espécie foi encontrada junto ao sistema radicular de plantas de beterraba açúcareira e gramíneas nativas não identificadas (Pelotas), alho (Rio Grande). Obteve-se dois exemplares adultos e cinco larvas. O gênero já havia sido encontrado associado à raízes de cafeeiro na Bahia (SHARMA \& LOOF, 1973).

\section{Tylenchorhynchus sp. "A"}

$$
\text { (Fig. 3, A - E) }
$$

Mensurações

$$
\begin{aligned}
& \text { Fêmeas }(n=7): L=0,44(0,42-0,47) \mathrm{mm} ; \\
& a=26,1(25,4-27,7) ; b=4,4(4,0-5,0) ; c=14,7 \\
& (14,0-15,7) ; c^{\prime}=2,5(2,2-2,8) ; 0=14,6(14,2-15,3) ; \\
& V=58,5(57,0-60,0) ; \mathrm{St}=21,0(19,5-22,0) \mu \mathrm{m} . \\
& \quad \text { Machos }(\mathrm{n}=5): L=0,39(0,37-0,44) \mathrm{mm} ; \\
& a=25,9(22,0-29,4) ; b=4,2(4,0-4,6) ; c=13,2 \\
& (12,4-14,7) ; c^{\prime}=2,6(2,5-2,8) ; 0=15,0(14,2-15,3) ;
\end{aligned}
$$


$S t=19,5 \mu \mathrm{m} ; \mathrm{Esp}=17,7(16,5-19,5) \mu \mathrm{m} ; \mathrm{Gub}=12,0 \mu \mathrm{m}$.

Holótipo (fêmea): $L=0,43 \mathrm{~mm} ; \quad a=25,9$;

$\mathrm{b}=4,2 ; \mathrm{c}=14,2 ; \quad \mathrm{c}^{\prime}=2,5 ; \mathrm{V}=57,8 ; \mathrm{st}=21,0 \mu \mathrm{m}$.

Alotipo: $\mathrm{L}=0,38 \mathrm{~mm} ; \mathrm{a}=25,5 ; \mathrm{b}=4,1$;

$c=12,7 ; c^{\prime}=2,5 ; \quad S t=19,5 \mu \mathrm{m} ; \mathrm{Esp}=19,5 \mu \mathrm{m} ; \quad \mathrm{Gub}=$ $12,0 \mu \mathrm{m}$.

Descrição

Fêmeas: apresentam o corpo curvado ventra 1 mente, formando um "C" aberto, quando relaxadas. Região labial elevada, distintamente separada do corpo por constrição e por ter menor diâmetro, $\operatorname{com} 3,6 \mu \mathrm{m}$ de altura por 6, $3 \mu \mathrm{m}$ de largura e achatada anteriormente. Presença de 4 - 5 anéis de difícil visualização e esqueleto cefálico fracamente esclerotizado. Estilete variando de 19,5 a $22,0 \mu \mathrm{m}$ de comprimento, com bulbos basais com ligeira inclinação posterior. Anéis do corpo delicado. Esôfago típico do grupo, com bulbo médio musculoso situado a 45,0 $50 \mu \mathrm{m}$ da extremidade anterior e lóbulo posterior periforme situado a $90,0-103,0 \mu \mathrm{m}$. Anel nervoso situado mais ou menos na porção intermediária do istmo. Poro excretor ao nível ou pouco antes do início do bulbo posterior do esôfago, situado em média a $68,4-76,6 \mu m$ da extremidade anterior. Hemizonídio de tamanho equivalente a largura de 1,5 ané is do corpo e localizado $2-3$ anéis anteriores ao poro excretor (Fig. 3, A). Cutícula sem estrias longitu- 

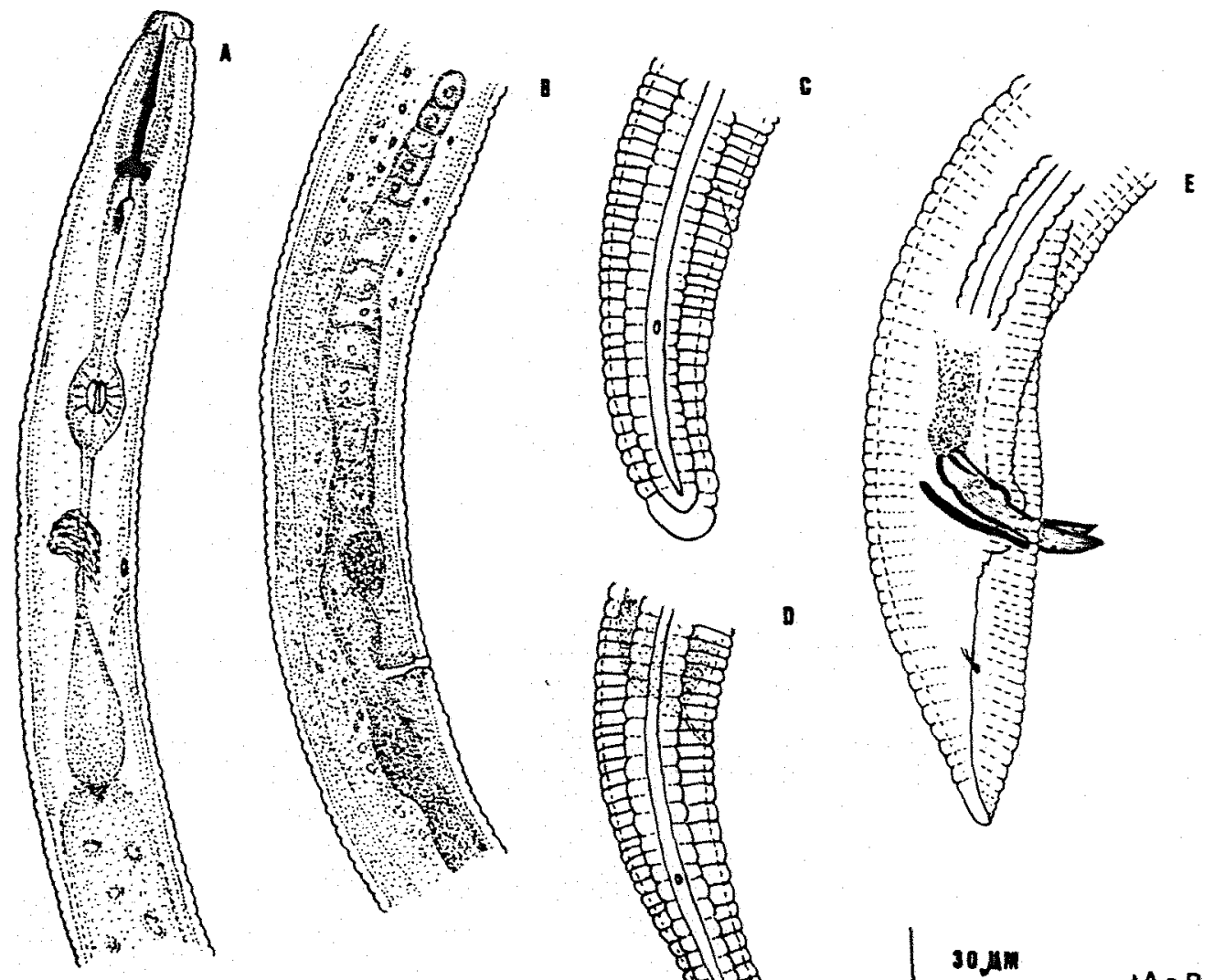

FIG. 3. Tylenchorhynchus sp: "A" Fêmea: A - Regiao esofagiana; B - Gônada anterior; C e D - Variaçaes na forma da cauda. Machos: E - Cauda. 
dinais, fora dos campos laterais. Campo lateral marcado por 4 incisuras, sendo a faixa interna não areolada e presente até o final da cauda, faixas externas areoladas em toda a extensão do corpo. Ovários pareados e distendidos com espermateca funcional (Fig.3, B). Cauda subcilindrica com $27,0-31,5 \mu m$ de comprimento e $17-20$ anéis no lado ventral. Extremidade final arredondada e sem anelação (Fig. 3, C - D). Fasmídio localizado entre 7 10 anéis posteriores ao nível anal.

Machos: apresentam características morfológicas semelhantes às da fêmeas exceto para os órgãos reprodutores, com espículos tendo comprimento médio de $17,7 \mu \mathrm{m}$ e gubernáculo com $12 \mu \mathrm{m}$. Cauda com 26,0 - 28,5 $\mu \mathrm{m}$ de comprimento, pontiaguda. com bursa envolvendo a extremidade final (Fig. 3, E).

Diagnose

A espécie em questão diferencia-se das demais espécies do gènero, exceto para $T$. ebriensis seinhorst, 1963 (SEINHORST, 1963) e T. agri Ferris. 1963 (FERRIS. 1963), por apresentar a seguinte combinacão de caracteristica: corpo sen estrias longitudinais, cauda conica com $17-20$ aneis e extremidade do corpo lisa. Difere de $T$. ebriensis por apresentar menor comprimenuo do corpo $(L=0,42-0,47$ Vs. $0,52-0.59 \mathrm{~mm})$, menor número de aneis na cauda 1 Ran $=17-20 \mathrm{Vs} .25$, alem de 
apresentar a regiao cefálica distinta. Difere de T. agri por apresentar menor comprimento do corpo $(L=0,42-0,47$ Vs. $0,66-0,77 \mathrm{~mm})$.

Ocorrência

A espécie em questao foi encontrada em solo junto ao sistema radicular de plantas de caquizeiro, citros e eucalipto (Pelotas).

40. Tylenchorhynchus sp. "B"

(Fig. 4, A - F )

Mensurações

Fêmeas $(n=10): L=0,71(0,65-0,89) \mathrm{mm}$;

$a=30,9(29,3-32,8) ; b=5,1(4,5-6,0) ; c=15,2$ $(14,0-17,5) ; \quad c^{\prime}=2,9(2,4-3,5) ; \quad 0=18,1 ; \quad y=54,1$ $(52,3-56,5) ; \mathrm{St}=17,5(16,0-18.0) \mu \mathrm{m} ; \mathrm{M}=54,5$.

Holótipo (Fêmea): $L=0,70 \mathrm{~mm} ; \quad a=31,3$;

$b=4,9 ; \quad c=14,2 ; \quad c^{\prime}=3,0 ; \quad V=53,1 ; \quad s t=18,0 \mu \mathrm{m}$. Macho: não encontrado.

Discriçāo

Fêmeas: apresentamo corpo curvadoventralmente formando um" C" fechado, quando relaxadas (Fig. 4, Fl. Regiào labial separada do corpo, artedondada anteriormente, $\operatorname{com} 6$ a 7 anéis e medindo $4,6 \mu m$ de altura por $8,1 \mu m$ de largura. Armadura labial pouco esclerotizada. 
Corpo sem estrição longitudinal. Estilete delicado, com os bulbos basais pouco desenvolvidos. Bulbo médiano do esôfago situado a $67,5-72,0 \mu \mathrm{m}$ da extremidade anterior. Bulbo basal do esôfago periforme. Junção esôfago-intest ino situada aproximadamente a $130,0 \mu \mathrm{m}$ da extremidade anterior. Poro excretor abrindo-se na altura do bulbo posterior do esôfago e a uma distância aproximada de $121,5 \mu m$ da extremidade anterior. Hemizonídio localizado a $1-2$ anéis anterior ao poro excretor e tamanho equivalente a largura de dois anéis do corpo (Fig. 4, A). Campo lateral iniciando ao nível da base do estilete, entre o $9 \underline{0}-11$ o anel do corpo, marcado por 4 incisuras formando três faixas distintas. As incisuras externas são crenadas e as internas lisas até o final da cauda (Fig. 4, B - D). Presença de do is ovários opostos e distendidos, com espermateca redonda e vazia. Cauda conóide a subcilíndrica, com comprimento médio de $36,0 \mu m$ e presença de 15 a 18 anéis bem demarcados no lado ventral. A cauda equivale a 2,5 diâmetros do corpo ao nível anal. Fasmídios localizados entre $4-6$ anéis posteriores ao nível anal e a $10-14$ anéis da extremidade final da cauda, pelo lado ventral. Extremidade final da cauda com pequenas variaçöes morfológicas mas sem anelaçào (Fig. 4, B - E). 

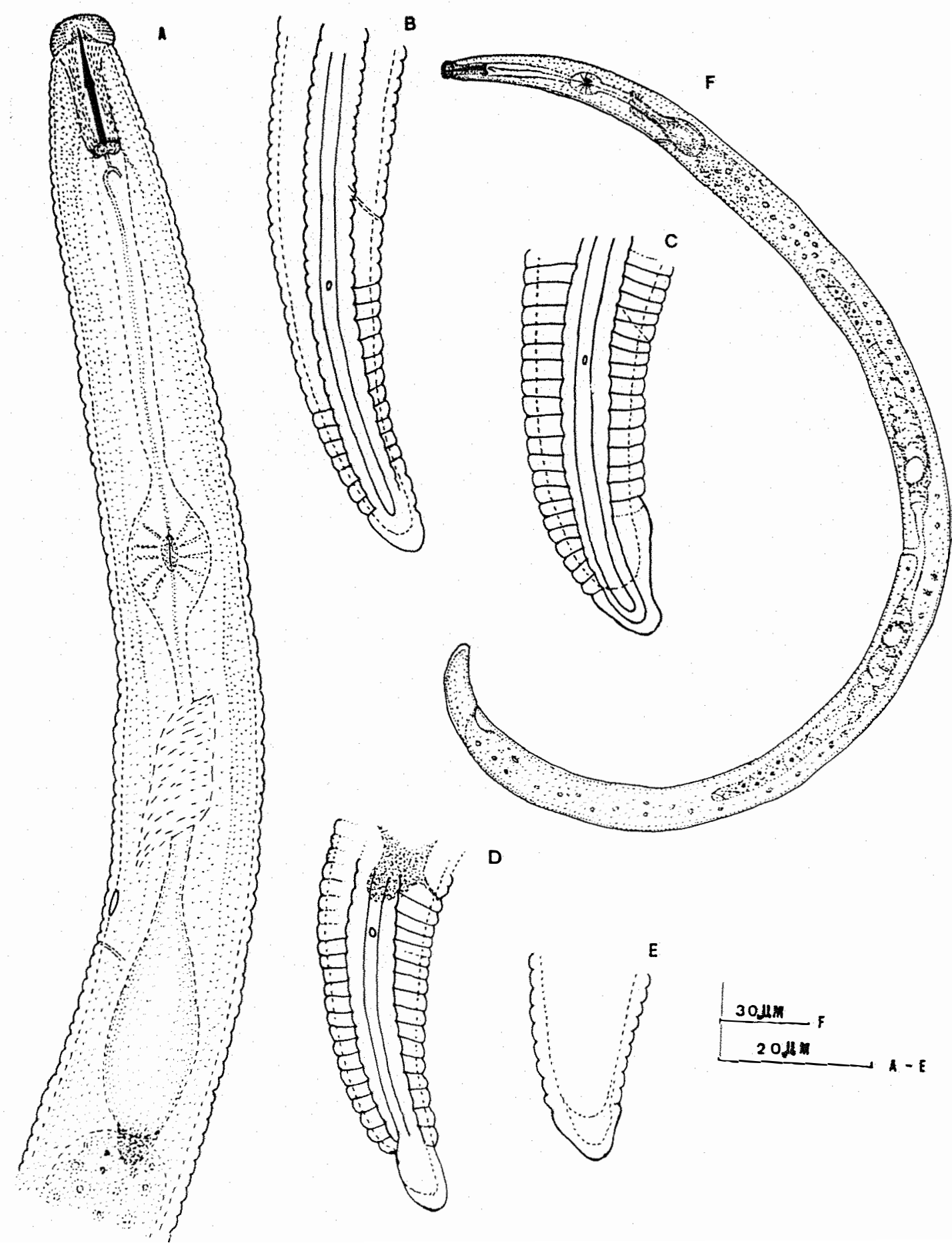

FIG. 4. Tylenchorhynchus 5p. "B" Femea: A - Regiao esofagiana: B - E - Variaçoes na forma da cauda; F - Corpo. 


\section{Diagnose}

Tylenchorhynchus sp. "B" diferencia-se das demais espécies do grupo, exceto T. aduncus De Guiran, 1967 (DE GUIRAN, 1967), por apresentar região labial separada e com $6-7$ anéis, estilete com 16,0-18,0 $\mu$ m de comprimento, campo lateral com 4 incisuras e não areolado, cutícula sem estrias longitudinais e cauda com $15-18$ anéis e com extremidade lisa. Difere de $T$. aduncus por apresentar estilete ligeiramente mais curto ( $\mathrm{St}=16,0-$ $18,0$ Vs. $18,0-20 \mu m)$, maior número de anéis labiais (6 -

7 Vs. 4 - 5) e menor número de anéis caudais (Ran = 15 18 Vs. $19-27)$.

Tylenchorhynchus sp. "B" diferencia-se de Tylenchorhynchus sp. "A" pela posição mais posterior do poro excretor e mais anterior do fasmídio, ter porção lisa do extremo caudal maior e pela ausência de machos. Ocorrência

Essa espécie foi encontrada em solo de rizosfera de gramineas nativa não identificadas (Pelotas).

41. Helicotylenchus sp. (Fig. 5, A - F)

Mensuração

Fêmeas $(\mathrm{n}=8): \mathrm{L}=0,70(0,59-0,75) \mathrm{mm}$; 


$$
\begin{aligned}
& a=28,1(24-34,5) ; b=6,0(5,0-6,7) ; b^{\prime}=4,6(4,2- \\
& 5,1) ; \quad c=49,0(42,9-56,8) ; \quad c^{\prime}=0,9(0,8-1,0) ; M= \\
& 46,2(43,7-50,0) ; \quad \mathrm{V}=63,7(61,5-67,2) ; \quad \mathrm{st}=24,8 \\
& (22,5-27,0) \mu \mathrm{m} ; \quad t=13,5(12,0-15,0) \mu \mathrm{m} . \\
& \text { Holotipo (Fêmea): } L=0,75 \mathrm{~mm} ; \quad a=29,4 \text {; } \\
& b=6,0 ; \quad b^{\prime}=4,5 ; \quad c=41,6 ; \quad c^{\prime}=1,0 ; \quad V=64,1 ; \quad s t= \\
& 25,5 \mu \mathrm{m} \text {. }
\end{aligned}
$$

\section{Macho: não encontrado}

\section{Descrição}

Fêmea: apresentam o corpo em forma de espiral aberta à fechada, quando relaxada (Fig. 5, B - C). Região labial hemisférica e com 4 - 5 anéis. Estilete com cone medindo 13,5 $\mu \mathrm{m}$ e a haste $12,6 \mu \mathrm{m}$, com bulbos basais medindo $1,8 \mu \mathrm{m}$ de altura e 9,0 $\mu \mathrm{m}$ de largura, achatados anteriormente e arredondados posteriormente. Bulbo mediano do esôfago com base a $83,7 \mu m$ a extremida anterior e medindo $13,5 \mu \mathrm{m}$ de comprimento por 9,0 $\mu \mathrm{m}$ de largura (Fig. 5, A). Poro excretor localizado aproximalamente a 99,0 $\mu \mathrm{m}$ da extremidade anterior e a $5-7$ anéis anteriores a junçăo esôfago-intestino. Hemizonídio equivalente ao tamanho de 1,5 anel do corpo e localizado a 1 - 2 anéis anteriores ao poro excretor. Campo lateral formado por t incisuras. que são separadas até o seu final, e com areolacăona porção anterior do corpo. Aparelho reprodutor anfidélfico com ovários distendidos e espermatecas redondas e vazia. 
Fasmídio localizado entre $4-5$ anéis anteriores ao nível anal. Cauda com o lado dorsal curvado ventralmente com extremidade irregularmente arredondada e $7-10$ anéis ventrais. Os anéis terminais da cauda são de tamanho irregular e menores que os demais do corpo (Fig. 5, D - F).

Diagnose

Helicotylenchus sp. dist ingue-se das demais espécies, exceto para H. varicaudatus Yuen, 1964 (SHER, 1966), por apresentar as seguintes características: região labial hemisférica, com $4-5$ anéis e sem discolabial visivel, estilete com $25-27 \mu m$ de comprimento e provido de bulbos basais arredeondados, campo lateral com 4 incisuras até o seu final, cauda irregularmente hemisférica e sem projeção ventral e com estriação distal mais fina que em sua parte anterior, machos não conhecidos e espermateca vazia. Aproxima-se de $H$. varicaudatus e dele se separa por apresentar menor comprimento do estilete $(S t=22,5-27,0$ Vs. 29,0-32,0 $\mu \mathrm{m})$ e por apresentar anelação distal da cauda mais fina que na porção anterior. 


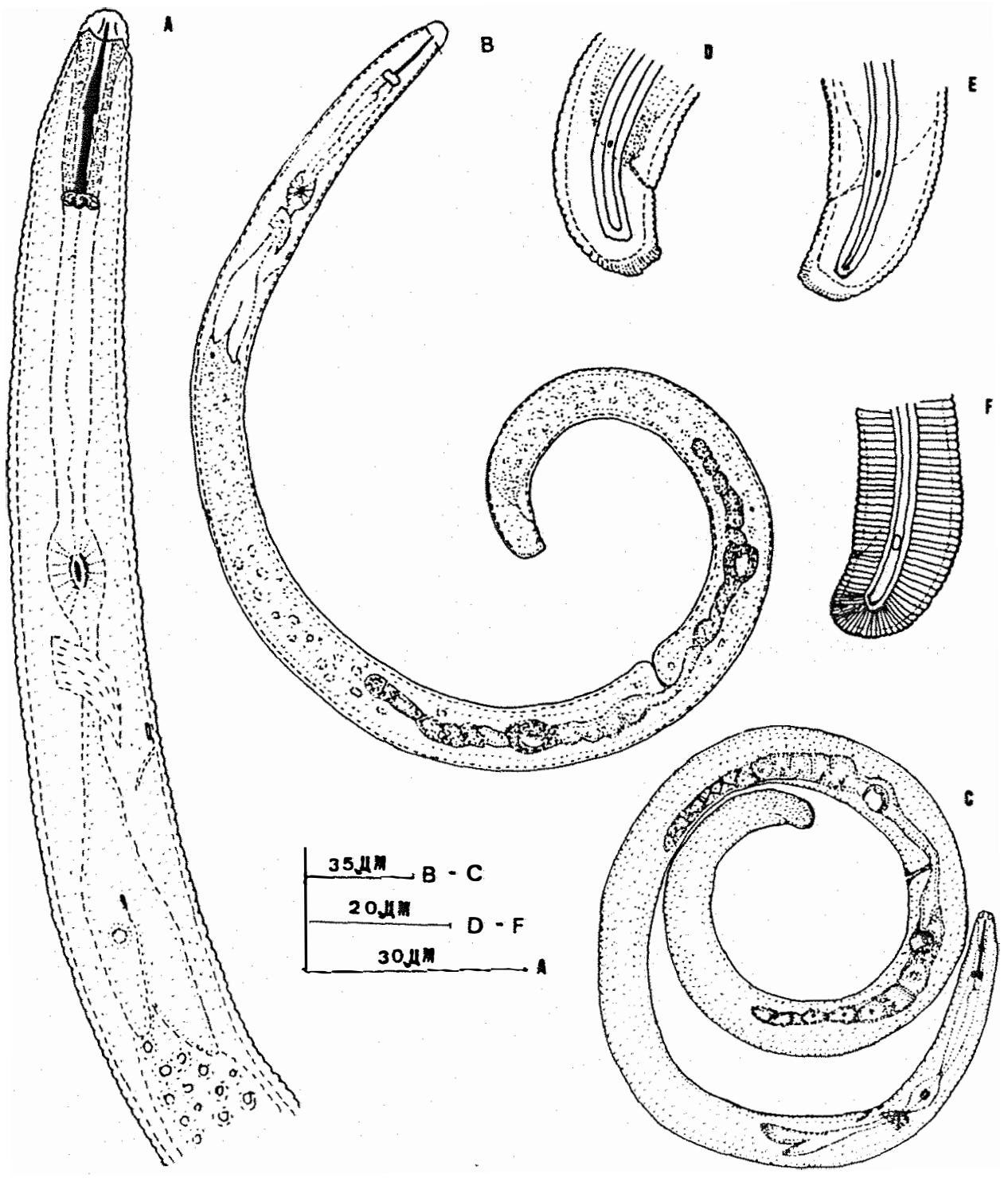

FIG. 5. Helicotylenchus sp. Fêmea: A - Regizo esofagiana: $\mathrm{B}$ e C - Formas do corpo quando relaxadas; D - F - Variaçes na morfologia da cauda. 
Ocorrência

Essa espécie foi encontrada em solo junto do sistema radicular plantas de chorão, eucalipto, canade-açúcar, gramíneas nativas não identificadas e pessegueiro (Pelotas) e morangueiro (Feliz).

\section{Criconema sp. "A"}

(Fig. 6, A - E)

Mensurações

Fêmeas $(\mathrm{n}=7): \mathrm{L}=0.40(0.39-0.42) \mathrm{mm}$ :

$a=14.1(13 .+-15.7): \quad b=4.0(3.7-4.1): \quad c=13.8$

$(11.6-15.1): M=84.0(81.2-86.6):$ St $=69.4(67.5-$ $73.5)$ un: $V=86.6(8+.6-88,0): R=8+(82-86):$ RSt $=$ $15(12-16):$ ROes $=22(19-25):$ Rex $=24(21-26):$ RV $=$ $11-12:$ RVan $=3-4$, Ran $=6-7:$ VL/VB $=1.8(1.6-$ $2.01 ; S t \% L=16.9(15.7-19.0):$ St\%oes $=68.1164 .7-$ $72.71: \mathrm{VL} / \mathrm{St}=0 .-(0.69-0.88): \mathrm{Ga}=+1.3(35.0-51.0)$.

Holót ipo (Fêmea ): $L=0,40 \mathrm{~mm} ; \quad \mathrm{a}=13, \mathrm{t}$ : $b=3.7: c=12.7: V=85.8: s t=69.0 \mu \mathrm{m}: R=82: \mathrm{KSL}=$ 15: ROes $=21:$ Rex $=24:$ RV $=10 ;$ RVan $=4:$ Ran $=6$. Macho: näo encontrado.

Descricões

Fêmeas: apresentam o corpo subcilindrico e esguio com af ilamento em ambas extremidades. assumindo 
a forma arcada ventralmente quando relaxadas (Fig. 6, E). Região labial formada por um anel em forma de pires e seis pseudolóbulos bem desenvolvidos, com 5, $6 \mu \mathrm{m}$ de altura por 13,5 $\mu \mathrm{m}$ de largura. Anéis do corpo retrosados, com margem posterior lisa. Anastomoses ausentes ou raras $(0-3)$. Os ané is do meio do corpo medem 4,5 um de largura 5,6 $\mu \mathrm{m}$ de espessura. Na cauda, alguns anéis podem apresentar margem posterior com entalhe (Fig. 6, B ). Estilete robusto, com cone medindo $59,4-63,0 \mu \mathrm{m}$ e haste $9,0-12,6 \mu \mathrm{m}$ de comprimento. O cone equivale 6,0-6,5 vêzes o comprimento da haste. Bulbos basais do estilete medindo 2,7 - 3,6 $\mu \mathrm{m}$ de altura por 7,2 - 9,0 um de largura, com formato de âncora. Poro excretor localizado entre $1-3$ anéis posteriores a junção esôfago-intestino, correspondendo a 90 $120 \mu \mathrm{m}$ da extremidade anterior. Vulva fechada, situada no $11-12$ anel a contar do final corpo. Vagina levemente sigmóide (Fig. 6, B - D). Ovário alcançando o terço anterior do corpo, com espermateca pequena, redonda e cheia de espermatozóides esféricos. Ânus localizado no 60 anel a contar do final do corpo e intestino não se sobrepondo ao reto. Cauda cònica, com $31,5 \mu m$ de comprimento médio, afilamento gradativo e com o ultimo anel livre, isto é, não embutido no penúltimo (Fig. 6, B - D). 


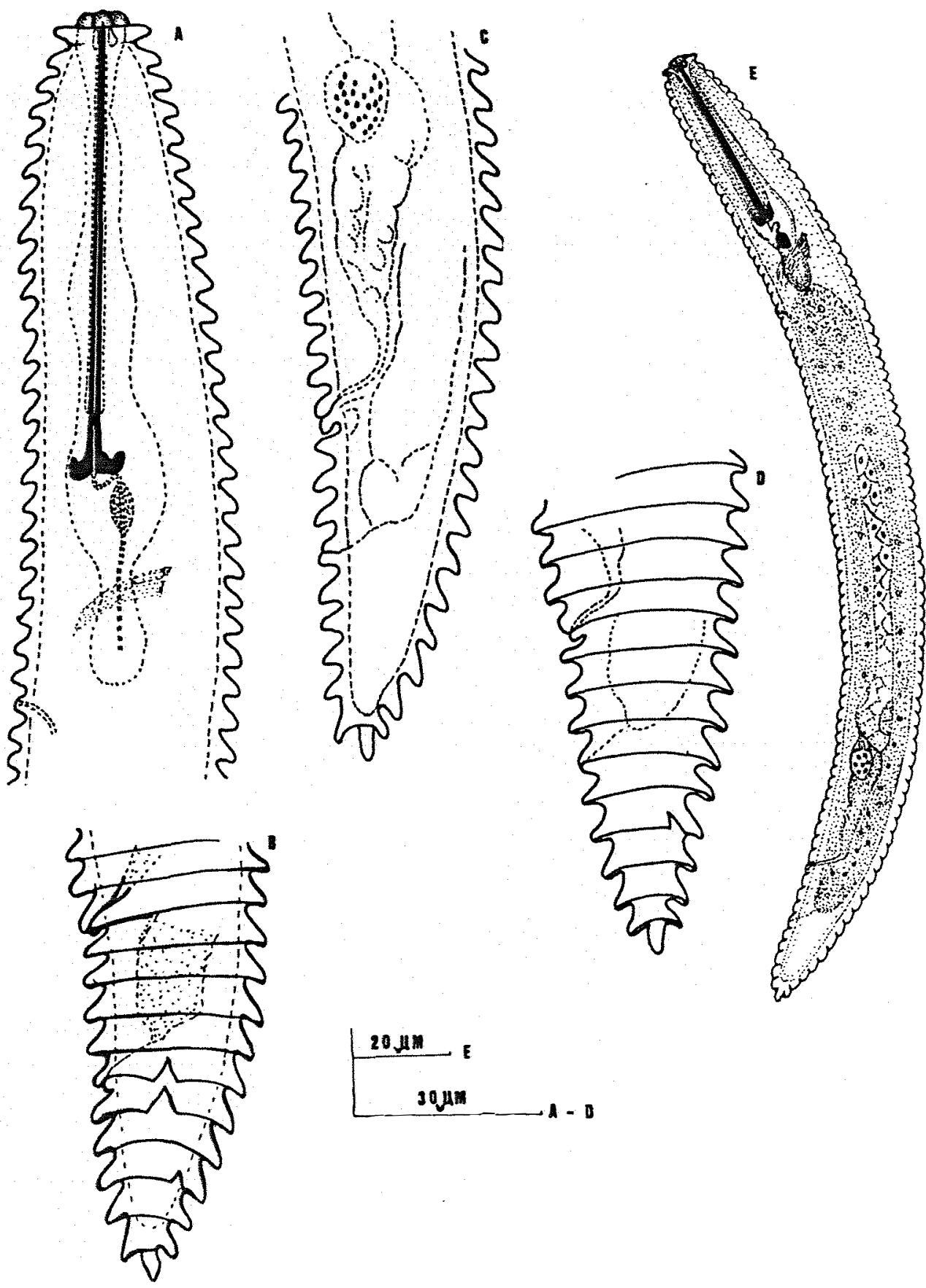

FIG. 6. Criconema sp. "A" Fêmea: A - Regiào esofagiana; B - D - Variaçoses na morfologia da cauda; E - Corpo. 


\section{Diagnose}

Criconema sp. "A" pertence ao grupo de espécies do gênero sem nenhuma ornamentação na margem posterior de todos os anéis do corpo da fêmea e região labial formada por um único anel diferenciado dos anéis do corpo. É mais próxima de Criconema paraguayense (Andrássy, 1968) Raski \& Luc, 1984 (ANDRÁSSY, 1968; RASKI \& LUC, 1984) e de Criconema annuliferum (De Man, 1921) Micoletzky, 1925 (DE GRISSE, 1969). Difere de C. paraguayense por apresentar maior número de anéis do corpo $(R=82-86$ Vs. $76-$ 79) e maior comprimento do estilete (St $=67,5-73,5 \mathrm{Vs}$. $55-58 \mu \mathrm{m})$. Difere de C. annuliferum por apresentar estilete menor (St $=67,5-73,5 \mathrm{Vs} .89-113 \mu \mathrm{m})$, maior número de anéis no corpo $(R=82-86$ Vs. $58-78)$ e não apresentar anel na região do colar.

Ocorrência

Sete exemplares da espécie foram encontrados em solo de rizosfera de plantas de Chorão (Pelotas).

$$
\begin{aligned}
& \text { 43. Criconema sp. "B" } \\
& \text { (Fig. 7, A - D) }
\end{aligned}
$$

Mensurações

Fêmeas $(\mathrm{n}=14): \mathrm{L}=0,36(0,31-0,45) \mathrm{mm}$; $a=13,2(11,1-15,7) ; b=3,8(2,8-5,0) ; c=24,7$ 
$(20,3-30,0) ; M=79,0(76,3-81,0) ; \mathrm{St}=54,7(52,5-$ $57,0) \mu \mathrm{m} ; \mathrm{V}=91,5(89,1-93,5) ; \mathrm{R}=90(82-94) ; \mathrm{RSt}=$ $13(12-15) ; \quad$ ROes $=22(20-26) ; \quad \operatorname{Rex}=26(21-29) ;$ $\mathrm{RV}=8-11 ; \quad \mathrm{RVan}=2-3 ; \quad \operatorname{Ran}=6-8 ; \quad \mathrm{VL} / \mathrm{VB}=1,1$ $(0,7-1,3) ;$ St\%L $=13,9(12,0-17,3) ; \quad$ St\%Oes $=57,4$ $(52,8-62,2) ; \quad \mathrm{VL} / \mathrm{St}=0,6(0,4-0,8) ; \quad \mathrm{EP}=103(87-$ 120) $\mu \mathrm{m}$.

Holótipo (Fêmea): $\mathrm{L}=0,36 \mathrm{~mm} ; \mathrm{a}=13,6$; $b=3,9 ; c=27,3 ; M=78,3 ; \mathrm{St}=55,5 \mu \mathrm{m} ; \mathrm{V}=91,8 ; \mathrm{R}=$ $88 ;$ RSt $=14 ;$ ROes $=22 ; \quad$ RVan $=4 ; \quad$ Ran $=3$.

Macho: não encontrado.

Descriçao

Fêmeas: apresentam o corpo cilíndrico, com extremidade posterior cônica, com postura variando entre quase retilínea ou forma de "c" abertoquando relaxadas (Fig. 7, D). Região labial elevada, com 4,5 $\mu \mathrm{m}$ de altura e 12,6 $\mu \mathrm{m}$ de largura, formada por um único anel direcionado lateralmente e seis pseudolóbulos bem separados entre sí. Constrição entre a região labial e o corpo equivalente a largura do primeiro anel do corpo. Estilete robusto, co-

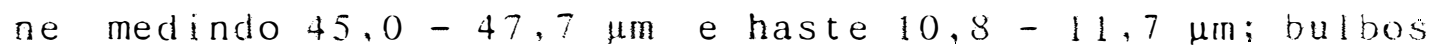
basais medindo $2,7 \mu m$ de altura por $9,0 \mu m$ de largura, com projeçăo anterior (Fig. 7 , A). Anastomoses ausentes ou raras $(0-1)$. Anéis do corpo retrosados, com 4,5 $\mu m$ de espessura e de largura, e margem posterior lisa. Margem in- 
dentada somente na região caudal. Poro excretor localizado entre 3 e 5 anéis posteriores a junção esôfago-intestino. Vulva situada a $9-10$ anéis da extremidade caudal, vagina levemente sigmóide. Ovário distendido na maioria dos exemplares mas reflexo em um deles, espermateca redonda, pequena e vazia (Fig. 7, B). Ânus situado a $6-8$ anéis da extremidade final e intestino formando pequeno saco pósretal. Cauda cônica medindo aproximadamente 18,0 $\mu \mathrm{m}$ (Fig. $7, B-C)$.

\section{Diagnose}

Criconema sp. "B" pertence ao mesmo grupo de Criconema sp. "A", sendo ma is próximo de C. pacificum (Andrássy, 1965) Raski \& Luc, 1984 (RASKI \& GOLDEN, 1965 ; RASKI \& LUC, 1984). Difere de C. pacificum por apresentar menor comprimento de estilete $(\mathrm{St}=52,5-57,0 \mathrm{vs} \cdot 62-$ $74 \mu \mathrm{m})$ e menor número de anéis entre vulva e ânus (RVan = $2-3$ Vs. $5-61$.

Criconema sp. "B" diferencia-se de Criconema sp. "A" por apresentar menor comprimento de estilete, maior número de anéis no corpo, a lém das diferenças morfológicas dos anéis terminais da cauda.

Considerando a grande variacäo nas mensuraçoes, bem como na morfologia da regiào labial e da cauda registradas para $C$. mutabile Taylor, 1936, é possivel que o material pertença a essa espécie. 

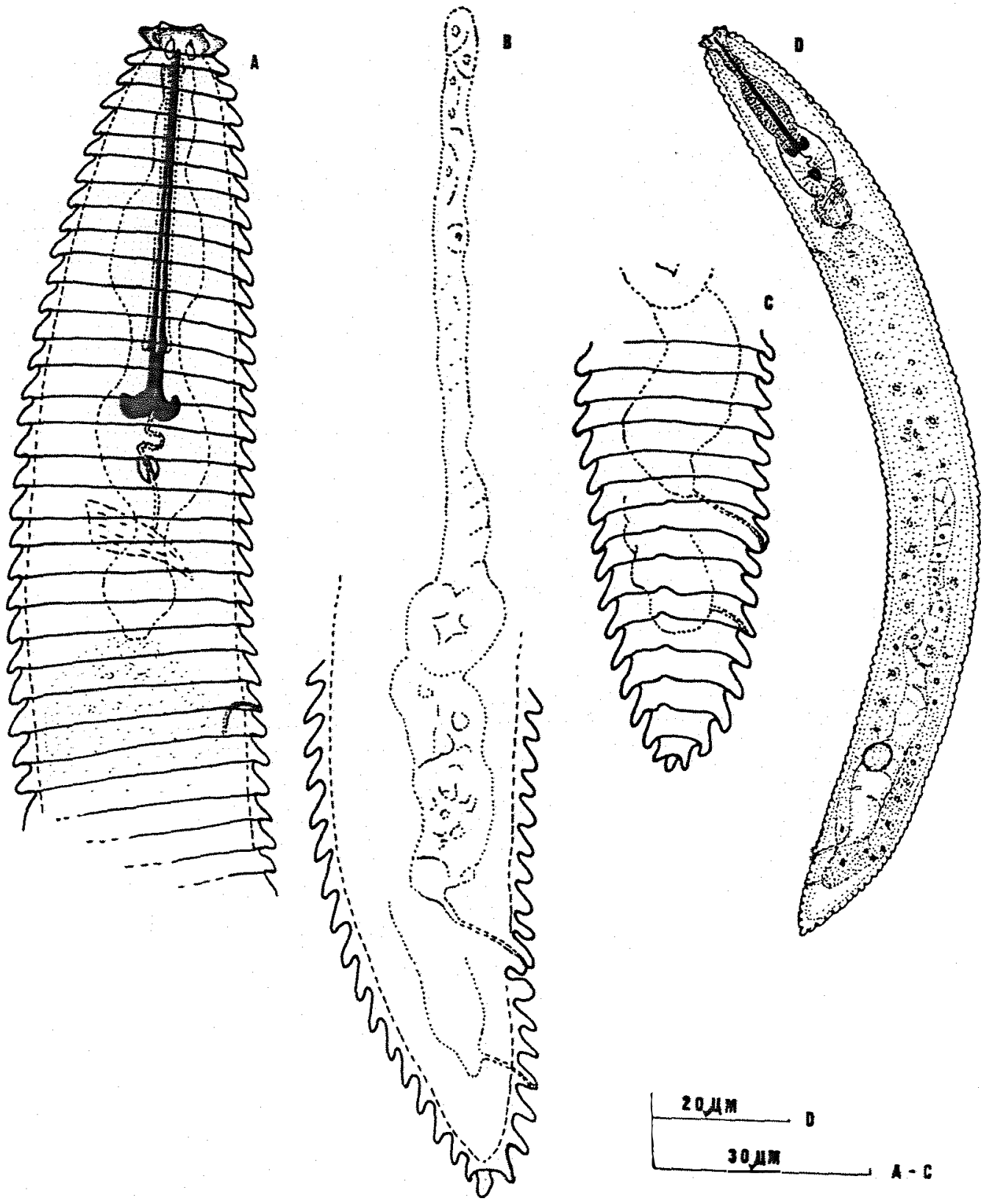

FIG. 7. Criconema 5p. "B" Fêmea: A - Regiăo esofagiana; B - Gônada; B - C - Variaçes na forma da cauda; D - Corpo. 


\section{Ocortência}

Essa foi encontrada em rizosfera de gramineas nativas não identificadas, pessegueiro, hortência. eucalipto (Pelotas) e de grama de jardim (Caxias do Sul).

\section{Criconeme1la sp.}

(Fig. 8, A - D )

Mensurações

Fêmeas $(n=12): L=0,41(0.36-0,46) \mathrm{mm}$ :

$a=17,6(15,8-20,2) ; b=4,4(4,0-4,9): c=33.5$ $(25,8-38,5) ; M=76,0(73,3-79,3) ; S t=45,0(43,5-$ $46,8) \mu m ; \quad V=95.0(94,0-95,5) ; \quad R=144(138-152) ;$ RSt $=20(13-21) ; \quad$ ROes $=35(31-39) ;$ Rex $=37(33-$ 411: RV $=8-10 ; \operatorname{RVan}=2-4 ; \operatorname{Ran}=5-8 ; \mathrm{St} \% \mathrm{~L}=10.8$ $(9,6-11,8):$ StgOes $=49,0(42,6-54,7) ; \quad$ VL/VB $=0.38$ $(0,80-1,0): \mathrm{VL} / \mathrm{St}=0,46(0,41-0.53): \mathrm{Ga}=37.2(28,5$ $-57,2) ; E P=88.8(81,0-100.0) \mathrm{\mu m}$.

Holót ipo (Fêmea): $L=0.40 \mathrm{~mm}: \quad a=16.8:$ $b=4.3: c=30,0: V=94,4 ; S t=45 \mu m: R=145:$ RSt $=$ 20: Roes $=35:$ Rex $=38:$ Rvan $=3:$ Ran $=5$.

Macho: näo encontrado.

Descricões

Fêmeas: apresentam o corpo em forma de "C." aberto quando relaxadas (Fig. 8. A). cilindrico. com pe- 
queno afilamento nas extremidades. Região labial baixa com $0,9 \mu \mathrm{m}$ de altura e 7,2 $4 \mathrm{~m}$ de largura, com um pequeno anel labial circundando o disco oral; lobulos labiais submediano presentes. Disco labial ligeiramente mais estreito que o primeiro anel do corpo. Estilete sobusto, cone medindo 34,2 - 35,1 e haste 9,9-11,7 $\mu \mathrm{m}$ de comprimento (Fig. 8, D). Anéis do corpo retrosados e de aparência angular, com margem posterior lisa. Anastomoses variando de 1 a 10 por exemplar. Anéis do corpo com $2,9 \mu \mathrm{m}$ de largura e $1,8 \mu \mathrm{m}$ de espessura. Abertura do poro excretor ao nível da junção esofago-intestino. Vulva aberta situada a $8-10$ anéis caudais correspondendo aproximadamente a $21,6 \mu \mathrm{m}$ da extremidade do corpo. Vagina levemente sigmóide, ovário pouco desenvolvido com espermateca redonda e vazia. Saco pós-intestinal pequeno e não se sobrepondo ao reto. Ânus situado a 5 - 8 anéis terminais correspondendo a $12,3 \mu \mathrm{m}$ da extremidade final da cauda. Término caudal hemisférico, geralmente curvada para o lado dorsal, e consistindo de dois anéis embutidos telescopicamente (Fig. $8, \mathrm{~B}-\mathrm{C})$.

Diagnose

Criconemella sp. filia-se ao grupo das espécies sem lóbulos labiais submedianos, com cauda trapezoidal, mostrando término curvado dorsalmente e anéis terminais embutidos telescopicamente (Criconemella sensu De Grisse, 1969). Difere de C. humilis (Raski \& Riffle, 1967) 

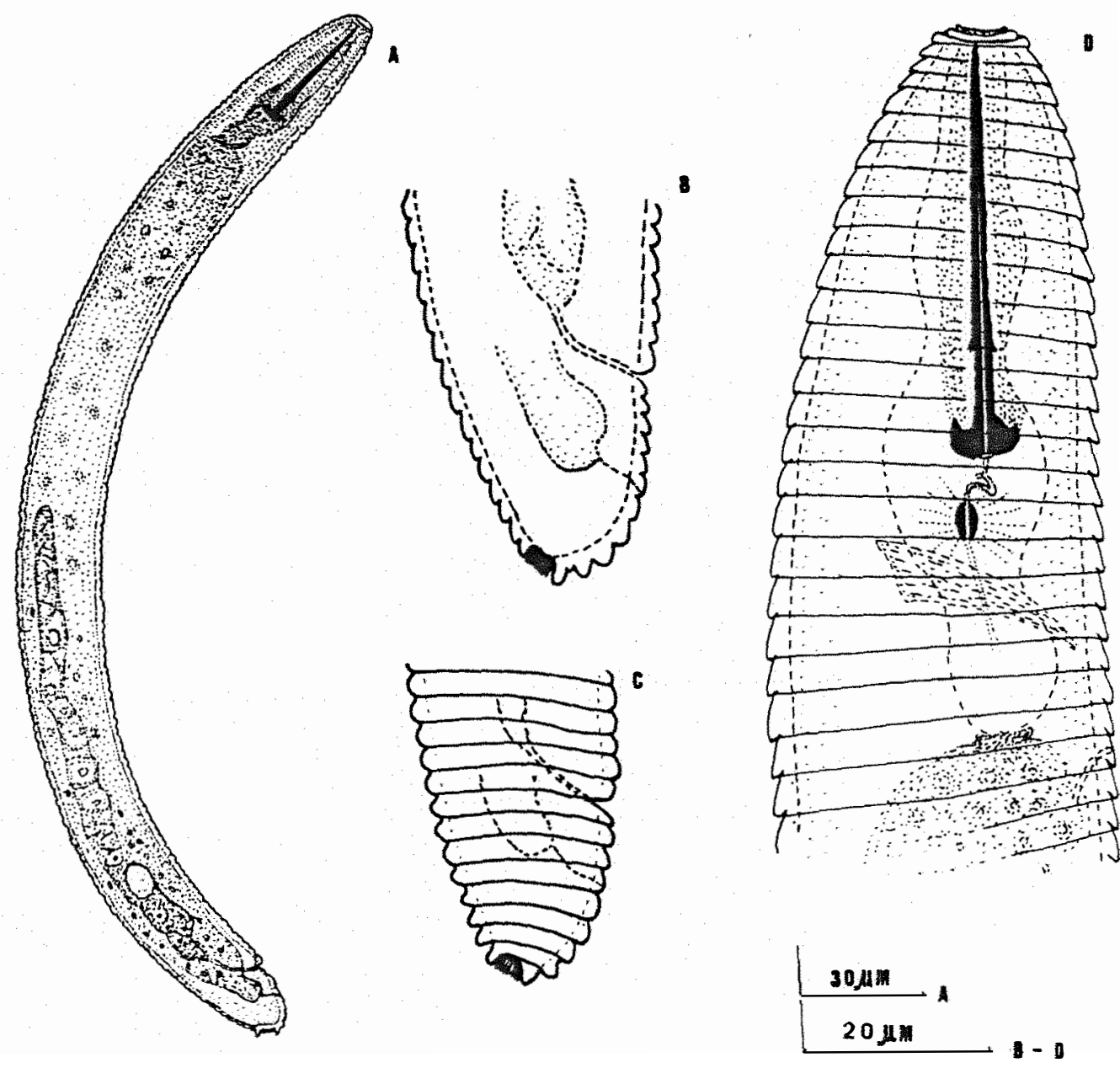

FIG. 8. Criconemella sp. Fêmea: A - Corpo; B - C - Cauda; D - Regiao do esófago. 
Luc \& Raski, 1981 (RASKI \& RIFFLE, 1967; LUC \& RASKI, 1981 ) por apresentar maior número de anéis no corpo ( $R=$ 138 - 152 Vs. 106 - 122), poro excretor situado ligeiramente mais posterior $(\operatorname{Rex}=33-41$ Vs. $28-34)$ e ânus situado mais anteriormente ( $\operatorname{Ran}=6-8$ Vs.4-6). Difere de C. brevistylus (Sing \& Khera, 1976) Luc \& Raski, 1981 (SING \& KHERA, 1976; LUC \& RASKI, 1981) por apresentar menor comprimento do corpo $(L=0,36-0,46$. Vs. $0,58-$ $0,67 \mathrm{~mm})$ e menor comprimento do estilete (St $=43,5-46,8$ Vs. $56,0-60,0 \mu \mathrm{m})$.

Ocorrência

Essa espécie foi encontrada em rizosfera de gramíneas nativas e trigo (Pelotas) e resteva de arroz irrigado (Camaquã).

\section{Discocriconeme l la sp.}

$$
\text { (Fig. 9, A - E) }
$$

Mensurações

$$
\begin{aligned}
& \text { Fêmeas }(\mathrm{n}=17): \mathrm{L}=0,34(0,29-0,39) \mathrm{mm} ; \\
& \mathrm{a}=12,5(10,8-15,0) ; \mathrm{b}=3,8(3,2-4,3) ; \mathrm{c}=23,9 \\
& (20,0-26,6) ; \mathrm{M}=80,7(78,9-82,5) ; \mathrm{St}=56,1(51,0- \\
& 60,0) \mu \mathrm{m} ; \mathrm{V}=90,0(86,5-94,9) ; \mathrm{R}=98(93-103) ; \mathrm{RSt}= \\
& 18(15-20) ; \operatorname{ROes}=26(24-32) ; \operatorname{Rex}=27(25-32) ; \\
& \text { RV }=9(8-10) ; \operatorname{RVan}=1-3 ; \operatorname{Ran}=6-7 ; \mathrm{St} \% \mathrm{~L}=16,3
\end{aligned}
$$


$(13,3-18,0) ; \quad$ St\%Oes $=63,5(56,9-73,2) ; \mathrm{VL} / \mathrm{VB}=1,1$ $(1,0-1,4) ; \mathrm{VL} / \mathrm{St}=0,59(0,47-0,74)$.

Hol6tipo (Fêmea): $L=0,38 \mathrm{~mm} ; \quad a=14,3$; $\mathrm{b}=4,3 ; \mathrm{c}=21,5 ; \mathrm{V}=94,9 ; \mathrm{St}=57,0 \mu \mathrm{m} ; \mathrm{R}=99 ; \mathrm{RSt}=$ $17 ;$ ROes $=25 ; \operatorname{Rex}=27 ; \operatorname{RVan}=5 ; \operatorname{Ran}=4$.

Macho: não encontrado.

\section{Descrição}

Fêmeas: apresentam o corpo cilíndrico, cur vado ventralmente aparentando a forma de "C" aberto quando relaxadas (Fig. 9, E). Região labial achatada anteriormente e com vista frontal circular ou fracamente hexagonal, formada pelo disco labial com 4,0-4,5 $\mu$ m de altura e $10,8-11,7 \mu m$ de largura destacada do corpo por um nítido colar. Abertura oral em forma de uma fenda reta dorso-ventral. As aberturas anfidiais são levemente recurvada, uma em cada lábio lateral lembrando parênteses que enceram a abertura oral. Os lábios laterais são bem mais desenvolvidos que os medianos (subdorsais e subventrais). Estilete robusto, cone medindo $46.8-8,6 \mu m$ e haste com 9,9 10,8 $\mu m$ de comprimento. Bulbos basais do estilete em forma de âncora, com 1,8-2,7 4 m de altura e 7,2 - 9,0 $\mu m$ de largura (Fig. 9, A). Anéis do corpo com 4,5 $\mu \mathrm{m}$ de altura e $3,6 \mu \mathrm{m}$ de espessura. Poro excretor situado a $2-3$ ané is posteriores a junção esôfago-intestino. Anastomoses ausentes ou raras $(0-2)$. Vulva fechada, situada a $8-10$ 
anéis ou a 30,6 - 36,0 um da extremidade final do corpo. Vagina sigmóide, ovário distendido e espermateca redonda e cheia de espermatozóides esféricos. Ânus situado a 6 7 anéis ou $16,2-19,8 \mu \mathrm{m}$ da extremidade final. Cauda cônica, com os três últimos anéis levemente direcionados dorsalmente (Fig. 9, B - D).

Diagnose

Discocriconemella sp. é única por apresentar região labial com disco circular ou levemente hexagonal e um colar nítido. D. discolabia (Diab \& Jenkins, 1966) De Grisse, 1967 (ORTON WILLIAMS, 1979) e D. inarata Hof fman, 1974 (HOFFMAN, 1974), também apresentam disco labial circular mas não têm colar. Outras diferenças em relação a D. discolabia são: a) corpo mais longo ( $L=0,29-$ $0,39$ Vs. $0,22-0,30 \mathrm{~mm})$, b) maior estilete $(\mathrm{st}=51,0-$ $60,0$ Vs. $37,0-40,0 \mu \mathrm{m})$, c) menor número de anéis no corpo $(R=93-103$ Vs. $162-172)$ e d) menor número de anéis na cauda $(\operatorname{Ran}=3-5$ Vs. $10-14)$. De D. inarata difere ainda por: a) menor comprimento do $\operatorname{corpo}(L=0,29$ - 0,39 Vs. 0,35-0,48 min), b) maior número de anéis entre vulva e ânus (Rvan $=4-6$ Vs. 2).

Ocorrência

A espécie foi encontrada associada à grama de jardim, na cidade de Caxias do sul. 

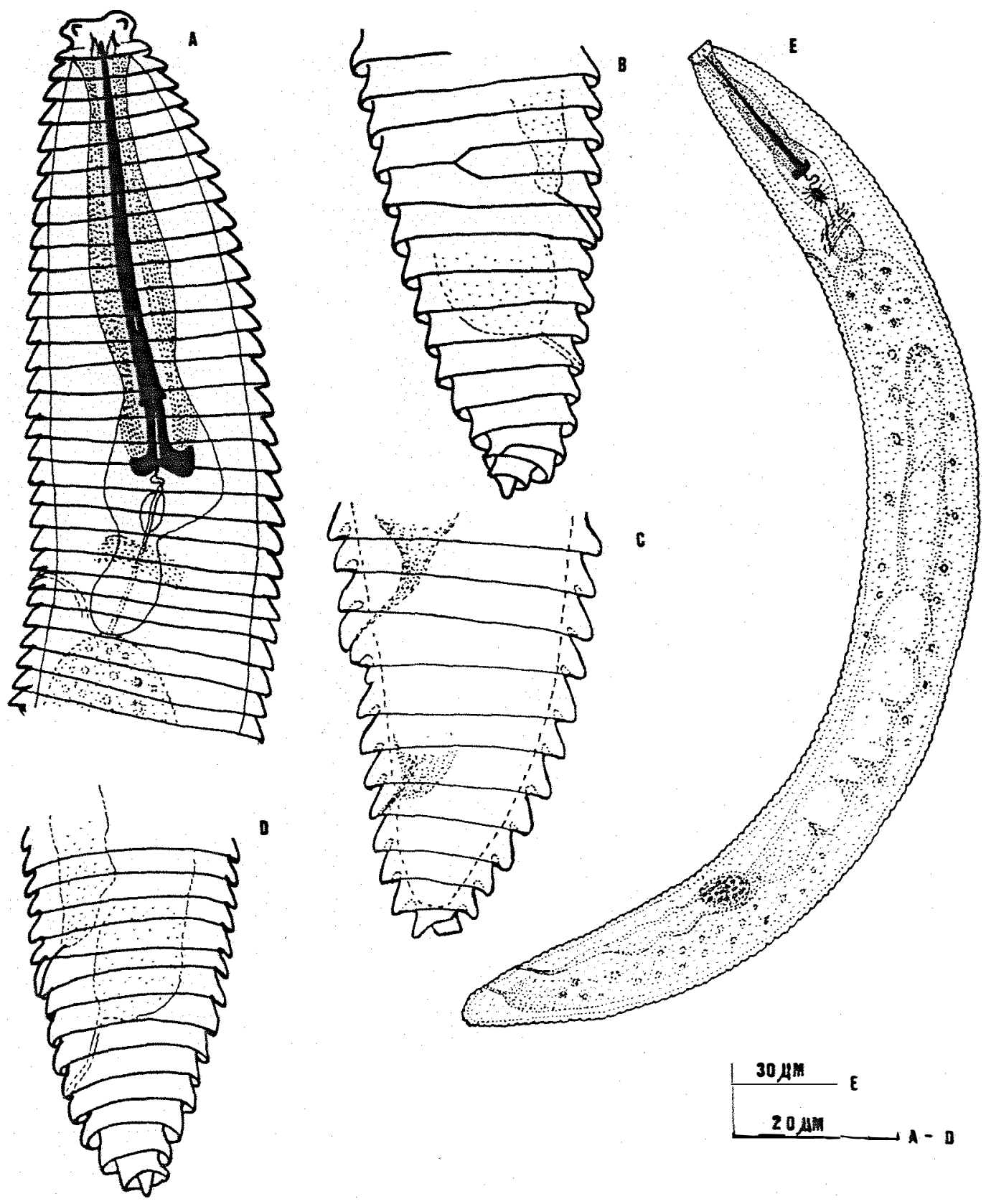

FIG. 9. Discocriconemeila sp. Femea: A - Regiäo esofagiana; B - D - Variaçoes na morfologia da cauda; C - Corpo. 


\section{REFERÊNCIAS BIBLIOGRÁFICAS}

ALKEMADE, J.R.M. \& LOOF, P.A.A. The genus Xiphinema Cobb, 1913 (Nematoda: Longidoridae) in Perú. Revue Némato1., $13(3): 339-348.1990$.

ANDRÁSSY, I. Nematoden aus Chile, Argentinien und Brasilien, gesammelt von Prof. Dr. H. Franz. Opusc. Zool. Bdpest, 7(1): $3-34.1967$.

ANDRÁSSY, I. Fauna Paraguayensis. 2. Nematoden aus den Galeriewãeldern des Acaray-Flusses. Opusc. Zool. Bdpest, 8(2): $167-315.1968$.

ANDRÁASY, I. Evolution as a basis for the systematization of nematodes. London, S. Franscisco, Melbourne, Pitman Publishing, 1976.288 .

ANDRÁssy, I. Tylenchus davainei. C.I.H. Descriptions of Plant-Parasitic Nematodes. Set 7, no 97. 1977. 3p. 
ANDRÁSSY, I. The genera and species of the family Tylenchidae Orley, 1980 (Nematoda). The genera Cephalenchus (Goodey, 1962) Golden, 1971 and Allotylenchus gen. $n$. Acta Zoo 1. Hung., $30(1 / 2): 1$ - 28. 1984 .

ANTONIO, H. \& LEHMAN, O. L. Nota sôbre a ocorrência de nematóides do gênero Meloidogyne em algumas ervas daninhas nos Estados do Paraná e do Rio Grande do Sul. Soc. Brasil. Nemato1., 3:29-32. 1978 .

BARKER, K. R. Consultant report in nematology for the national soybean project. Porto Alegre, RS, Brazil. 1974.9p. (mimeogr.).

BONETTI, L.P. \& TRAGNAGO, J.L. AvaliaçÁo de resistência de cultivares de soja a nematóides causadores de galhas. In: ReuniAo de Pesquisa da Soja na Regío Sul. Porto Alegre, RS, 27 a 29 de Julho de 1982. p.4060 .

BRANCALION, A. M., ZANON, J.I. \& ZEM, A. C. Ocorrência de Heteroderafici no Rio Grande do Sul. Rev. Agric., Piracicaba, $56(1 / 2): 4.1981$. 
BRASIL, J. F. de A. Doenças do Trigo In: : A Cultura dos Campos. 3a. ed. Paris, Mounier, Jeabin \& Cia. 1910. p. $204-205$.

CAFé Filho, A. C. \& HUANG, C. S. Nematóides do gêneto Pratylenchus no Brasil. Fitopatol. Brasileira., 13 (3): $232-235 . \quad 1988$.

CAFE FILHO, A. C. \& HUANG, C. S. Description of Pratylenchus pseudofallax n. sp. with a key to species of the genus Pratylenchus Filipjev 1936 (Nematoda:Pratylenchidae). Revue Nématol.,12 (1): 7 - 15. 1989.

CAIN, S. C. Meloidogyne exigua. C.I. H. Descriptions of Plant-Parasitic Nematodes. Set. 4, no 49. 1974 4p.

CAMPOS, V. P.; D'ARC DE LIMA, R. \& ALMEIDA, V. F. Nematóides parasitos de grandes culturas identificados em localidades de Minas Gerais e São Paulo. Nematol. Brasileira. 11: $226-232.1987$.

CESNIK, R. Dois nematódeos parasitando Tropaeoluin majus L.. Rev. Agric.. Piracicaba, 32(4): 253 - 260. 1957. 
CHARCHAR, J. M.; HUANG, C.S.; MENEZES SOBRINHO, J. A. \& LOPES, C. A. Nematóides fitoparasitas associados a plantas de alho (Allium sativum L. e A. ampeloprasum L.) coletadas nos principais Estados produtores do Brasil. Fitopatol. Brasileira., 5 (1): 105 - 114. 1980 .

CHAVES, E. Criconematoidea (Nematoda) from Argentina. Nematologica, $29(4): 404-424.1983$.

CORBETT, D. C. M. Pratylenchus brachyurus. C.I.H. Descriptions of Plant-Parasitic Nematodes. Set 6 , no 89. $1976.4 \mathrm{p}$.

CORBETT, D. C. M. \& CLARK, S. A. Surface features in the taxonomy of Pratylenchus species. Revue Nématol., $6(1): 85-98.1983$.

COSTA NETO, J. P. da Duas doenças que at acam as partes subterrâneas dos Vegetais: A galha de côroa (bacterium tumefaciens) e as galhas por Nematóides (Heterodera radicicola). Secretaria do Estado dos Negócios da Agricultura, Indústria e Comércio. Porto Alegre - RS. Bol. No. 53. 1937. 16 p. 
DE GRISSE, A. Contribution to the morphology and the sys-. tematic of the Criconematidae (Taylor, 1936) Thorne, 1949. Thesis, Univ. Gent., Belgium, 1969. 143p.

DE GUIRAN, G. Description de deux espèces nouvelles du genre Tylenchorhynchus Cobb, 1913 (Nematoda: Tylenchinae) accompagnée d'une clé des femelles, et précisions sur T. mamillatus Tobar-Jimenez, 1966. Nematologica, $13(2): 217-230 . \quad 1967$.

DIAB, K.A. \& JENKINS, W.R. Three new species of Criconemoides (Nematoda: Criconematidae). Proc. helminth. Soc., $33(1): 5-7.1966$.

DOUCET, M.E. Description de deux nouveaux Peltamigratus et d'une population D'Hoplolaimus galeatus lNematoda: Tylenchida) de la province de Córdoba, Argentine. Nematologica, $26(1): 34-46.1980$.

DOUCET, M. E. Description de Dolichodorus longicaudatus n. sp. et Neodolichodorus leiocephalus n. sp. (Nemata: Tylenchida). Revue Nématol. , 4 (2): 191-197. 1981. 
DOUCET, M. E. Quatre nouvelles espèces du genre Hemicyliophora De Man, 1921 (Nematoda: Tylenchida) provenant d'Argentine. Revue Nématol., 5 (2):309-320. 1982.

DOUCET, M. E. Description de Dolichodorus aquaticus n.sp. (Nematoda: Dolichodoridae). Nematologica, 31(2): 143 -150.1985 .

EISENBACK, J. D.; HIRSCHMANN, H.; SASSER, J.N. \& TRIANTAPHYLlOU, A. C. A guide to the four most common species of root-knot nematodes (Meloidogyne Species), with a pictorial key. Coop. Publ. Dep. Plant Pathol. NCSU \& USAID, Raleigh, N.C. 1981. $111 \mathrm{p}$.

ESSER, R. P. Three additional species in the genus Hemicriconemoides Chitwood and Birchfield, 1957 (Nemata: Tylenchida). Nematologica, 5 (1): $64-71.1960$.

FERRAZ, L.C.C.B. Observations on some Xiphinema species found in Brazil (Nematoda:Dorylaimoidea). Nematol. Mediterrânea, 8 (2): $141-151.1980$.

FERRIS, V. R. Tylenchorhynchus silvaticus n. sp. and Tylenchorhynchus agri n. se. (Nematoda:Tylenchida). Proc. Helminth. Soc., 30(2): 165-168. 1963. 
FLEGG, J.J.M. \& HOOPER, D. J. Extration of free-living stages from soil. In: SoutheY, J.F. Laboratory Methods for Work with Plant and Soil Nematodes. London, Comm. Agric. Bur., 1970. p.5-22. (Tech. Bul1.2).

FORTUNER, R. Pratylenchus zeae. C.I.H. Descriptions of Plant-Parasitic Nematodes. Set 6, no 77. 1976. 3p.

FORTUNER, R. Morphometrical variability in Helicotylenchus Steiner, 1945. 5: On the validity of ratios. Revue Némato1., 7 (2): 137 - 146. 1984a.

FORTUNER, R. Morphometrical variability in Helicotylenhus Steiner, 1945. 6: Value of the characters used for specific identification. Revue Nématol., 7 (3): 245 264. $1984 \mathrm{~b}$.

FORTUNER, R. A reappraisal of Tylenchina (Nemata).8. The family Hoplolaimidae Filipjev 1934. Revue Nématol., 10 (2): $219-232.1987$.

FORTUNER, R. \& LUC, M. A reappraisal of Tylenchina lNemata). 6. The family Belonolaimidae Whitehead, 1960. Revue Nématol., $10(2): 183-202.1987$. 
FORTUNER, R. \& MAGGENTI, A. R. A reappraisal of Tylenchina (Nematoda). 4.The family Anguinidade Nicoll, 1935 (1926). Revue Nématol., 10 (2): 163 - 176. 1987.

FORTUNER, R.; MERNY, G. \& ROUX, C. Morphometrical variability in Helicotylenchus steiner, 1945. 3: Observations on African populations of Helicotylenchus dihystera and considerations on related species. Revue Nématol., $4(2): 235-260.1981$.

FRANKLIN, M.T. \& SIDDIQI, M.R. Aphelenchoides besseyi. C.I.H. Descriptions of Plant-Parasitic Nematodes. Set 1, กㅇ 4. 1972. 3p.

FREDERICK, J.J. \& TARJAN, A.C. A compendium of the genus Pratylenchus Filipjev, 1936 (Nematoda: Pratylenchidae). Revue Nématol., 12 (3): 243 - 256. 1989.

GERAERT, E. \& RASKI, D. J. A reappraisal of Tylenchina (Nemata). 3. The family Tylenchidae Orley, 1880. Revue Némato 1., $10(2): 143-161.1987$.

GOMES, J. E. S.; GUTTERRES, J . P. \& LEHMAN, P. Aval i açAo de resistência de cultivares de soja ao nematóide Meloidogyne javanica no Rio Grande do Sul. In: IV Reuni- 
ao Conjunta de Pesquisa da Soja RS/SC. S. Maria - RS, 23 a 27 de Agosto de 1976. p.1 - 7 .

HANDOO, Z. A. \& GOLDEN, A.M. A key and diagnostic compendium to the species of the genus Pratylenchus Filipjev, 1936 (Lesion nematodes). J. Nemato1., 21 (2): $202-218.1989$.

HARTMAN, K. L. \& SASSER, J. N. Identification of Melo $\underline{i}$ dogyne species on the basis of differential host test and perineal-pattern morphology. In: BARKER, K. R.; CARTER, C. C. \& SASSER, J. N. An advanced treatise on Meloidogyne. Methodology. Vol. II.Coop. Publ. Dep. Plant Pathol. NCSU \& USAID, Raleigh, N.C. 1985. p.70-77.

HOFFMANN, J.K. Discocriconemella inarata n. sp. and Criconemoides inusitatus n. sp. (Nematoda) from Iowa. J. Nematol., 6(4): $210-214.1974$.

HOOPER, D.J. Hand ling, Fixing, Staining and Mounting Nematodes. In: : SouThEy, J. F. Laboratory Methods for Work with Plant and Soil Nematodes. London, Comm. Agric. Bur., 1970a. p.39-54. (Tech. Bul1.2). 
HOOPER, D. J. Drawing and Measuring Nematodes.In: : SOUTHEY J. P. Laboratory Methods for Work with Plant and Soil Nematodes. London, Comm. Agric. Bur. 1970b. p.59 - 65. (Tech. Bu11.2).

HOOPER, D. J. Ditylenchus dipsaci.C.I.H. Descriptions of Plant-Parasitic Nematodes. Set. 1, no $14.1972 .4 \mathrm{p}$.

HOOPER, D. J. Aphelenchoides avenae. C.I.H. Descriptions of Plant-Parasitic Nematodes. Set 4, no 50. 1974. 4 p.

HOOPER, D. J. Paratrichodorus minor. C.I.H. Descriptions of Plant-Parasitic Nematodes. Set 7 , no 103.1977.3p.

HUANG, C. S.; SPERANDIO, C. A.; RIBEIRO, A. S . \& UESUGi, C. H. Ocorrência de Meloidogyne hapla em arroz irrigado no Rio Grande do Sul. Fitopatol. Brasileira., 9 (2): 417 . 1984 .

JENKINS, W.R. A rapid centrifugal-flotation technique for separating nematodes from soil. Pl. Dis. Reptr, 48(9): 692. 1964. 
JEPSON, S. B. Identification of Root-Knot Nematodes (Meloidogyne species). Wallingford, United Kingdon. Comm. Agric. Bur., International. 1987. 265 p.

KNOBLOCH, N.A. Description of the male Cephalenchus leptus (Siddiqi, 1963 ) Golden 1971 with notes on the presence of vulval flaps in the females. Indian $J$. Nemato1., 2(2): $202-204$. 1972 .

LAMBERTI, F. \& BLEVE-ZACHEO, T. Studies on Xiphinema americanum sensu lato with descriptions of fifteen new species (Nematoda: Longidoridae). Nematol. Mediterrânea, $7(1): 51-106.1979$.

LAMBERTI, F.; ROCA, F.; SHARMA, R.D.; PIMENTEL, J.P. ; AGOSTINELLI, A.; ANTONIO, H. \& LORDELLO, R.R.A. On the occurrence of species of Xiphinema in Brazil. Nematol. Brasileira, 11: 286 - 291. 1987.

LEHMAN, P. S.;MACHADO, C. C. \& TARRAGO, M.T. Frequència e severidade de doenças de soja nos Estados de Santa Catarina e Rio Grande do Sul. Fitopatol. Brasileira, $1(3): 183-193.1976$. 
Loof, P. A. A. Taxonomic studies on the genus Pratylenchus (Nematoda). T. Plziekt., 66(1): 29-90. 1960.

LOOF, P. A. A. Taxonomy of Hemicycliophora species from West and Central Europe (Nematoda: Criconematoidae). Meded. Landb. Hogesch. Gent, 68(14): 1-48. 1968 .

LOOF, P. A. A. The genus Pratylenchus Filipjev, 1936 (Nematoda: Pratylenchidae). A review of its anatomy, morphology, distribution, systematics and identification. Vãxtskyddrapp., Jordbruk, 5: 1 - 50. 1978 .

LOOF, P.A.A. Pratylenchus scribneri. C.I.H. Descriptions of Plant-Parasitic Nematodes. Set 8, no $110.1985 .4 \mathrm{p}$.

LORDELlo, L. G. E. Xiphinema krugi n. sp. (Nematoda: Dorylaimidae) from Brazil with a key to the species of Xiphinema. Proc. Helminth. Soc. Wash., 22 (1):1621. 1955 .

LORDELLO, L. G. E. A note on nematode parasites of red anthurium (Anthurium andreanum Lind.) with a description of Rotylenchus boockin. sp. Nematologica 2:273 $-276.1957$. 
LORDELlo, L. G. E. Nematóide ataca a beterraba no Rio Grande do Sul. Rev. Agric., Piracicaba, 44 (1): 13 14. $1969 \mathrm{a}$.

LORDELLO, L. G. E. Ocorrência do nematóide Aphelenchoides besseyi em arroz no Brasil. Rev. Agric., Piracicaba, $44(4): 129-131.1969 b$.

LORDELLO, L. G. E. \& MARINI, P.R. Alguns nematóides parasitas de plantas do Rio Grande do Sul. Rev. Agric., Piracicaba, 49(1): $15-18.1974$.

LORDELlO, L. G. E. \& ZAMITH, A. P. L. On morphology of the coffee root-knot nematode, Meloidogyne exigua Goeldi, 1887. Proc. Helminth. Soc., 25(2): $133-$ 137. 1958 .

LORDEllo, L. G. E.; ZAMITH, A. P. L. \& BOOCK, O. J. NOvo nematodeo parasito da batatinha. Bragantia, 13(11): $141-149.1954$.

LUC, M. Trois nouvel les espèces af ricaines du gente Hemicycliophora De Man, 1921 (Nematoda: Criconematidae). Nematologica, 3(1): $15-23.1958$. 
LUC. M. Contribution à l'étude du genre Criconemoides Taylor, 1936 (Nematoda: Criconematidae). Cah. ORSTOM, Sér. Biol., 11(1): $69-131.1970$.

LUC, M. A reappraisal of Tylenchina(Nemata). 7. The family Pratylenchidae Thorne, 1949."Revue Nématol., 10(2): $203-218 . \quad 1987$.

LUC, M. \& FORTUNER, R. A reappraisal of Tylenchina: Nematoda 5. The family Dolichodoridae Chitwood, 1950. Revue Nématol., 10(2): 177-181. 1987.

LUC, M. \& RASKI, D. J. Status of the genera Macroposthonia, Criconemoides, Criconemella, and Xenocriconemella (Criconematidae: Nematoda). Revue Nématol., 4(1):321. 1981 .

LUZ, W. C. Nematóides fitoparasitos associados com trigo no Rio Grande de Sul. Pesq. Agropec. Brasileira, 17 (2): $215-217.1982$.

LUZZARDI, G.C. Observações sôbre a ocorrência de nematóides em trigo. In: : VI Reuniao Conjunta de Pesquisa de Trigo. Porto Alegre, RS, 1 a 5 de Abril de 1974. 2 p. 
MAGGENT I, A. R.; LUC, M.; RASKI, D.J. ; FORTUNER, R. \& GERAERT, E. A reappraisal of tylenchina (Nemata). 2 . Classification of the suborder Tylenchina (Nemata: Diplogasteria). Revue Nématol., 10(2): 135- 142 . 1987 .

MENDES, M. L. Ocorrência do nematóide Ditylenchus dipsaci no Estado do Rio Grande do Sul. In: : XI Congresso Brasileiro de Nematologia, Viçosa - MG, 16 a 20 de Fev. de 1987. p.39 (resumo).

MENDONÇA, M. M. Estudo sôbre Hoplolaiminae encontrados no Brasil (Nemata: Tylenchoidea). ESALQ/USP/Piracicaba. 1976. 91p. (Dissertação).

MERNY, G. Nématodes D'afrique tropicale: Un nouveau Paratylenchus (Criconematidae), deux nouveaux Longidorus et observations sur Longidorus laevicapitatus Williams 1959 (Dorylaimidae). Nematologica, 12(3): 385 - 395. 1966.

MONTEIRO, A.R. Nematóides em fol has de morangueiro l nota prévia). Rev. Agric., 38(4): 196. 1963. 
monteiro, A. R. \& COVOLO, G. Pratylenchus penetrans parasita a soja (Glycine max), no Brasil. Nematol. Brasileira, 9: 14. 1985 (resumo).

MONTEIRO, A. R. \& FERRAZ, L. C. C. B. Curso de identificação de nematóide parasitos de plantas. ESALQ/USP, Piracicaba, SP. 1988. 241p. (mimeogr.).

MONTEIRO, A. R . F FERRAZ, L . C. C. B . ; INOMOTO, M. M. \& MORAIS, S.R. A. C. Ocorrência de Criconemella xenoplax associada a pessegueiro com declínio no Brasil. Nematol. Brasileira, 14:4. 1990 (resumo).

MONTEIRO, A. R.; FERRAZ, L. C. C.B.; PIVETA, F. A. \& SANHUEZA, R. M. V. Ocorrência de Pratylenchus scribner $i$ em pomares e viveiros de macieira da regiÁo de Vacaria RS. Nematol. Brasileira, 11: 30. 1987.

MONTEIRO, A . R . \& LORDELlo, L. G. E. A Description of Hemicycliophora poranga n. sp. from Brazil (Nemata). Rev. Brasil. Biol., 38(3): $569-571 . \quad 1978$.

MONTEIRO, A. R.: LORDELLO, L. G. E. \& CRUZ, F. Z. Ditylenchus dipsaci prejulica a cultura de alfafa (Medica- 
go sativa), no Brasil. Nematol. Brasileira, 9: 11 12. 1985 (resumo).

MONTEIRO, A.R.; LORDELLLO, L.G.E. \& LORDELLO, R.A.A. Oorrência no Estado de S. Paulo do nematóide Heterodera fici.kirjanova, 1954 nocivo à figueira. Soc. Brasil. Nematol., 2: $101-108.1977$.

MOREIRA, W. A. O gênero Hel i cotylenchus Steiner, 1945 no Brasil (Nematoda: Hoplolaimidae). UnB/Brasilia/DF. 1980. 87p. (Dissertação).

ORTON WILliAMS, K. J. Meloidogyne javanica. C.I.H. Descriptions of Plant-Parasitic Nematodes. Set 1, no 3 , $1972 \mathrm{a} .4 \mathrm{p}$.

ORTON WILLIAMS, K. J. Macrophosthonia xenoplax. C.I.H. Descriptions of Plant-Parasitic Nematodes, Set. 1 . กㅇ 12. 1972b. $2 \mathrm{p}$.

ORTON WILliAMS, K. J. heloidogyne incognita. C.I.H. Descriptions of Plant-Parasitic Nematodes. Set 2 , no $18,1973 a \cdot 4 p$. 
ORTON WILLIAMS, K. J. Hoplolaimus galeatus. C.I.H. Descriptions of Plant-Parasitic nematodes, set 2 , no 24. $1973 \mathrm{~b} .2 \mathrm{p}$.

ORTON WILLIAMS, K.J. Mactoposthonia sphaerocephala. C.I.H. Descriptions of Plant-Parasitic Nematodes. Set. 2 , no 28. $1973 \mathrm{c} .2 \mathrm{p}$.

ORTON WILLIAMS, K. J. The Discocriconemella species of the Fiji Is lands (Nematoda: Criconematoidea). Syst. Parasitology, 1(1): $75-82.1979$.

ORTON WILLIAMS, K. J. \& SIDDIQI, M. R. Radopholus similis. C.I.H. Descriptions of Plant-Parasitic Nematodes. Set 2, no $27,1973.4 \mathrm{p}$.

RASHID, F.; GERAERT, E. \& SHARMA, R. D. Seven species of Tylenchida from Brazil with description of a new species (Nematoda: Tylenchoidea). Nematol. Mediterrânea, 15(1): $29-45.1987$.

RASKI, D. J. \& GERAERT. E. Descriptions of two new species and other obsevations on the genus cephalenchus Goodey, 1962. (Nemata: Tylenchidae). Nematologica, 32(1):56-78. 1986. 
RASKI, D. J. \& GOLDEN, A. M. Studies on the genus Criconemoides Taylor, 1936 with descriptions of eleven new species and Bakernema variabile n.sp. (Criconematidae: Nematoda). Nematologica, 11(4): 501 - 565. 1965.

RASKI, D. J. \& LUC, M. A reappraisal of the genus Criconema Hofmanner \& Menzel, 1914 (Nematoda: Criconemat idae). Revue Nématol., 7(4): $323-334.1984$.

RASKI, D. J. \& LUC, M. A reappraisal of Tylenchina (Nematoda) 10. The superfamily criconematoidea Taylor, 1936. Revue Nématol., 10(4): 409-444. 1987.

RASKI, D. J . \& RIFFLE, J. W. Two new species and further notes on Criconemoides Taylor, 1936 (Criconematidae : Nematoda). Proc. Helminth. Soc. Wash., 34: 212 219. 1967 .

R I BE IRO, A.S . ; SPERANDIO, C.A. ; SELISTRE, F.J . \& OLIVEIRA, J.V. Novo nematóide ataca o arroz irrigado no Rio Grande do Sul. Lavoura Arrozeira, 37 (350): $6-7$. 1984.

SEINHORST, J. W. Five new Tylenchorhynchus species from west Africa. Nematologica 9 (2): 173-180. 1963. 
SHARMA, R. D. Nematodes of the cacao region of the state of Espírito Santo, Brazil. II. Nematodes associated with field crops and forest trees. Revista Theobroma, 6(4): $109-117.1976$.

SHARMA, R.D. Nematóides Fitoparasitas associados com cereais e outras culturas no Rio Grande do Sul, Brasil. Fitopatol. Brasileira, 3 (3) : 132. 1978.

SHARMA. R. D. \& LOOF, P. A. A. Nematodes of the cocoa region of Bahia, Brazil. I. Plant-Parasitic and free living nematodes associated with rubber (Hevea brasi1 iensis Mue11. Arg.). Revista Theobroma, 3(1): $36-$ 41. 1973 .

SHARMA. R. D. \& LOOF, P. A. A. Nematodes of the cocoa region of Bahia, Brazil. III. Plant-Parasitic and free living nematodes in the rhizosferes of six different plants species. Revista Theobroma, 4(1): $39-43$. 1974.

SHARMA, R.D. \& LOOF, P.A.A. Nematodes associated with diferent plants at Passo Fundo, Rio Grande do Sul. Brasil. In: IV Congresso Brasileiro de Entomologia. Goiânia, 6 a 11 de Fevereiro de 1977. p. 68 - 69. 
SHARMA, R. D. \& LOOF, P. A. A. Nematodes associated with banana in Bahia, Brazil. Nematol. Brasileira, 8: 7 . 1984.

SHARMA, R. D. \& SHER, S, A. Nematodes of the cocoa region of Bahia, Brazil. II. Occurence and distribution of Plant-Parasitic Nematodes associated with cocoa (Theobroma cacao L.). Revista Theobroma, 3(3): $17-24.1973$.

SHARMA R. D. \& SHER, S. A. Nematódios da região cacaueira do Espírito Santo, Brasil. I. Nematódios associados ao cacaueiro ( Theobroma cacao L. ). Revista Theobroma, $4(4): 26-31.1974$.

SHER, S.A. Revision of the Hoplolaiminae (Nematoda). I I. Hoplolaimus Daday, 1905, and Aorolaimus n. gen., Nematologica, $9(2): 267-295.1963 a$.

SHER, S.A. Revision of the Hoplolaiminae (Nematoda). III. Scutellonema Andrássy, 1958. Nematologica, 9(3):421443. $1963 b$. 
SHER, S. A. Revision of the Hoplolaiminae (Nematoda). V. Rotylenchus Filipjev, 1936. Nematologica, 11(2): 173198. 1965 .

SHER, S. A. Revision of the Hoplolaiminae (Nematoda). VI. Helicotylenchus Steiner, 1945. Nematologica, 12 (1): $1-56.1966$.

SHER, S. A. Revision of the Genus Radopholus Thorne, 1949 (Nematoda: Tylenchoidea). Proc. Helminth. Soc. Wash., $35(2): 219-237.1968$.

SHER, S. A. \& ALLEN, M. W. Revision of the genus Pratylenchus (Nematoda: Tylenchidae). Univ. Calif. Publ. Zool. 57: $441-470.1953$.

SIDDIQI, M. R. Helicotylenchus dihystera. C. I. H. Descriptions of Plant-Parasitic Nematodes, set 1 , no 9 , $1972.3 p$.

SIDDIQI, M. R. Scutellonema brachyurum. C.I.H. Descriptions of Plant-Parasitic Nematodes. Set 4, no 54. 1974. 3p. 
SIDDIQI, M.R. New plant nematode genera Plesiodorus (Dolichodorinae), Meiodorus (Meiodorinae subfam. n.), Amplimerlinius (Merlinimae) and Gracilancea (Tylodoridae grad. n.). Nematologica, 22 (4):390-416. 1976.

SIDDIQI, M.R. Six new species of Coslenchus Siddiqi, 1978 (Nematoda:Tylenchidae). Nematologica, 26 (4): 432 447. 1980a.

SIDDIQI, M. R. The origin and phylogeny of the nematode orders Tylenchida Thorne, 1949 and Aphelenchida n. ord. Helminth. Abstr. (B), 49(4): 143-170. 1980b.

SIDDIQI, M. R. Tylenchida parasites of plants and insects. Slough, UK, Common. Inst. Parasitol., 1986. $645 \mathrm{p}$.

SING, R. V. \& KHERA, S. Plant parasitic nematodes from rhizosphere of vegetable crops around Calcuta. 1. Nematoda:Criconematidae). Indian J. Nematol., 5 (1): $120-122 . \quad 1976$.

SOUTHEY, J.F. Laboratory methods for work with plant and soil nematodes.London, Ministry of Agriculture, Fisheries and Food. 1970. 148p. (Tech. Bull. 2). 
SPERANDIO, C. A. Ocorrência de Aphelenchoides besseyi Christie, 1942 em associaçÁo com Aphelenchoides fragariae (Ritzema Bos, 1891) Christie, 1932 em morangueiro (Fragaria sp.) no Rio Grande do Sul. In: XVIII Congr. Brasil. de Fitopatol., Fortaleza - CE, 8 a 12 de Julho de 1985. p.355. (resumo).

SPERANDIO, C. A. Levantamento preliminar de fitonematóides no Rio Grande do Sul. In: XI Congr. Brasil. de Nematol., Viçosa - MG, 16 a 20 de Fev. de 1987. p.10 ( resumo).

SPERANDIO, C. A. \& QUEIROZ FILHO, A. A. Ocortência de Ditylenchus dipsaci (Kühn, 1857) Filipjev, 1936, no Rio Grande do Sul, em Plantas de Alfafa (Medicago sativa L. ). In: XI Congr. Brasil. de Nematol.. Viçosa - MG, 16 a 20 de Fevereiro de 1987 . p.42.

SPERANDio, C. A. \& MONTEIRo, A. R. Ocortência de Meloidogyne graminicola em arroz irrigado no Rio Grande do Sul. In: XV Congr. Brasileiro de Nematologia, 18 a 22 de Fev. de 1991. Botucatu - SP. p.24 (resumo). 
SUDO, S. \& ESPINDOLA, E.E. Levantamento das espécies de nematóide das galhas em raízes de fumo na regiAo sul do Brasil. Fitopatol. Brasileira, 12 (2): 150. 1987.

TAYLOR, A. L. \& SASSER, J. N. Biology, identification and control of root-knot nematodes (Meloidogyne species) Coop. Publ. Dep. Plant Pathol., North Caroline State Univ., e U. S. Agency Int. Dev., Raleigh, N.C. 1978. $111 \mathrm{p}$.

TAYLOR, A. L. ; DROPKIN, V. H. \& MARTIN, G. C. Perineal patterns of roots-knot nematodes. Phytopathology, 45: $25-34.1955$.

THORNE, G. On the classification of the Tylenchida, new order (Nematoda, Phasmidia). Proc. Helminth. Soc. Wash., 16(2): $37-73.1949$.

UESUG I, C. H. \& HUANG, C. S. Nematóides fitoparasitos encontrados na rizosfera de arroz (oryza sativa L.) naregiÁo Centro-Oeste do Brasil. Fitopatol. Brasileira, $9(2): 417 . \quad 1984$.

VAN DEN BERG, E. Two new Rotylenchus species from the Cape Province with notes on some known Rotylenchus 
species (Rotylenchinae: Nematoda). Phytophylactica, 18: $169-176.1986$.

VAN DEN BERG, E. \& HEYNS, J. South African Hoplolaiminae. 2. The genus scutellonema. Andrássy, 1958. Phytophylactica, 5: $23-40.1973$.

WU, L. Y. Criconema celetum, n. sp. (Nematoda: Criconematidae) from african violets in Canada. Can. J. Zool., 38:913-916. 1960.

ZEM, A.C.; ZANON, J.I. \& MONTEIRO, A.R. Nota sôbre a ocorrência de nematóides associados à cultura do fumo nos Estados de Santa Catarina e Rio Grande do Sul. Nematol. Brasileira, 9: 37. 1985. 
APÊNDICE 1

Lista de gênero e espécies de nematóides fitoparasitos, por ordem alfabética, encontrados no Estado do Rio Grande do Sul, entre os anos de 1910 a 1991.

Anguina tritici (?)...........Brasil, 1910

Aphelenchoides besseyi.......Lordello, 1969b

A. fragariae.......................... 1985

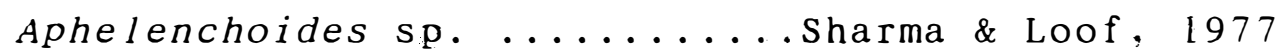

Aphelenchus avenae.............ordello \& Marini, 1974

Aphelenchus sp. ...................... 1980

Criconemoides sp. .............hehman et al. 1976

Ditylenchus dipsaci..........uz, 1982

Ditylenchus sp. ....................... \& Loof, 1977

Helicotylenchus dihystera.....Barker, 1974

H. erythrynae .............Andrássy, 1967

H. multicinctus .............Sharma \& Loof, 1977

H. rotundicauda .............Moreira, 1980

Helicotylenchus sp. ..........Lordello \& Marini, 1974

Luzzardi . 1974

Hemicycliophora sp. ............harchar et al. 1980

Heterodera radicicola ..........Neto, 1937 


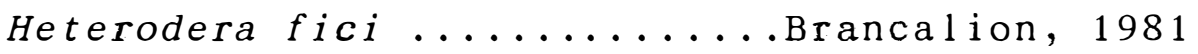

Hoplolaimus tylenchiformis.....Luz, 1982

Hoplolaimus sp. .............hehman et al. 1976

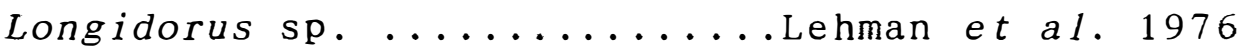

Meloidogyne acrita ...........uz, 1982

M. arenaria(?) ..............Lordello \& Marini, 1974

M. hapla (?)................Huang et al. 1984

M. graminicola......................... 1991

M. incognita....................... \& Marini, 1974

M. javanica........................

Meloidogyne spp. ..........Barker, 1974

Nothocriconema mutabile .......Sharma \& Loof, 1977

Paratrichodorus minor..........Sharma, 1978

Paratrichodorus sp. .............. et al. 1985

Paratylenchus sp. .............. 1982

Peltamigratus holdemani........Sharma \& Loof, 1977

Pratylenchus brachyurus.........Lordello \& Marini, 1974

P. coffeae..................... Fafilho \& Huang, 1988

P. jordanensis .................. Filho \& Huang, 1988

P. minyus...............uz, 1982

P. penetrans.................Charchar et al. 1980

P. pseudofallax................ Fafé ilho \& Huang, 1989

P. scribneri............Monteiro et al. 1987

P. zeae........................... 1980

Prat.vlenchus sp. ...........Barker, 1974 
Psilenchus sp. ........................... 1985

Radopholus sp. .................. 1982

Rotylenchulus reniformis.......Sharma \& Loof, 1977

Scutellonema sp. ..................... 1976

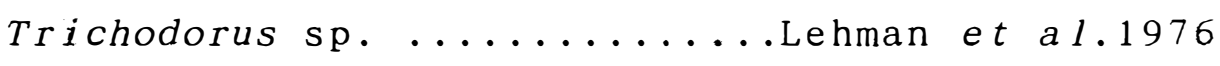

Tylenchorhynchus striatus .....Luz, 1982

Tylenchorhynchus sp.........Luzzardi, 1974

Tylenchus leptosoma...........Sharma \& Loof, 1977

T. minutus ............................. \& Lof, 1977

T.sakia(?)................................ 1977

Tylenchus sp........................... \& Loof, 1977

Tylenchulus semipenetrans......sperandio, 1985.

Xiphinema brasiliense .........Charchar et al. 1980

X. elongatum ....................... et al. 1985

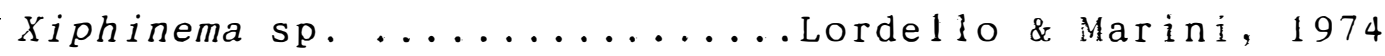

Luzzardi , 1974 


\section{APÊNDICE 2}

Lista de plantas identificadas, das quais foram coletadas amostras de solo e raizes, em ordem alfabética dos nomes vulgares.

01. Acácia-Negra = Acacia mollissima Willd.

02. Alamo-branco = Populus alba L.

03. Alface = Lactuca sativa L.

04. Alfafa = Medicago sativa L.

05. Alho $=$ Allium sativum L.

06. Aspargo = Asparagus officinalis L.

07. Arroz = oryza sativa L.

08. Batata = Solanum tuberosum L.

09. Bambú-comum = Bambusa atundinacea Retz

10. Berinjela = Solanum melongena L.

11. Beterraba = Beta vulgaris L.

12. Cana-de-açucar = Saccharum spp.

13. Caquizeiro = Diospyros kaki L.

14. Cebola = Allium cepa L.

15. Chorá = Salix babylonicaL.

16. Citros = Citrus spp.

17. Crotalarta = Crotalaria junceal. 
18. Erva mate = I lex paraguariensis St. Hil.

19. Eucalipto = Eucalyptus spp.

20. Figueira = Ficus carica L.

21. Fumo = Nicotiana tabacum L.

22. Hortência = Hydrangea macrophyl.la Ser.

23. Macieira = Pyrus malus L.

24. Milho $=$ Zea mays L.

25. Morangueiro = Fragaria spp.

26. Pessegueiro = Prunus persica (L.) Stokes.

27. Pinos $=$ Pinus spp.

28. Soja = Glycine $\max$ Merril

29. Sorgo = Sorghum vilgare Pers.

30. Tomateiro = Lycopersicon esculentum Mil1.

31. Trigo = Triticum spp.

32. Videira = Vitis vinifera L. 